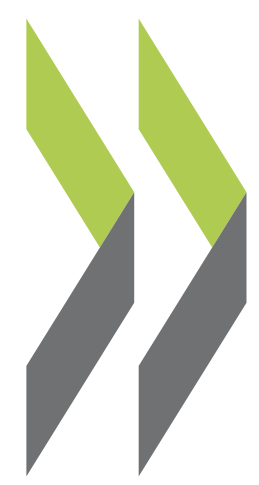

OECD Working Papers on International Investment 2013/04

\title{
Temporal Validity
}

of International Investment

Agreements: A Large

\section{Joachim Pohl}

Sample Survey of Treaty Provisions 


\section{OECD WORKING PAPERS ON INTERNATIONAL INVESTMENT}

The international investment working paper series - including policies and trends and the broader implications of multinational enterprise - is designed to make available to a wide readership selected studies by the OECD Investment Committee, OECD Investment Division staff, or by outside consultants working on OECD Investment Committee projects.

The papers are generally available only in their original language English or French with a summary in the other if available.

This work is published on the responsibility of the Secretary-General of the OECD. The opinions expressed and arguments employed herein do not necessarily reflect the official views of the Organisation or of the governments of its member countries.

This document and any map included herein are without prejudice to the status of or sovereignty over any territory, to the delimitation of international frontiers and boundaries and to the name of any territory, city or area.

Comment on the series is welcome, and should be sent to either investment@oecd.org or the Investment Division, OECD, 2, rue André Pascal, 75775 PARIS CEDEX 16, France.

\section{OECD WORKING PAPERS ON INTERNATIONAL INVESTMENT}

are published on www.oecd.org/investment/working-papers.htm

\section{(C) OECD 2013}

Applications for permission to reproduce or translate all or part of this material should be made to: OECD Publishing, rights@oecd.org or by fax 33145249930.

This work is published on the responsibility of the Secretary-General of the OECD. The opinions expressed and arguments employed herein do not necessarily reflect the official views of the Organisation or of the governments of its member countries.

This document and any map included herein are without prejudice to the status of or sovereignty over any territory, to the delimitation of international frontiers and boundaries and to the name of any territory, city or area. 


\title{
Abstract
}

\section{Temporal validity of international investment agreements: a large sample survey of treaty provisions}

\author{
by \\ Joachim Pohl*
}

International investment agreements (IIAs) almost universally define their temporal validity and thus set conditions for States' exit from these treaties.

This study presents the results of the survey of language that determines the temporal validity of 2,061 bilateral investment agreements that the 55 economies participating in the OECD-hosted Freedom of Investment Roundtables have concluded with any other economy.

The paper summarises in its first part past and current treaty practice in this regard: how do States design the parameters that define the temporal validity of their treaties and the duration of the obligations contained therein? How has this design evolved over time? Do different kinds of IIAs take different approaches to this matter? Have individual States developed distinct practices or policies?

The second part of the paper presents key findings that result from the analysis of treaty practice in a large number of agreements. It highlights characteristics of the provisions on temporal validity employed in IIAs; emphasises the collective engagement that results from the clauses in IIAs and the consequences of country-specific practice; and suggests questions on intriguing policy choices that a large comparative study reveals.

\section{JEL Classification: F21, F23, F53, F55, K33, K41, N40, P45.}

Keywords: foreign investment; international investment; international investment law; international investment agreements; investment treaties; bilateral investment treaties; comparative law; investment law.

\footnotetext{
Joachim Pohl, Investment Division, OECD Directorate of Financial and Enterprise Affairs, (joachim.pohl@oecd.org). This paper does not necessarily reflect the views of the OECD or of governments that participate in the OECD-hosted Freedom of Investment Roundtable.

Further information on investment-related work at the OECD may be found at www.oecd.org/investment.
} 



\section{TABLE OF CONTENTS}

INTRODUCTION

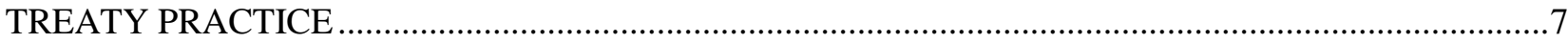

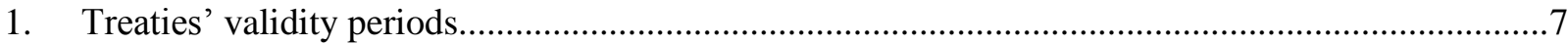

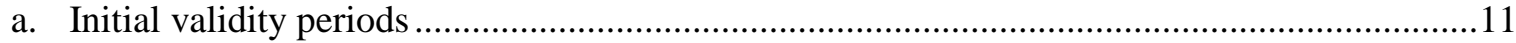

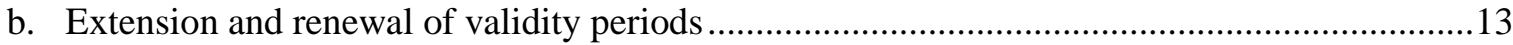

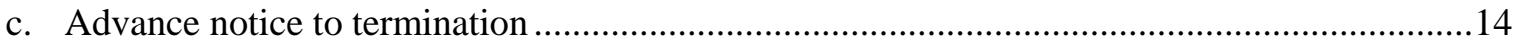

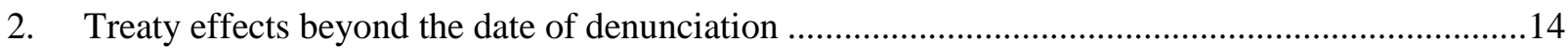

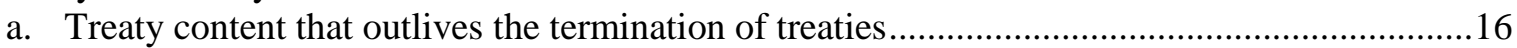

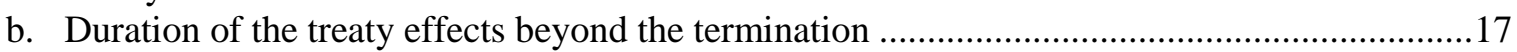

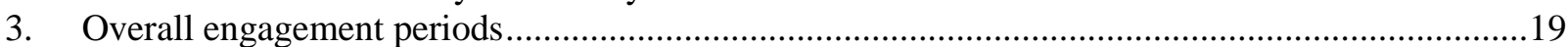

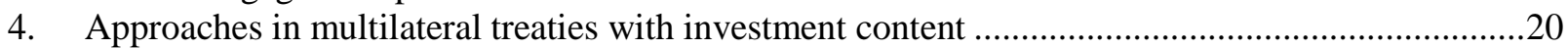

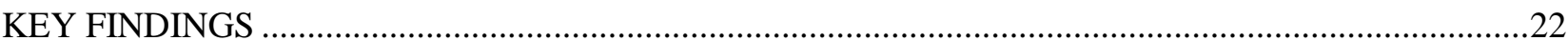

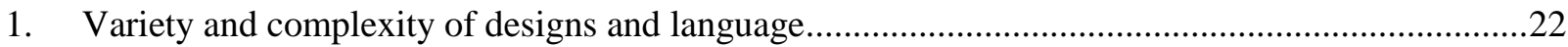

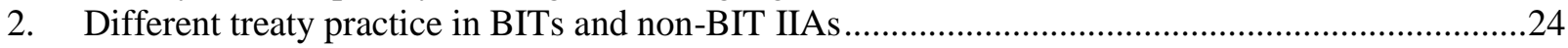

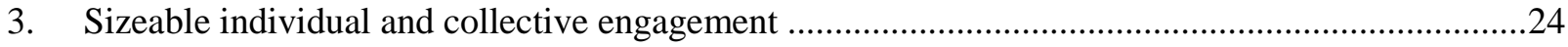

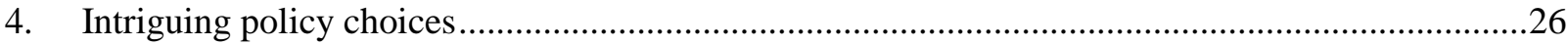

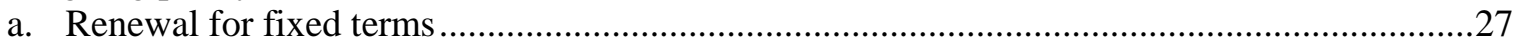

b. Undifferentiated treaty effects beyond the end of the treaty validity ........................................28

c. Uncertainty of an investment's cover by treaty effects beyond the end of the treaty

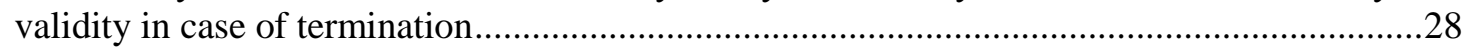

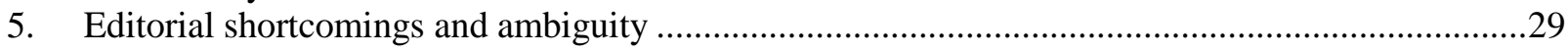

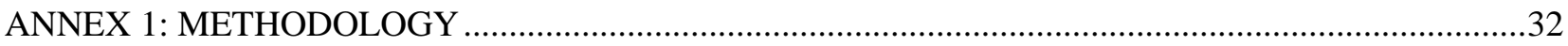

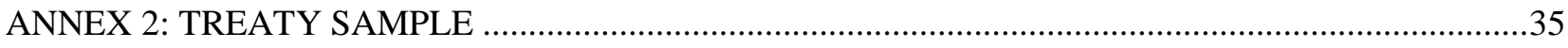

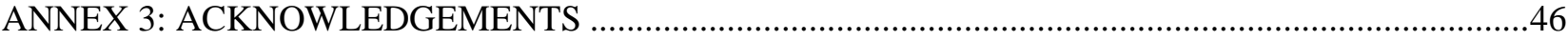

\section{Figures}

Figure 1. Graphic representation of a typical definition of an IIAs validity period. .................................7

Figure 2. Approach to the definition of treaty validity - frequency of use over time..............................11

Figure 3. Length of initial validity periods: evolution of distribution and average over time. ................12

Figure 4. Average length of the initial validity period of a given country's treaty population in relation to the average age of this country's treaty population .................................................13

Figure 5. Length of after-effect periods: evolution of distribution and average per year over time..............18

Figure 6. Average length of the after-effect period of a given country's treaty population in relation to the average age of this country's treaty population .................................................19

Figure 7. Average length of engagement in the treaties of a given country's treaty population in relation to the average age of this country's treaty population ..............................................20

Figure 8. Projection of future validity of treaties and extent of effects after termination .......................25

Figure 9. Projection of future validity of treaties concluded by selected countries ...............................26

Figure 10. Residual treaty validity of selected treaties at given points in time .......................................27

Figure 11. Number of sample treaties concluded by year in period 1959-2013 .....................................33 


\section{INTRODUCTION}

In their considerations of international investment law, participants from the 55 economies that participate in the OECD-hosted Freedom of Investment Roundtables ${ }^{1}$ have expressed interest in better understanding mechanisms that allow them to influence the contents and interpretation of the International Investment Agreements (IIAs) after their conclusion.

In response to this mandate, the OECD Secretariat has studied the two principle avenues available to States in this respect: "exit" from a given treaty, arguably the most comprehensive way to influence its contents or "voice", that is, by means of influencing how the treaty contents is understood. ${ }^{2}$

The present paper contains the results of the Secretariat survey on "exit" from international investment agreements. It is based on an analysis and categorisation of the language that determines the temporal validity of 2,061 bilateral investment agreements that economies participating in the Freedom of Investment Roundtables have concluded with any other economy.

The paper summarises in its first part past and current treaty practice in this regard: How do States design the parameters that define the temporal validity of their treaties and the duration of the obligations contained therein? How has this design evolved over time? Do different kinds of IIAs take different approaches to this matter? Have individual States developed distinct practices or policies?

The second part of the paper presents key findings that result from the analysis of treaty practice in a large number of agreements. It highlights characteristics of the provisions on temporal validity employed in IIAs; emphasises the collective engagement that results from the clauses in IIAs and the consequences of country-specific practice; and suggests questions on intriguing policy choices that a large comparative study reveals.

1 These economies are Argentina, Australia, Austria, Belgium, Brazil, Bulgaria, Canada, Chile, China, Colombia, Costa Rica, Czech Republic, Denmark, Egypt, Estonia, Finland, France, Germany, Greece, Hungary, Iceland, India, Indonesia, Ireland, Israel, Italy, Japan, Jordan, Korea, Latvia, Lithuania, Luxembourg, Malaysia, Mexico, Morocco, Netherlands, New Zealand, Norway, Peru, Poland, Portugal, Romania, Russian Federation, Saudi Arabia, Slovakia, Slovenia, South Africa, Spain, Sweden, Switzerland, Tunisia, Turkey, United Kingdom, United States and the European Union.

2 The concepts of "exit" and "voice" are due to Anthea Roberts, 'Power and Persuasion in Investment Treaty Interpretation: The Dual Role of States' (January 12, 2010). American Journal of International Law, Vol. 104, page 192. Her categorisation is in turn based on Albert Hirschman (1970) Exit, Voice, and Loyalty: Responses to Decline in Firms, Organizations, and States. Cambridge, MA: Harvard University Press. 


\section{TREATY PRACTICE}

\section{Treaties' validity periods}

Under international law, treaties may or may not contain rules on the duration of their validity. For cases where the treaty itself does not contain rules on its validity or termination, Part V of the Vienna Convention on the Law of Treaties (1969) provides for a comprehensive set of such rules. IIAs almost universally set explicit treaty-specific rules on their validity and termination. Among the 2,061 IIAs analysed for this study, only two treaties were found that do not specify the conditions for their temporal validity. ${ }^{3}$

The description of the temporal validity of IIAs is relatively complex. Its constituting elements have not substantially changed since the first IIAs were developed. Almost all IIAs contain, in the final provisions, the definition of an initial validity period; at the end of this initial validity period, the treaty is extended tacitly either for an unlimited time or for repeated fixed terms. Denunciation is possible at certain points in time, but requires an advance notice. In the case of a denunciation, most treaties define an additional period during which the treaty unfolds effects for existing investments beyond its validity. Figure 1 represents the sequence of periods in a typical IIA.

Figure 1. Graphic representation of a typical definition of an IIAs validity period.

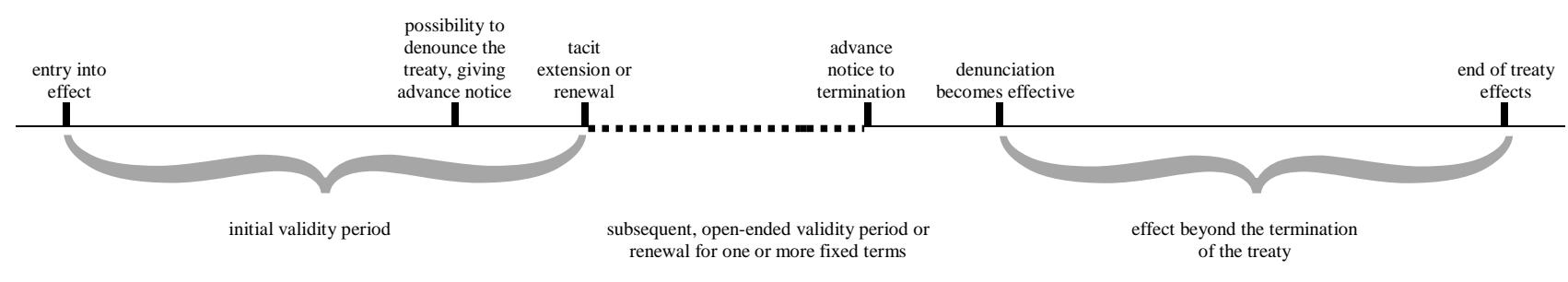

This represented sequence is, albeit the most common, not the only approach to define an IIA's temporal validity, and a range of different approaches exists. The overwhelming majority of treaties follow one out of four approaches:

- $60 \%$ of the treaties in the sample set an initial validity period, followed by a tacit ${ }^{4}$ extension for an unlimited period. While the treaty cannot be denounced unilaterally before the end of the

3 The India-Korea BIT (1996) and the Indonesia-Uzbekistan BIT (1996) set no rules for the validity period or the conditions for termination, but nonetheless refer to the date of termination. Moreover, the India-Korea BIT (1996) is silent on the conditions for the treaty's entry into force. The ASEAN Comprehensive Investment Agreement (2009) defines the conditions for its entry into force, but does not dwell on its duration or the possibilities on termination or withdrawal.

4 In the sample, one treaty, the France-Guatemala BIT (1998), requires an explicit extension; the treaty states that it "can" be extended to an unlimited period after the initial validity period of ten years has ended. 
initial validity period, denunciation is possible at any time thereafter, with a specified advance notice. ${ }^{5}$ Approximately $29 \%$ of the treaties in this group give the treaty partners an additional possibility to denounce the treaty to the end of the initial validity period before it is tacitly extended for an unlimited time.

- $32 \%$ of the treaties in the sample set an initial validity period, but rather than extending it for an unlimited period, tacitly renew the treaty for fixed terms of a specified duration. These treaties can only be terminated to the end of each validity period. ${ }^{6}$

- About $4.5 \%$ of the treaties in the sample are open-ended from the start and do not set an initial validity period; treaty partners may denounce the treaty at any time, respecting a set advance notice.

- Slightly over $1 \%$ of the treaties in the sample set an initial period, and foresee a tacit extension for one additional validity term before the treaty expires. ${ }^{8}$ A definite end of the treaty's validity period is thus included in the design of the treaty. Some of the treaties that fall into this category allow denunciation at any time in the second validity term. ${ }^{9}$

Typical treaty language reflecting this approach can be found for instance in United Kingdom-Albania BIT (1994), which states: "This Agreement shall remain in force for a period of ten years. Thereafter, it shall continue in force until the expiration of twelve months from the date on which either Contracting Party shall have given written notice of termination to the other."

Typical treaty language reflecting this approach can be found for instance in Belgium/LuxembourgColombia BIT (2009), which states: "Unless notice of termination is given by either Contracting Party at least twelve months before its period of validity, this agreement shall be tacitly extended each time for a further period of ten years, it being understood that each Contracting Party reserves the right to terminate this Agreement by notification sent through diplomatic channels given at least twelve months before the date of expiry of the current period of validity."

7 Typical treaty language reflecting this approach can be found for instance in Canada-Philippines BIT (1995): "This Agreement shall remain in force unless either Contracting Party notifies the other Contracting Party in writing of its intention to terminate it. The termination of this Agreement shall become effective one year after notice of termination has been received by the other Contracting Party." A number of treaties concluded by the Netherlands, Sweden and Switzerland in the 1960 and 1970s come close to this result in practice, as the initial validity periods were inordinately short, at times less than a year. These treaties with initial validity periods of one year or less include Netherlands-Cameroon BIT (1965), Netherlands-Cote d'Tvoire BIT (1965), Netherlands-Senegal BIT (1965), Sweden-Cote d'Tvoire BIT (1965), Sweden-Madagascar BIT (1966), Sweden-Senegal BIT (1967), Switzerland-Burkina Faso BIT (1969), Switzerland-Cameroon BIT (1963), Switzerland-Chad BIT (1967), Switzerland-Congo (Republic of) BIT (1962), Switzerland-Cote d'Tvoire BIT (1962), Switzerland-Gabon BIT (1972), Switzerland-Malta BIT (1965), Switzerland-Mauritania BIT (1976), and Switzerland-Niger BIT (1962).

8 E.g. Italy-Angola BIT (1997) and Italy-Kazakhstan BIT (1994)). Typical clauses read, as in Italy-Angola BIT (1997): "The present Agreement remains in force for 10 years from the date of notification [of the conclusion of the constitutional procedures] et remains in force for another period of 5 years, unless one of the two Contracting Parties denounces it in writing one year before its expiry." This suggests that the ItalyBelarus BIT (1995) for instance, which came into effect in 1997, has expired in 2012.

9 E.g. Austria-Cape Verde BIT (1991), China-Columbia BIT (2008), Italy-Libya BIT (2000). The Austria-Cape Verde BIT (1991) for instance states: "This agreement remains in force for ten years; after the expiry of this period, it is extended for another ten years and may be terminated by the Contracting Parties by a notice through diplomatic channels giving 12 months written notice." 
The remaining treaties, which together account for less than $2 \%$ of the sample feature unique approaches or ambivalent language that does not permit a classification in one of the above category. These treaties have one of the following features:

- One single treaty, the Germany-Oman BIT (2007), sets an initial validity period, followed, if not denounced, by a second, slightly shorter fixed-term, which is then followed, again, if not terminated, by an indefinite validity period; termination is possible at any time in this last period. ${ }^{10}$

- Some treaties, especially treaties concluded by Hungary, the Czech Republic and Korea, contain language that suggests their indefinite extension after the initial validity period, while referring to renewal terms, the length of which remains undefined. ${ }^{11}$

- Some treaties, especially treaties concluded by India and Indonesia, set fixed renewal periods. However, despite these fixed term periods, these treaties can be denounced at any time once the initial validity period has elapsed, including in the midst of a validity term. ${ }^{12}$ The fixed validity terms thus seem to have no particular effect.

- Some treaties concluded by Italy use the singular for the renewal period, thus suggesting that the treaty has a definite end; at the same time, the treaties refer to subsequent renewal periods, suggesting the opposite. ${ }^{13}$

- Some treaties concluded by Indonesia state, with respect to the treaty renewal, that the agreement "shall continue in force thereafter for similar period" (sic); it is unclear whether the parties intended to say "for similar periods", or "for a similar period". ${ }^{14}$

The South Africa-Congo (Democratic Republic) BIT (2004) similarly defines three different validity periods, but the renewal after the initial period is not automatic.

$11 \quad$ Typical treaty language, taken from the Czech Republic-Hungary BIT (1993), states: "This agreement shall remain in force for a period of ten years and shall continue in force thereafter unless, one year before the expiry of the initial or any subsequent periods, either Contracting Party notifies the other in writing of its intention to terminate the Agreement." (emphasis added).

The India-FYROM BIT (2008), and, similarly, India-Uzbekistan BIT (1999), states: "Thereafter it shall remain in force for a similar period or periods unless, either Contracting Party notifies the other Contracting Party of its intention to denounce the Agreement. The notice of denunciation shall become effective one year after it has been received by the other Contracting Party." The Indonesia-Cambodia BIT (1999) states: "[The agreement] shall remain in force for a period of ten years and shall continue in force thereafter for another period of ten years and so forth unless, after the expiry of the initial period of ten years, either Contracting Party notifies in writing of its intention to termination this Agreement. The notice of termination shall become effective one year after it has been received by the other Contracting Party”. The Indonesia-Malaysia BIT (1994) and Indonesia-Romania BIT (1997), which are tacitly renewed for ten year periods, state that the notice of termination can be given at any time: "Each Contracting Party may, by giving one (1) year's written notice to the other Contracting Party, terminate this Agreement at the end of the initial ten (10) year period or anytime thereafter". The same feature also appears in Belgium/Luxembourg-Malaysia BIT (1979).

E.g. Italy-Angola BIT (1997), Italy-Armenia BIT (1998), Italy-Croatia BIT (1996), Italy-Kazakhstan BIT (1994).

Indonesia-Morocco BIT (1997), Indonesia-Mozambique BIT (1999), Indonesia-Singapore BIT (2005), Indonesia-Thailand BIT (1998). 
- The Greece-Romania BIT (1997) appears to allow the termination during the initial validity period. ${ }^{15}$ Also, the treaty requires that governments "review the agreement six months before the expiry date with a view to adapting it to the principles of market economy" without stating the consequences of an absence of such review for the validity of the treaty. Similarly, the South Africa-Angola BIT (2005) and the South Africa-Congo (Democratic Republic) BIT (2004) "may" be renewed once the initial validity period has expired, but this renewal is not automatic. After the second fixed-term validity term, the South Africa-Congo (Democratic Republic) BIT (2004) is automatically extended for an unlimited period. ${ }^{16}$

- The France-Philippines BIT (1976) - which was superseded in 1996 by the FrancePhilippines BIT (1994) and is no longer in force - sets two competing initial validity periods, of 5 and 10 years, without clarifying which is applicable. ${ }^{17}$

- The India-Korea BIT (1996) and the Indonesia-Uzbekistan BIT (1996) set no rules for the validity period or the conditions for termination, but nonetheless refer to the date of termination. The India-Korea BIT (1996) is also silent on the conditions for the treaty's entry into force.

Overall, the shares of the use of the main approaches to define treaty validity periods has remained relatively stable: Between 1985 and 2010, the period in which the bulk of the treaties in the sample were concluded, between $50 \%$ and $70 \%$ of treaties concluded each year set an open ended treaty validity after an initial period. In the same period, repeated validity terms after an initial validity period can be found in between $20 \%$ and $40 \%$ of treaties concluded in a given year in the same period (Figure 2). The frequency in which this latter approach is used seems to decline slightly over time. ${ }^{18}$

Among the treaties concluded since the mid-2000s, an increasing share omits to set initial validity periods. The driver behind this trend are the increasing number of FTAs and EPAs that have been concluded since the mid-2000s and which tend to not have initial validity periods. Figure 2 shows the proportion of non-BIT IIAs that do not include initial validity periods separately and demonstrates that these treaties contribute strongly to the rise in the proportion of IIAs following this model. BITs continue to contain almost systematically initial validity periods. Despite this recent increase in the proportion of

15 The Greece-Romania BIT (1997) states: "It shall remain in force for a period of three years, unless notice of termination has been given by either contracting party at least six months before the date of expiry of its validity."

Article 12 (3) of the South Africa-Congo (Democratic Republic) BIT (2004) reads: "This Agreement shall remain in force for a period of ten years whereafter it may be extended for a further period of ten years by mutual consent of the Parties. Thereafter it shall continue in force until the expiration of twelve months from the date on which either Party shall have given written notice of termination to the other."

The treaty clause in article XI of the France-Philippines BIT (1976) reads: "Le présent accord restera en vigueur pendant dix ans à compter de la date de sa mise en application et demeurera applicable à moins que le Gouvernement de la République des Philippines n'y mette fin moyennant un préavis écrit de six mois au moins adressé par la voie diplomatique. Nonobstant les dispositions ci-dessus, le Gouvernement de la République des Philippines peut moyennant un préavis d'un an au moins adressé au Gouvernement de la République Française, mettre fin au présent accord au bout de cinq ans à compter de la date de sa mise en application." Some treaties concluded by China - e.g. China-Algeria BIT (1996) and China-Cap Verde BIT (1998) - also seem to feature contradicting provisions on the lenght of the initial validity period, but the error may be only in the published treaty text, not in the signed treaty.

Years in which less than $1 \%$ of the treaties in the sample were concluded are grey shaded in Figure 2 as the data may not be significant. 
treaties that set open ended validity from the start, the absolute number of treaties that do not set initial validity periods remains small.

Figure 2. Approach to the definition of treaty validity - frequency of use over time.

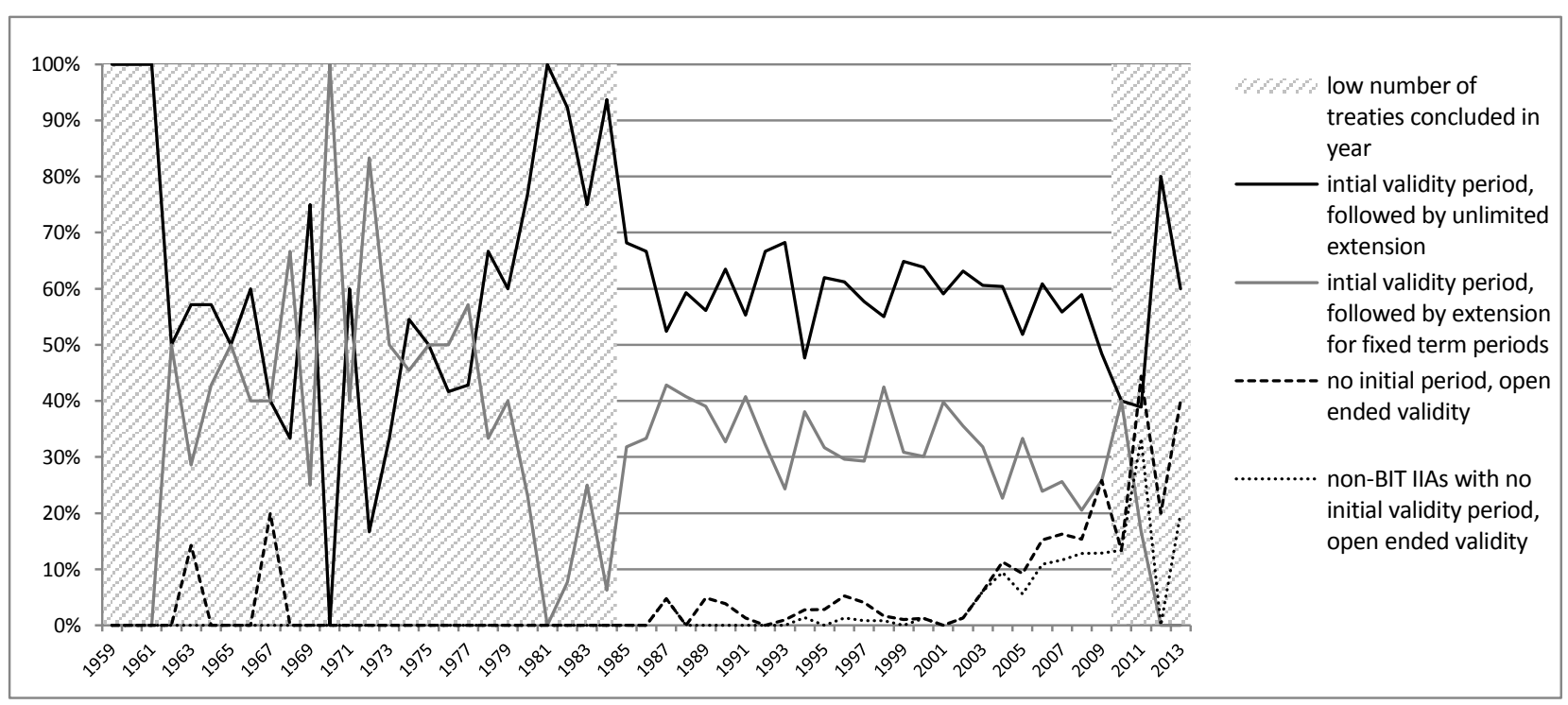

Some countries show clear preferences for a specific approach to defining the validity of treaties. Treaties concluded by the United Kingdom, Germany, Israel and Denmark, for instance, are almost exclusively extended for indefinite periods once the initial validity period has elapsed, with $97 \%$ to $92 \%$ of these countries' sample treaties falling in this category. The Netherlands, Belgium-Luxembourg and Switzerland in turn show a strong preference for using fixed renewal terms, present in $92 \%$ and $79 \%$ of their treaties in the sample. Canada's treaties most frequently use open-ended validity periods without an initial validity period; $85 \%$ of the country's treaties in the sample use this approach, followed with great distance by Colombia and Peru, which each use this approach in only $33 \%$ of their treaties. ${ }^{19}$

\section{a. Initial validity periods}

The length of the initial periods varies significantly among treaties; the shortest initial validity period is less than six months, ${ }^{20}$ while the longest initial validity period in the sample is 30 years. ${ }^{21}$ Short initial validity periods are prevalent in some old treaties concluded by Sweden and Switzerland in the 1960 and $1970,{ }^{22}$ but have become very rare since. ${ }^{23}$ Long periods of 25 and 30 -year periods are almost exclusively

19 New Zealand also uses this approach in $56 \%$ of its treaties, but the sample only contains 9 treaties concluded by New Zealand.

20 Switzerland-Congo (Republic of) BIT (1962); the treaty came into effect on 11 July 1964 and its initial validity period ended on 31 December 1964. Similarly short was the initial validity period of the SwitzerlandCameroon BIT (1963), which entered into force on 6 April 1964 and its initial validity period ended 9 months later, also on 31 December 1964.

In Austria-Kuwait BIT (1996), Belgium/Luxembourg-Kuwait BIT (2000), Finland-Kuwait BIT (1996), JapanKuwait BIT (2012), Jordan-Kuwait BIT (2001), Korea-Kuwait BIT (2004), Lithuania-Kuwait BIT (2001), Malaysia-United Arab Emirates BIT (1991), Sweden-Kuwait BIT (1999).

Treaties with initial validity periods of two years or less found in the sample are Netherlands-Cameroon BIT (1965), Netherlands-Cote d'Tvoire BIT (1965), Sweden-Cote d'Tvoire BIT (1965), Sweden-Madagascar BIT (1966), Sweden-Senegal BIT (1967), Switzerland-Benin BIT (1966), Switzerland-Burkina Faso BIT (1969), 
observed in treaties concluded with Kuwait and remain a marginal phenomenon. The average length of the initial validity period, which is 10.7 years in the entire sample, has been relatively stable since the early 1970s and ranges between 10 and 12 years for treaties concluded in a given year (see red dots in Figure 3). The graph suggests a decline of the average recently, driven by the absence of initial validity periods in some very recent treaties; this average is based on a very small number of treaties, however.

The distribution of initial validity periods across the range shows convergence towards 10 year periods and, at the margins, a trend towards longer initial validity periods or the absence of initial validity periods. Clearly favoured, 10-year initial validity periods are observed in $72 \%$ of all treaties in the sample, and another $15 \%$ set 15 -year initial validity period. Initial validity periods of less than 5 years or more than 15 years remain thus rare, even though much shorter and much longer periods are occasionally observed. Both short and long initial validity periods remain marginal phenomena in absolute numbers of treaties.

Figure 3. Length of initial validity periods: evolution of distribution and average over time.

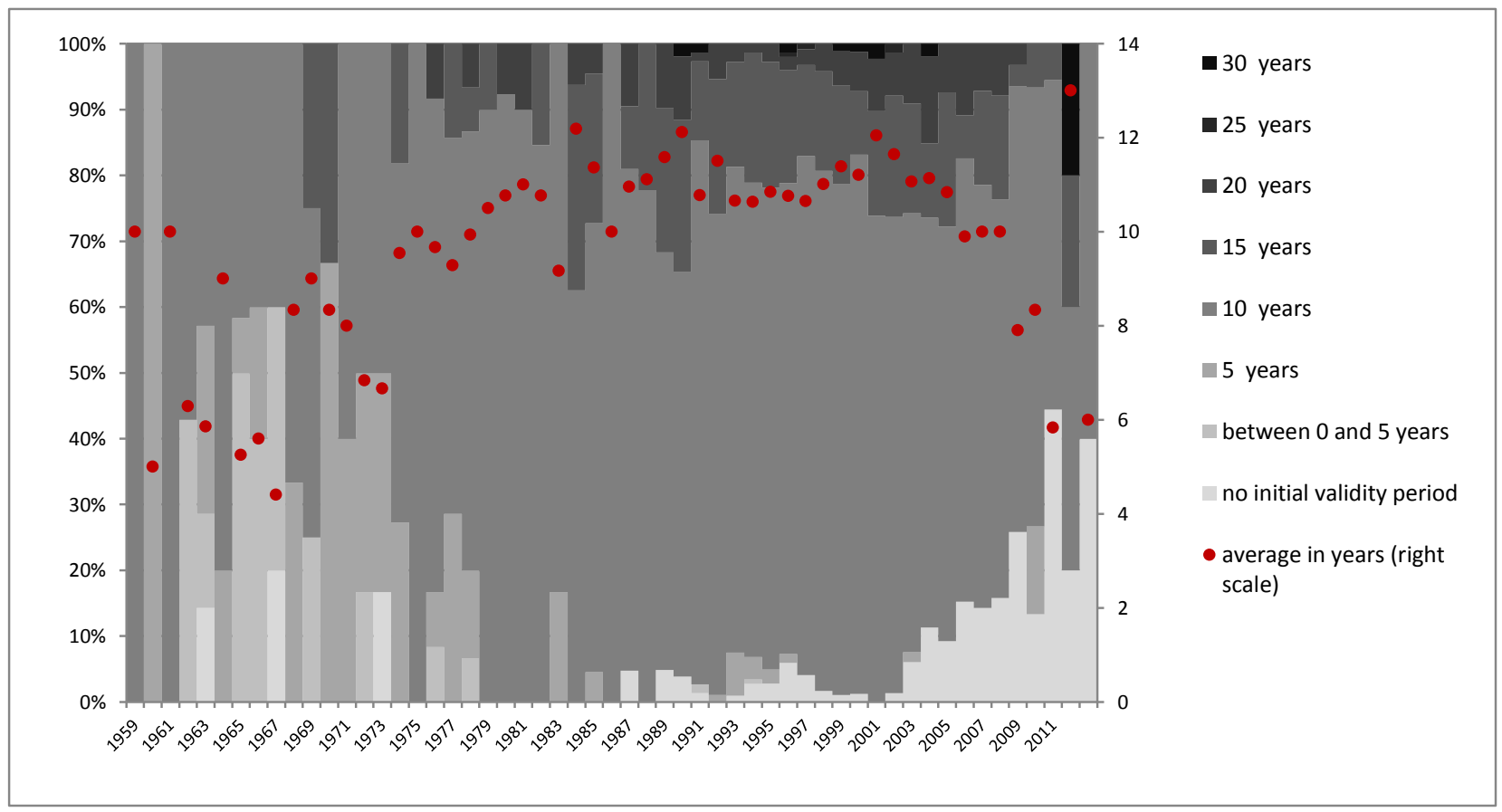

Despite the broad overall homogeneity with respect to the use and the length of individual invalidity periods, individual countries show clear preferences in this respect. Among the populations of countries that participate in the Freedom of Investment Roundtables, Sweden and Finland have average initial validity periods of over 16 years, while the average of initial validity period of treaties concluded by Canada is less than 2 years. Kuwait, a country that does not participate in the Roundtables, stands out in this respect: Treaties concluded with Kuwait have an initial validity period of almost 22 years, more than twice the overall average in the sample.

Switzerland-Cameroon BIT (1963), Switzerland-Chad BIT (1967), Switzerland-Cote d'Tvoire BIT (1962), Switzerland-Gabon BIT (1972), Switzerland-Madagascar BIT (1964), Switzerland-Malta BIT (1965), Switzerland-Mauritania BIT (1976), Switzerland-Niger BIT (1962), Switzerland-Senegal BIT (1962).

Initial validity periods of less than five years had last been included in treaties in 1978, but the GreeceRomania BIT (1991) and the Colombia-Mexico FTA (1994) returned to 3 year initial validity periods. 
The choices for longer or shorter initial validity periods do not seem to be correlated to the age of a country's treaty population. ${ }^{24}$ Figure 4 shows the length of the average initial validity period of each country's treaty population, as well as the average age of these populations.

Figure 4. Average length of the initial validity period of a given country's treaty population in relation to the average age of this country's treaty population

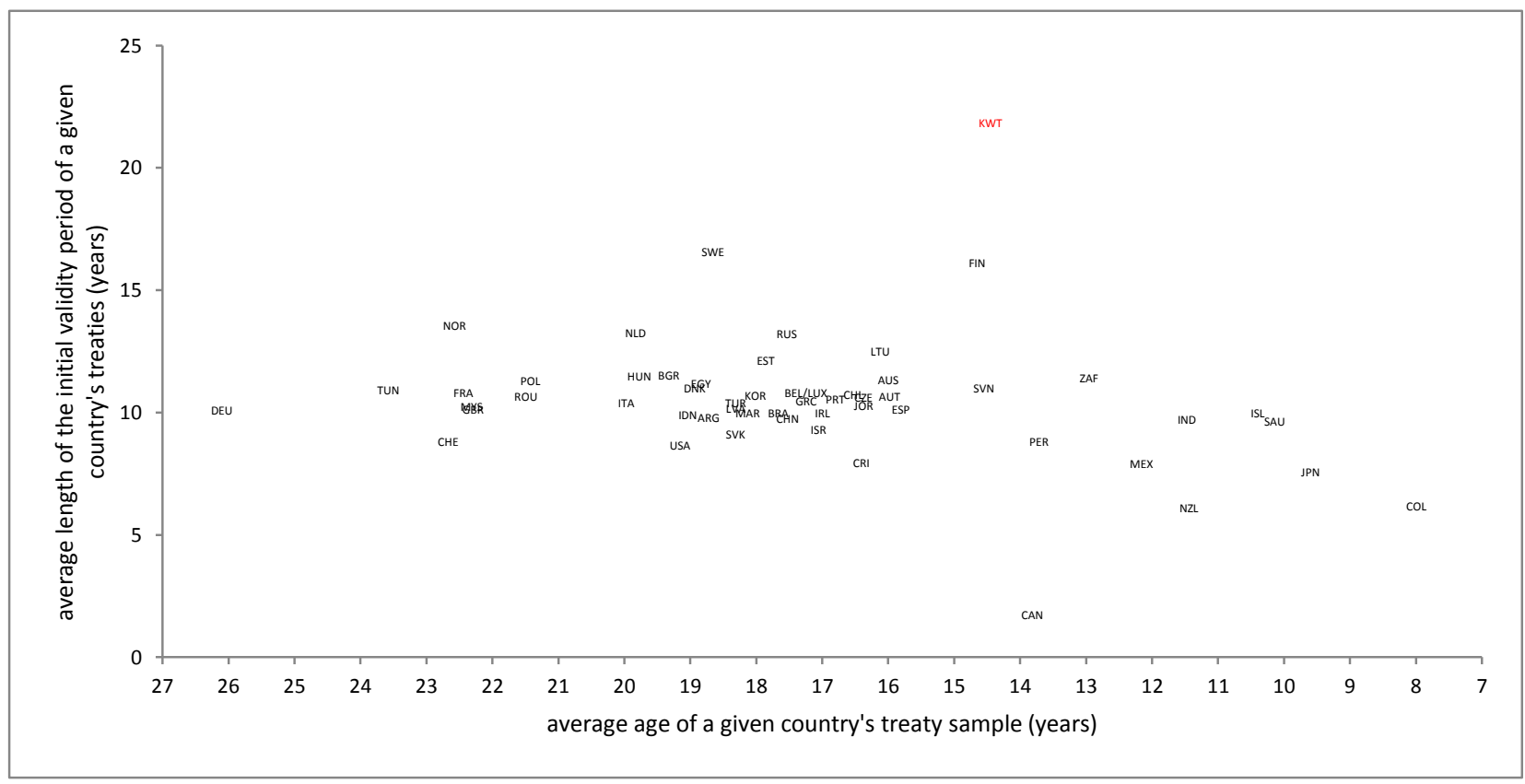

While initial validity periods are an almost universal feature in BITs, they are almost entirely absent in FTAs and other IIAs with investment chapters: only one of the 52 non-BIT IIAs in the sample - the Colombia-Mexico FTA (1994) - sets an initial validity period.

As of 2013 , only $24 \%$ of the 1724 treaties that are in force -415 treaties - are still in their initial validity period. The remaining $76 \%$ of the treaties have either passed their initial period $(70 \%)$ or do not foresee such a period at all $(6 \%)$.

\section{b. $\quad$ Extension and renewal of validity periods}

Treaties that set initial validity periods almost systematically contain provisions that extend or renew the validity at the end of the initial validity period's expiry. The overwhelming majority of treaties in the sample that contain initial validity periods foresee a tacit renewal for a specified period or a tacit unlimited extension once the initial validity period has elapsed. Only 25 treaties - or $1.2 \%$ of the sample - are designed in a way that leads to their expiry at a certain point in time.

24 The average age of a given country's treaty population has contributed to explaining features of countries' treaty populations in earlier studies of investment treaty practice. Dispute settlement provisions in international investment agreements: A large sample survey, OECD Working Paper on International Investment, No. 2012/2. 
Treaties in the sample almost universally require an advance notice should one treaty partner wish to terminate the treaty. ${ }^{25}$ This observation holds true for both BIT and non-BIT treaties and regardless of the approach to the definition of the treaty validity.

Two different formulations have been observed in the treaty sample: most treaties establish the advance notice by directly stating that a treaty partner can denounce the agreement "giving $x$ months' notice" ${ }^{26}$ A smaller share of treaties takes a different approach and declares that the notice "takes effect $x$ months after having reached the treaty partner". ${ }^{27}$

The overwhelming majority of treaties with an open-ended validity or an indefinite extension - 93\% require 12 months' notice to the denunciation. Other periods have also been found, albeit rarely. ${ }^{28}$ Treaties that are renewed for fixed terms have, on average, shorter notice periods than those of treaties with unlimited extension. $47 \%$ of these treaties require only a 6 -month period, and $50 \%$ set a 12 -month period. Also, $3 \%$ of the treaties in this subsample set 3-month periods; such short periods occur in treaties that set short renewal periods of 1 year or less.

Treaties that are extended for an indefinite period once the initial validity period has elapsed contain at times an additional possibility to terminate the treaty to the end of the initial period. ${ }^{29}$ About $29 \%$ of these treaties provide this additional possibility to terminate the agreement; again, most set 12 month periods for the denunciation at this moment, but 6-month periods have also been observed in the treaty sample.

\section{Treaty effects beyond the date of denunciation}

Most international investment agreements provide that all or at least some of their effects outlive their denunciation. These effects cover only investments that have been made - or approved or committed $-{ }^{30}$ prior to the termination of the treaty.

25 The sole exception found in the is the Bulgaria-Slovakia BIT (1994), which does not explicitly specify whether and which advance notice is required for the termination of the treaty once it has passed its initial validity period. Article 56 of the Vienna Convention on the Law of Treaties (1969) would arguably provide for the applicable advance notice.

Such language can for instance be found in the China-Switzerland BIT (2009), which states in Article 13: " $S$ ' $i l$ n'est pas dénoncé par écrit avec un préavis de six mois avant l'expiration de cette période, il sera considéré comme renouvelé..." (Emphasis added).

E.g. in several South African treaties and the Spain-FYROM BIT (2005); treaty language describing such a delayed effect of the notice in Egypt-South Africa BIT (1998) reads: "This Agreement shall remain in force for a period of ten years. Thereafter it shall continue in force until the expiration of twelve months from the date on which either Contracting Party shall have given written notice of termination to the other."; the SpainFYROM BIT (2005) reads: "La notificación de denuncia surtirá efecto un año después de haber sido recibida por la otra Parte Contratante."

Notices of 6 months occur in $6 \%$ of the treaties in the sample. The Costa Rica-Ecuador BIT (2001) requires a 9-month advance notice, and the Egypt-Singapore BIT (1997) sets a five year advance notice.

29 German treaties for instance systematically include this possibility.

The inclusion of investments that are approved but not yet made at the time of termination of the treaty is rare but can for instance be found in South Africa-Mozambique BIT (1997). The treaty effects of the CanadaTanzania BIT (2013) include "investments or commitments to invest". 
Clauses on treaty effects beyond the date of denunciation are an almost universal feature of IIAs. Only $3.2 \%$ of the treaties in the sample do not extend some or all treaty effects for a specified period beyond the effect of the denunciation. In BITs, the absence of such temporal extension of treaty effects is even rarer: only 20 BITs among the 2008 analysed BITs do not mention treaty effects beyond the denunciation, corresponding to $1 \%$ of the BIT population in the sample. In turn, $88 \%$ of FTAs, EPAs and CEPAs do not contain such extensions of treaty effects beyond the date of denunciation. ${ }^{31}$ That does not mean, however, that investments made under an FTA regime would generally not benefit from protection beyond the validity of the FTA. In fact, in four cases in the sample where a BIT had existed before an FTA came in place, the FTA merely suspends the BIT rather than replacing it. ${ }^{32}$ The termination of the FTA reinstates the suspended BIT or at least some of its provisions and thus brings provisions into effect beyond the termination of the FTA.

When considering exclusively BITs, only Egypt, Saudi Arabia, Tunisia and Jordan have a somewhat significant proportion of BITs that do not extend the treaty effects beyond the date of denunciation, with between $8.6 \%$ and $5.7 \%$ of their respective BIT population having this feature. ${ }^{33}$ Countries that tend to conclude non-BIT IIAs have a significantly higher proportion of treaties in their population that does not feature effects beyond the date of the denunciation; among Japan's 31 treaties in the sample, for instance, 9 IIAs, or $29 \%$, do not extend effects beyond the date of denunciation. ${ }^{34}$

Treaties in the sample follow three different approaches to establishing the duration of the treaty effects: The large majority of treaties subject investments that were made before the termination of the treaty to extended protection for a specified number of years, beginning with the termination of the treaty. In the sample, 39 treaties cut off the protection of investments made until the notice of denunciation rather than at the time of the effect of the termination. ${ }^{35}$ A few treaties, all concluded before the 1990s, mention a

31 Non-BIT IIAs that provide for treaty effects beyond the termination are: Canada-Peru FTA (2008), ChileColombia FTA (2006), India-Japan EPA (2011), India-Korea CEPA (2009), Mexico-Peru FTA (2011), and Peru-Singapore FTA (2008).

32 Suspension has been found in four treaties: the Korea-Switzerland BIT (1971) is suspended by the EFTAKorea Investment Agreement (2005), according to Article 27 of EFTA-Korea Investment Agreement (2005); the Canada-Panama BIT (1996) is suspended by the Canada-Panama FTA (2010) according to Article 9.38 of the FTA; the Canada-Peru BIT (2006) is suspended by the Canada-Peru FTA (2008), according to Article 845 of the FTA; and certain provisions, related to investor-state and state-to-state dispute settlement of the Morocco-United States BIT (1985) are suspended during the validity period of the Morocco-United States FTA (2004).

33 No explanation can be offered why the phenomenon appears to be more prevalent in the MENA region. The South Africa-Angola BIT (2005) and the South Africa-Congo (Democratic Republic) BIT (2004) provide for treaty effects beyond the validity period only in case of denunciation, not in the case of expiry of the treaty; in these treaties, expiry is the default outcome, as the treaties do not contain tacit renewal mechanism.

New Zealand has a still higher proportion of treaties with no treaty effects beyond the date of termination (56\%), but the sample contains only 9 treaties concluded by New Zealand.

These treaties include: Austria-Lebanon BIT (2001), Brazil-Finland BIT (1995), Bulgaria-Finland BIT (1997), Bulgaria-Romania BIT (1994), Bulgaria-Slovakia BIT (1994), Bulgaria-Vietnam BIT (1996), Chile-Colombia FTA (2006), Czech Republic-Lebanon BIT (1997), Czech Republic-Norway BIT (1991), Czech RepublicSpain BIT (1990), Czech Republic-Switzerland BIT (1990), Denmark-Romania BIT (1980), Egypt-Romania BIT (1994), Finland-South Africa BIT (1998), Finland-Tunisia BIT (2001), Germany-Lebanon BIT (1997), Indonesia-Norway BIT (1991), Italy-Lebanon BIT (1997), Korea-Bolivia BIT (1996), Korea-Switzerland BIT (1971), Latvia-Norway BIT (1992), Latvia-Romania BIT (2001), Lithuania-Norway BIT (1992), LithuaniaRomania BIT (1994), Norway-Slovakia BIT (1991), Poland-Romania BIT (1994), Romania-Armenia BIT (1994), Romania-Azerbaidjan BIT (2002), Romania-Belarus BIT (1995), Romania-Cuba BIT (1996), Romania-Georgia BIT (1997), Romania-Kazakhstan BIT (2010), Romania-Mauritius BIT (2000), Romania- 
temporal protection but rather than constituting it, refer to agreements on specific investments. ${ }^{36}$ One treaty in the sample, the Germany-Gabon BIT (1969) lets the period begin with the admission of the investment; this clause is combined with a minimum duration beginning with the termination of the treaty. ${ }^{37}$

\section{a. Treaty content that outlives the termination of treaties}

Descriptions of the treaty content that outlives the date of denunciation varies quite significantly among the treaties in the sample. Four approaches dominate:

- The survival of treaty content may be all-encompassing: treaties concluded by the United Kingdom for instance typically state that the agreement's "provisions continue in effect with respect to such investments for a period of $x$ years after the date of termination" ${ }^{38}$ Many treaties concluded by Australia state that the agreement "shall continue to be effective for a further period of $x$ years" ${ }^{39}$

- Certain treaties provide that specific articles of the agreement outlive the date of termination. German treaties for instance typically state that "In respect of investments made prior to the date of termination of this Treaty, the provisions of Articles 1 to 12 shall continue to be effective for a further period of twenty years from the date of termination of this treaty". ${ }^{40}$ The mentioned articles are in most cases all but the last article of the treaty, which contains the final provisions. The preamble, the protocol, as well as the final clause on the treaty's language versions are also not explicitly referred to under this approach.

Some of the treaties that refer to specific articles exclude a slightly broader scope of treaty provisions, e.g. on amendments, ${ }^{41}$ consultations among treaty partners, ${ }^{42}$ or the application of the treaty in relation to diplomatic relations between the treaty partners. ${ }^{43}$

Mongolia BIT (1995), Romania-North Korea BIT (1998), Romania-Pakistan BIT (1995), Romania-Qatar BIT (1996), Romania-Vietnam BIT (1994), and Switzerland-Liberia BIT (1963). Art. 10 (3) of the PolandRomania BIT (1994), for instance reads: "(3) In case of official notice as to the termination of the present agreement, the provisions of the Article 1 to 9 shall continue to be effective for the further period of ten years for investment made before official notice was given." (Emphasis added).

Belgium/Luxembourg-Indonesia BIT (1970), Germany-Liberia BIT (1961), Indonesia-Switzerland BIT (1974), Indonesia-United Kingdom BIT (1976), Korea-Bangladesh BIT (1986). The France-Paraguay BIT (1978) caps these investment-specific periods: "En cas de dénonciation, la présente Convention restera applicable aux investissements effectués ou autorisés antérieurement à sa dénonciation pour la durée prévue pour chacun d'eux. Cette durée ne sera pas inférieure à dix ans, ni supérieure à vingt ans, à compter de la date de la dénonciation."

Article 14 of the Germany-Gabon BIT (1969) states: "Pour les investissements effectués avant la date d'expiration du Traité, la durée d'application des articles 1 à 13 ne pourra 6etre inférieure à quinze ans à partir de la date d'agrément de l'investissement et ne pourra se terminer avant la fin de la douzième année suivant l'expiration du Traité."

This formula is used in United Kingdom treaties, e.g. United Kingdom-Nicaragua BIT (1996).

"Agreement shall continue to be effective for a further period of fifteen years", Australia-Czech Republic BIT (1993) and Australia-Hong Kong, China BIT (1993).

41 Australia-Czech Republic BIT (1993), Australia-Hong Kong, China BIT (1993), Australia-Hungary BIT (1991), Australia-India BIT (1999). 
A few treaties, especially early treaties concluded by Sweden and Switzerland, go even further and enumerate only one or a few specific articles that remain effective after the denunciation of the treaty. In substance, these articles are typically the core investment protection provisions and the clauses on investor-state dispute settlement. ${ }^{44}$

- Some treaties, especially treaties concluded by France, refer to a subset of the treaty content rather than to a subset of its articles. These treaties typically state "In case of termination of the period of validity of this Agreement, investments made while it was in force shall continue to enjoy the protection of its provisions for a further period of twenty years". ${ }^{45}$ Similarly, the Belgium/Luxembourg-Romania BIT (1996) states that investments "remain subject to the treaty's provisions" for 15 years. ${ }^{46}$

- A few treaties, typically treaties concluded in the 1960s, links the duration of effects beyond the termination of the treaty to investment contracts without establishing own rules.

Only the first and the last of the four approaches are straightforward, while the other ones have certain implications: Where reference is made to enumerated articles, the treaty preamble is nominally excluded from the scope, as is the clause on the interpretation of different language versions that can be found in many treaties in the final, unnumbered text preceding the signatures. Treaties that only include a few articles in the scope exclude MFN and other clauses that are arguably indissociable from the substance of the surviving articles. Finally, treaties that refer to the "protections of the treaty" open large room for interpretation, e.g. on whether the State-to-State dispute settlement mechanism is included in the protections of the treaty.

\section{b. $\quad$ Duration of the treaty effects beyond the termination}

Most treaties determine the duration of treaty effect beyond the termination by setting a fixed period. A few treaties, especially older treaties, refer to individual investment contracts rather than setting an absolute term. ${ }^{47}$ Some treaties set a fixed minimum period, while referring to investment specific agreements that may provide for longer periods. ${ }^{48}$

$42 \quad$ E.g. in Austria-Guatemala BIT (2006).

43 E.g. in Finland-Lebanon BIT (1997).

44 E.g. Sweden-Cote d'Tvoire BIT (1965), Sweden-Madagascar BIT (1966), Sweden-Senegal BIT (1967) and Switzerland-Benin BIT (1966), Switzerland-Burkina Faso BIT (1969), Switzerland-Cameroon BIT (1963), Switzerland-Central African Republic BIT (1973), Switzerland-Congo (Republic of) BIT (1962), SwitzerlandCote d'Tvoire BIT (1962), Switzerland-Gabon BIT (1972), Switzerland-Madagascar BIT (1964), SwitzerlandMauritania BIT (1976), Switzerland-Niger BIT (1962), Switzerland-Senegal BIT (1962).

E.g. France-Hong Kong, China BIT (1995); the Italy-Cameroon BIT (1999) is among the rare treaties not concluded by France that use this approach.

46 Art. 14 (3) of the Belgium/Luxembourg-Romania BIT (1996) states: "En cas de denunciation, les investissmenets effectués antérieurement à la date d'expiration du present Accord lui restent soumis pour une periode de quinze ans à compter de cette ddate."

E.g. Belgium/Luxembourg-Indonesia BIT (1970), Indonesia-Switzerland BIT (1974), Indonesia-United Kingdom BIT (1976), and Korea-Bangladesh BIT (1986).

E.g. South Africa-Mozambique BIT (1997). 
The shortest fixed period observed in the sample is 5 years, ${ }^{49}$ and the longest specified period is 25 years. ${ }^{50}$ Shorter and longer periods, respectively, are provided in treaties that have no after-effect and those treaties, concluded by France in the 1970s, that lock in the protections for existing investments for an unlimited period. ${ }^{51}$ Also, the France-Paraguay BIT (1978) sets a period between 10 and 20 years, depending on agreements for individual investments.

The average length of treaty effects beyond termination in the treaty sample has been stable over decades and stands at 12.5 years for the entire sample. ${ }^{52}$ About half of the treaties in the sample set the period at 10 years, and another quarter of the treaties in the sample at 15 years. Figure 5 shows how the distribution of different lengths of treaty effects beyond termination developed in treaties concluded in a given year. ${ }^{53}$

Figure 5. Length of after-effect periods: evolution of distribution and average per year over time

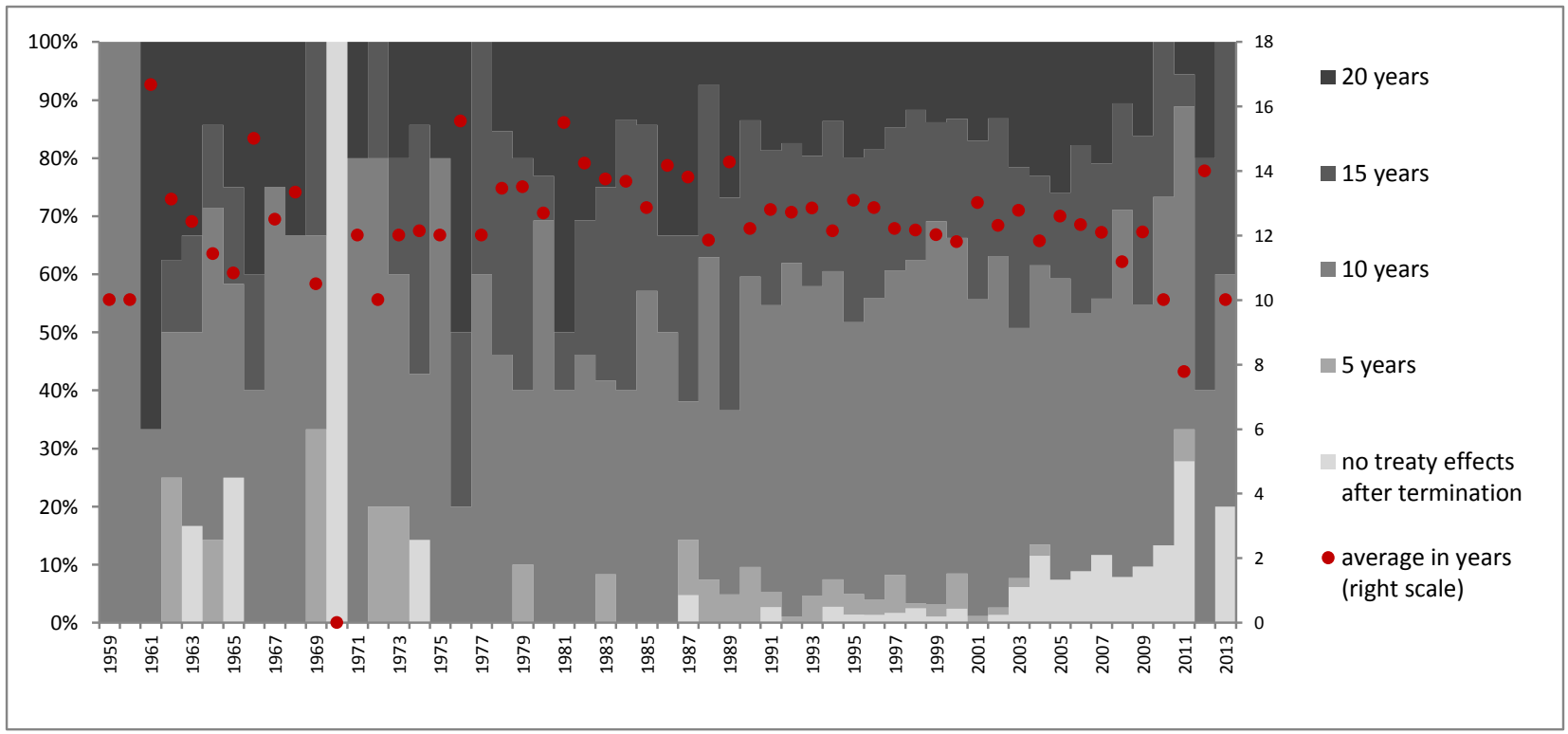

With respect to the duration of the extended protection, individual countries have different preferences that are reflected in the average length of the period during which existing investments enjoy the protection of the terminated treaty. These preferences do not appear to be correlated to the age of a given country's treaty population, however. Figure 6 shows the average length of these effects for each country in relation to the average age of this country's treaties.

$49 \quad$ Italy-Malaysia BIT (1988).

50 Belgium/Luxembourg-Albania BIT (1999).

51 France-Indonesia BIT (1973), France-Korea BIT (1977), France-Morocco BIT (1975), France-Serbia BIT (1974), France-Sudan BIT (1978), France-Tunisia BIT (1972), France-Yugoslavia BIT (1974).

52 If treaties that do not foresee any treaty effects beyond the end of their validity are excluded from the calculation of the average, the average duration of treaty effects beyond the termination is 12.9 years.

53 The apparent drop of the average since 2010 is due to the increasing proportion of FTAs concluded in these years; FTAs typically do not foresee effects after the termination of the treaty's validity. The absolute number of treaties in these years is low, however. 
Figure 6. Average length of the after-effect period of a given country's treaty population in relation to the average age of this country's treaty population

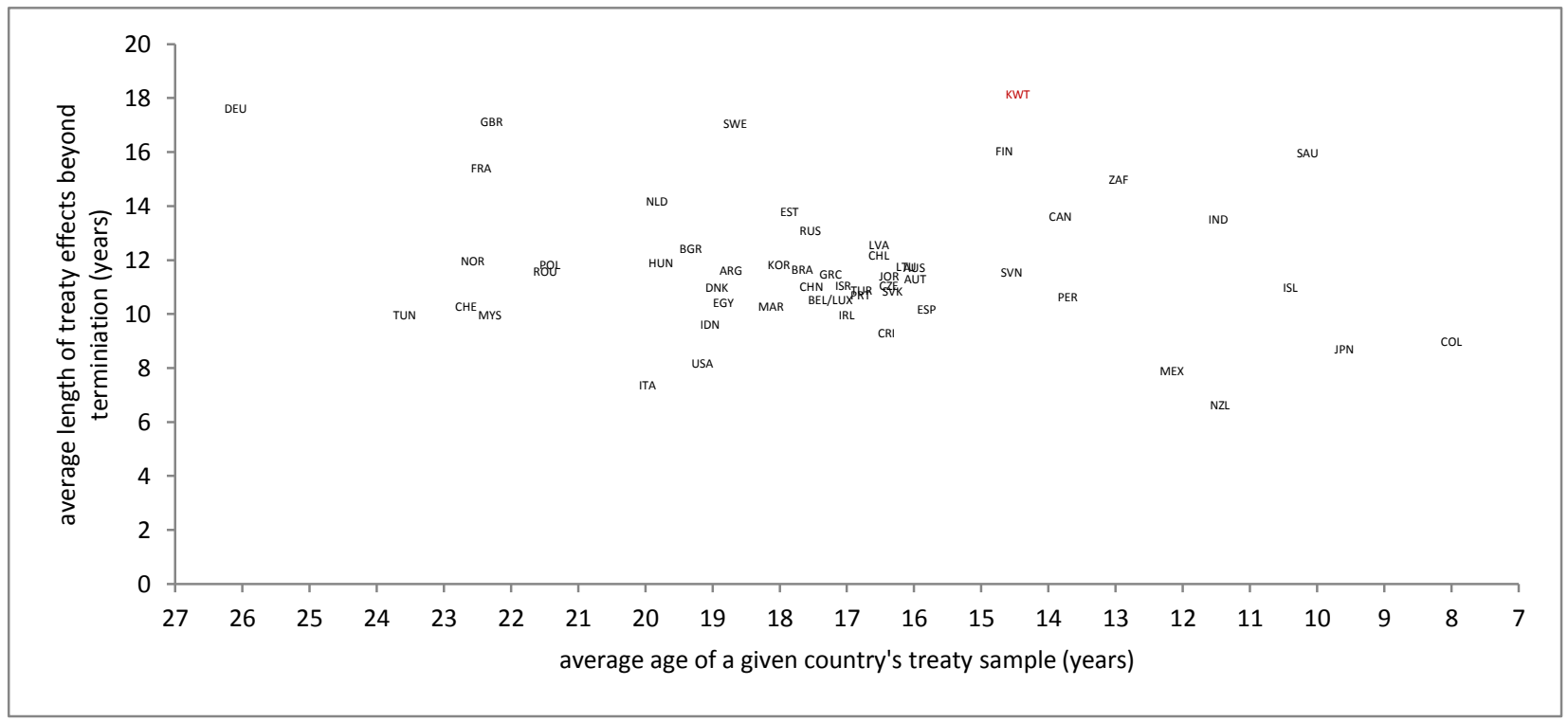

\section{Overall engagement periods}

The cumulation of initial validity periods and fixed periods during which a treaty continues to have effects beyond its validity engages signatories of these treaties for relatively long periods. Some treaties in the sample bind the treaty partners to the treaty content for half a century ${ }^{54}$ On average, treaty partners bind themselves for over 21.5 years when they bring a treaty into effect. ${ }^{55}$

Individual countries' treaty populations, as well as specific types of IIAs are associated with much shorter or much longer initial engagement periods, however. The initial engagement period agreed on in BITs is, on average of the 2008 BITs in the sample, over 22.4 years; for the 37 FTAs, the average initial engagement period is less than 1.4 years, and for the 12 EPAs and the CEPA, the average initial binding period is slightly less than 2 years.

Individual countries appear to have preferences when it comes to the length of the period for which they bind themselves and their treaty partners. Finland, Sweden and Germany - and Kuwait - tend to bind themselves and their treaty partners for longer periods, with average initial binding periods of around 28 years for Finland, Sweden and Germany - and 40 years for Kuwait. New Zealand, Australia and Canada tend to agree on shorter initial binding periods, with 10.7, 14 and 14.2 years on average, respectively. Figure 7 shows the length of the initial binding periods for individual countries' treaty populations in relation to the average age of these treaty populations.

54 Treaties that engage treaty partners initially for 50 years are Austria-Kuwait BIT (1996), Belgium/Luxembourg-Kuwait BIT (2000), Finland-Kuwait BIT (1996), Japan-Kuwait BIT (2012), JordanKuwait BIT (2001), Korea-Kuwait BIT (2004), Lithuania-Kuwait BIT (2001), Malaysia-United Arab Emirates BIT (1991), and Sweden-Kuwait BIT (1999). Treaties with unlimited engagement are FranceIndonesia BIT (1973), France-Korea BIT (1977), France-Morocco BIT (1975), France-Serbia BIT (1974), France-Sudan BIT (1978), France-Tunisia BIT (1972), France-Yugoslavia BIT (1974).

This calculation includes treaties that do not set initial validity periods and/or after-effect periods; it does not take into account treaties with unlimited after effects. 


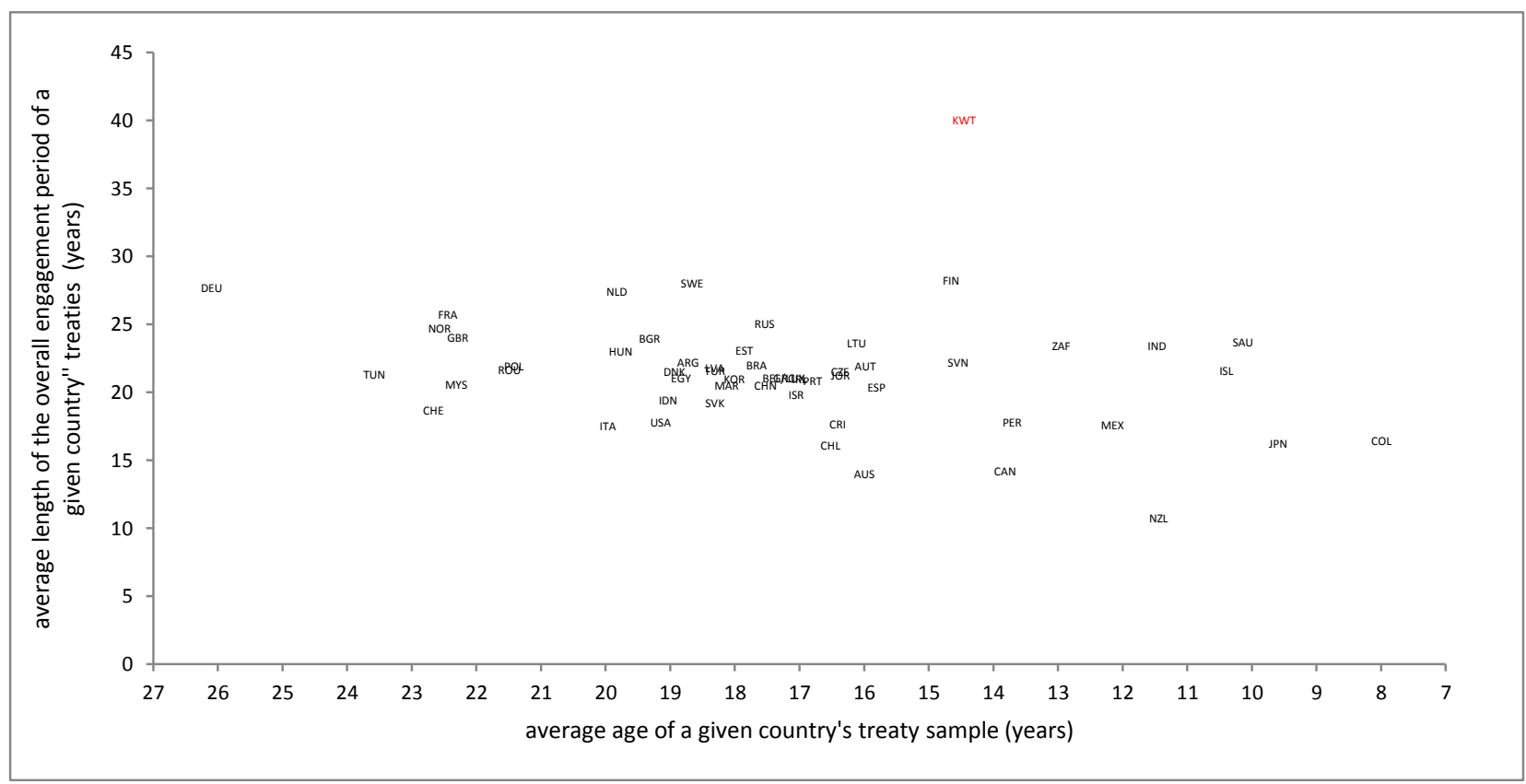

\section{Approaches in multilateral treaties with investment content}

Multilateral investment agreements or multilateral agreements that include investment chapters feature essentially the same design elements as bilateral agreements when it comes to approaches to defining treaty validity, rules on termination and effects beyond the termination. Approaches that have been observed in the large sample of bilateral investment agreements also occur in the small sample of multilateral treaties that has been analysed: some multilateral agreements with investment content set initial validity periods, some are open-ended from the beginning, and a definite end of a treaty has also been found in the sample of multilateral agreements.

The Energy Charter Treaty (1991) and the China-Japan-Korea trilateral Investment Agreement (2012), for instance, set initial validity periods of 5 and 10 years, respectively, followed by an open-ended validity period with the possibility to denounce the agreements with a 12-month advance notice. NAFTA (1992), CAFTA (2004) and the ASEAN Comprehensive Investment Agreement (2009) do not feature initial validity periods but set an open ended validity and provide the possibility to denounce the treaty at any time. The Investment Agreement for the COMESA Common Investment Area (2007) sets a definite end of the treaty validity after 20 years, composed of an initial validity period of ten years and a second validity term of the same length.

In contrast to bilateral agreements, multilateral treaties do not end systematically if one of the parties denounces the agreement. Typically, the treaty remains valid among the remaining treaty partners, as foreseen for example under NAFTA (1992) ${ }^{56}$, CAFTA (2004), the Energy Charter Treaty (1991), the China-Japan-Korea trilateral Investment Agreement (2012), and the Colombia-Mexico FTA (1994); this 
latter treaty was initially concluded as a trilateral treaty with Venezuela, but Venezuela denounced the treaty in $2006 .^{57}$

Multilateral agreements also contain clauses on treaty effects beyond the withdrawal of parties. The China-Japan-Korea trilateral Investment Agreement (2012), for instance, states that the treaty remains effective for the withdrawing party for 10 years after the denunciation becomes effective ${ }^{58}$ and the Energy Charter Treaty (1991) remains effective for 20 years after the withdrawal. ${ }^{59}$ CAFTA (2004) in turn does not provide for such effects for the withdrawing party. The Investment Agreement for the COMESA Common Investment Area (2007) sets different lengths for the effect: if the treaty is not renewed for a second and last validity term by consensus of all treaty parties or if the treaty expires after twenty years validity, the treaty effects last for another ten years. In the case of a unilateral withdrawal from the treaty, the treaty remains effective for only 5 additional years.

57 Venezuela's denunciation became effective in 2006. « Reporte de la relación commercial y de inversions entre México y Colombia », Secretaria de economia, Mexico, undated, p.2. "Tratado de Libre Comercio ColombiaMéxico”, OAS website.

The treaty also contains a clause for the effect beyond the treaty termination if it is denounced by a second of the three countries. 


\section{KEY FINDINGS}

The survey of treaty content with respect to the definition of their validity yields a number of findings that relate to

- $\quad$ variety and complexity found in the final provisions of IIAs related to validity periods, conditions for termination, and treaty effects beyond the termination of the treaties;

- $\quad$ significant differences in treaty practice in relation to these provisions in BITs on the one hand and non-BIT IIAs on the other;

- a sizeable length of engagement on specific treaty contents, both for individual countries and collectively;

- some intriguing policy choices the rational of which would require further research; and

- a relatively significant amount of editorial shortcomings and ambiguity in treaty text on treaties' validity and rules on termination.

\section{Variety and complexity of designs and language}

The sample of 2061 bilateral IIAs shows a broad variety and complexity of provisions on their validity. This variety exists at the level of the general approach to defining validity periods and their extensions. Within countries' treaty populations, various choices of design features and of language describing these features can be found.

Much of the structural variation came into existence in the early years of investment treaty making rather than resulting from differentiation over time. Most of the early approaches continue to be used in current treaty practice, and more specifically, individual countries tend to follow through with the model they have chosen in the beginning. Only very few designs and features have been abandoned in later treaty practice; among these are treaty validity renewals for very short periods, and investment specific extensions of treaty effects beyond the termination of the treaty. Two new features have emerged at a relatively late stage: the absence of initial validity periods and, less frequently, the absence of treaty effects beyond the termination of treaties. Both phenomena are closely associated to FTAs with investment provisions.

Convergence in treaty drafting can be observed mainly in details, such as the length of initial validity periods or the length of advance notice periods. Also, $99 \%$ of the treaties in the sample use a multiple of 5 to define the number of years of initial validity periods and periods of treaty effects beyond termination.

That different approaches continue to be used is partly due to the stability of individual countries' practices over decades and little convergence among the coexisting approaches. Germany, France and the United Kingdom for instance, among the countries with the largest and oldest treaty populations, have each used country-specific wording with almost no exception throughout their treaty populations; all three 
countries have systematically employed their specific approach, and have been using the exact same wording for dozens of treaties over several decades with no discernible trace of convergence among them.

In spite of such examples of steady use of identical wording, the treaty sample testifies of a great deal of variation in the wording of treaties, both within and across individual countries' populations. The observed differences in text do not always reflect different meaning, a finding that echoes a similar observation in an earlier study of investor-state dispute settlement provisions. ${ }^{60}$ The population of Italian treaties in the sample, for instance, uses at least a dozen different formulations to establish an identical rule: that the treaty validity is tacitly renewed for fixed terms. ${ }^{61}$

In addition to a large variety of approaches and language that defines the validity of IIAs, the analysis has revealed a high degree of complexity of these provisions within individual treaties. For instance, treaties define up to seven different time sequences to establish a complex combination of initial validity periods, extension periods, advance notice periods, and periods in which the treaty remains effective for existing investments, each of which is associated to specific rights and obligations of treaty partners or investors.

The final provisions of treaties would potentially be an area relatively favourable to convergence among different countries' treaty practices towards an approach collectively identified as good practice. The advantages of homogeneous language in treaties that exist in other areas - essentially resulting from MFN clauses and a better understanding of one's own treaty obligations - are arguably absent in this area.

Various reasons may contribute to explaining why such broad variety and complexity has been maintained in the design of final provisions of IIAs. The fact that very few of the assessed provisions has ever been used and tested has left certain approaches or design features unchallenged and built up no pressure to innovate or emulate other countries' models. In the entire sample, only eight treaties, or $0.4 \%$ of the treaty sample, are known to have been denounced unilaterally, and almost all these denunciations occurred too recently to have influenced the treaties in the sample. ${ }^{62}$

Joachim Pohl, Kekeletso Mashigo, Alexis Nohen (2012). "Dispute settlement provisions in international investment agreements: A large sample survey", OECD Working Papers on International Investment, No. 2012/2, OECD Investment Division.

61 Treaties that use different approaches to establish this renewal policy include: Italy-Kuwait BIT (1987) "continuerà a restare in vigore per un analogo periodo o periodi di tempo"; Italy-Pakistan BIT (1997): "successivamente continuerà a rimanere in vigore per ulteriore periodi di 5 anni"; Italy-Philippines BIT (1988): "esso resterà in vigore per un periodo di dieci anni e continuerà ad esserlo per un unteriore periodo di cinque anni e cosi di seguito"; Italy-Poland BIT (1989): "continuerà a restare in vigore per ulteriori periodi di cinque anni"; Italy-Romania BIT (1990): "sarà tacitamente rinnovato per successivi periodi di 5 anni"; Italy-Russian Federation BIT (1996): "resterà in vigore per ulteriori periodi di cinque anni"; ItalySenegal BIT (2000): "sarà rinnovato tacitamente ogni cinque anni”; Italy-Sri Lanka BIT (1987): "e resterà in vigore per un ulteriore periodo di cinque anni e così di seguito"; Italy-Turkey BIT (1995): "verrà tacitemente rinnovato per ulteriori periodi di 5 anni"; Italy-United Arab Emirates BIT (1995): "resterà in vigore per un ulteriore periodo o ulteriori periodi di 10 anni"; Italy-Uruguay BIT (1990): "si prorogherà tacitamente per successivi periodi di 5 anni"; Italy-Vietnam BIT (1990): "e sarà rinnovato per un periodo o dei periodi equivalenti". Only treaties that were available in Italian language have been analysed for variation for this paragraph.

According to information available to the OECD Secretariat at the time of writing, unilateral denunciation or withdrawal occurred in relation to the following treaties: Belgium/Luxembourg-South Africa BIT (1998); Indonesia-Norway BIT (1991); Netherlands-Venezuela BIT (1991); Romania-Ecuador BIT (1996); South Africa-Spain BIT (1998); South Africa-Switzerland BIT (1995); Spain-Bolivia BIT (2001); United States- 
Whether and how these treaties' rules on validity and termination have influenced -retarded or accelerated - the decision to terminate a treaty would require further research. Four of the denounced treaties were terminated at the end of the initial validity period. Also, four of the eight treaties would have been renewed for a further ten years had they not been denounced at that time. This suggests that the impending renewal for fixed periods may have actually sped up the denunciation, contrary to the likely intention of treaty negotiators to prolong the treaty's validity period. ${ }^{63}$

\section{Different treaty practice in BITs and non-BIT IIAs}

BITs and non-BIT IIAs, that is FTAs, EPAs, and CEPAs, do not generally reflect the same approach with respect to the definition of treaty validity. Important differences can be observed with respect to the existence of an initial validity period and of effects beyond the termination of the treaties. FTAs and similar agreements typically do not set either an initial validity period nor provide for effects beyond the end termination of the treaties, features that are almost universally present in BITs. Interestingly, non-BIT IIAs almost universally provide explicitly for the possibility of treaty amendments, a feature that can be found, but is rare, in BITs. ${ }^{64}$

\section{Sizeable individual and collective engagement}

The inclusion of initial validity periods and effects beyond treaties' termination, both almost universal features in IIAs, leads to sizeable initial engagements on treaty content by the treaty partners. In combination with the large number of treaties in effect, this leads to a collective engagement on the established system and content of IIAs, many of which were concluded under very different global economic conditions.

A fictitious scenario, in which all IIAs treaties in the sample would be denounced at the next possible moment, demonstrates this collective engagement. ${ }^{65}$ Figure 8 shows the percentage of treaties, based on treaties that are in force in 2013, that would be in force (grey graph) or would have effects (black graph) in a given year in the future under this fictitious scenario. It shows that the policy decisions made in existing treaties would continue to be binding almost all treaty partners until at least $2024 .^{66}$ More than half of the treaties that are in force in 2013 continue to apply in 2029, and in 20 years from now, in 2033, more than a quarter of the treaties would still have binding effects on treaty partners. Two treaties would have binding effects until 2053.

Bolivia BIT (1998). Also, Venezuela withdrew from the Colombia-Mexico FTA (1994) - initially a trilateral treaty, which continues to be in force among Colombia and Mexico.

According to the South African Government, the time of the denunciation of the Belgium/Luxembourg-South Africa BIT (1998) was driven by the otherwise foreseen renewal of the treaty for another ten years, see "Summary of Roundtable discussions of Roundtable on Freedom of Investment 17", p. 8. The South AfricaSpain BIT (1998) which South Africa denounced in mid-2013 also foresees renewals for fixed periods, albeit for unusually short 2-year terms. The South Africa-Switzerland BIT (1995), denounced in October 2013, did not feature fixed renewal periods, but could be denounced at any time once its initial period had ended.

For a more detailed analysis of such clauses on renegotiation of IIAs, see DAF/INV/WD(2013)9.

This scenario is fictitious in more than one way; it notably assumes that the ending of treaties would be achieved by unilateral denunciation, not by mutual agreement.

Very minor inaccuracies in the calculation may result from the fact that the exact day of the entry into force of the treaties has not been taken into consideration. 
Figure 8. Projection of future validity of treaties and extent of effects after termination

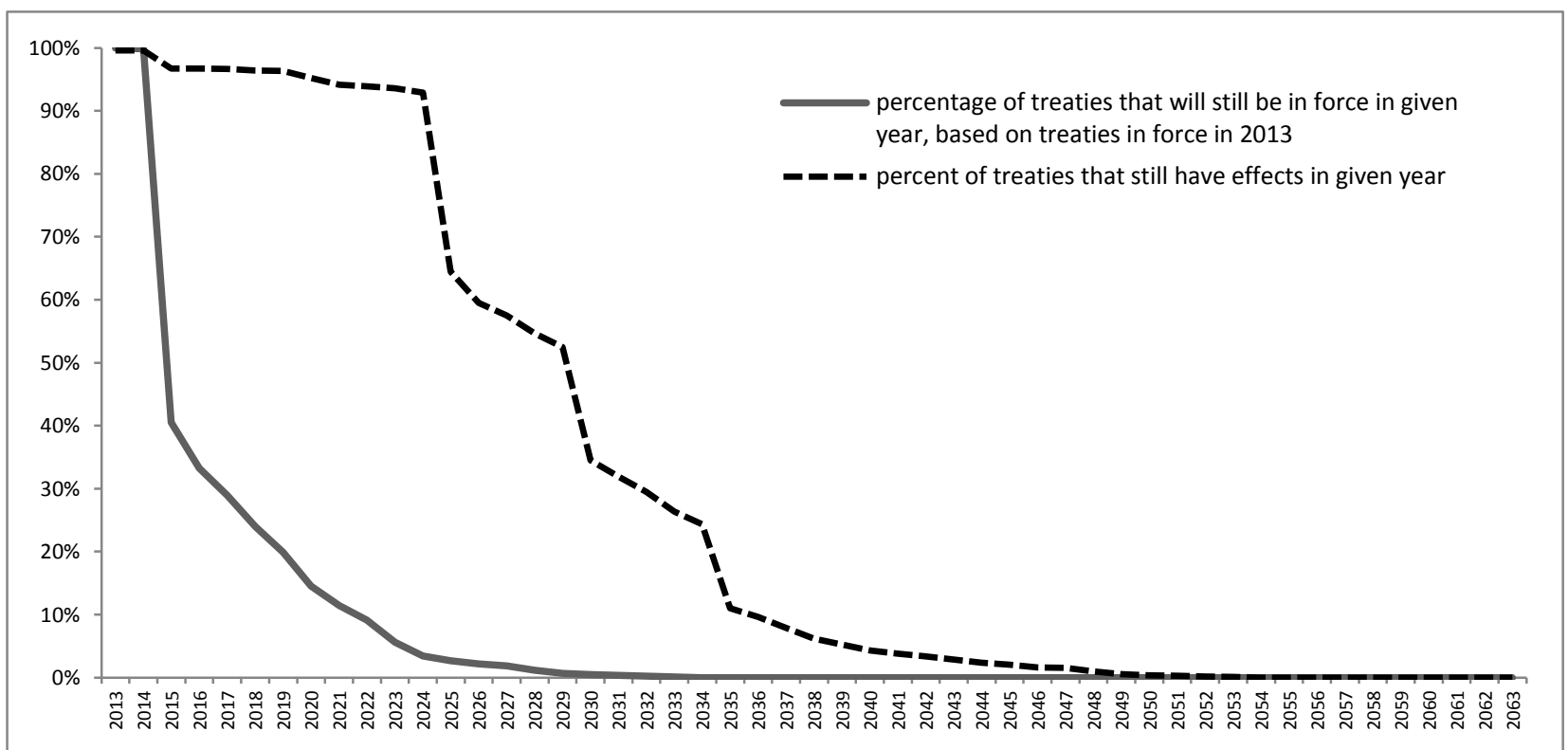

In turn, as the majority of treaties has no or has passed their initial validity period, within only one year, almost $60 \%$ of the treaties could be denounced. The remaining $41 \%$ of the treaties stay in force for longer, even for much longer: two treaties in the sample ${ }^{67}$ would remain in effect until 2033 were they denounced at the next possible occasion.

Individual countries' treaty populations would have quite different remaining lifespans under this fictitious scenario. These differences result from different policies with regard to the extension of treaty validities, existence and length of initial validity periods, and ages of treaty populations. Figure 9 shows a projection of the future validity of treaties concluded by selected countries under the fictitious scenario that all treaties would be denounced at the next possible occasion. Among these countries are the Netherlands and Belgium/Luxembourg, which have included treaty renewals for fixed periods in the large majority of their treaties; Sweden, Germany and the United Kingdom, which generally include clauses that extend the treaty for unlimited periods after the end of the initial validity periods; and Canada, which does generally not include initial validity periods and treaties and foresees the possibility to denounce the treaty at any time.

The policy choice for the extension of the treaty validity is the main driver for the different pace at which these countries' treaty populations would shrink. The slower decline of the number of Sweden's treaties is explained by the country's fairly long initial validity periods in combination with a great number of recently concluded treaties. The United Kingdom, in turn, would see the number of its treaties in force decline steeply, given that, compared to Sweden's treaties, the country's treaties are relatively old and have short initial validity periods. 


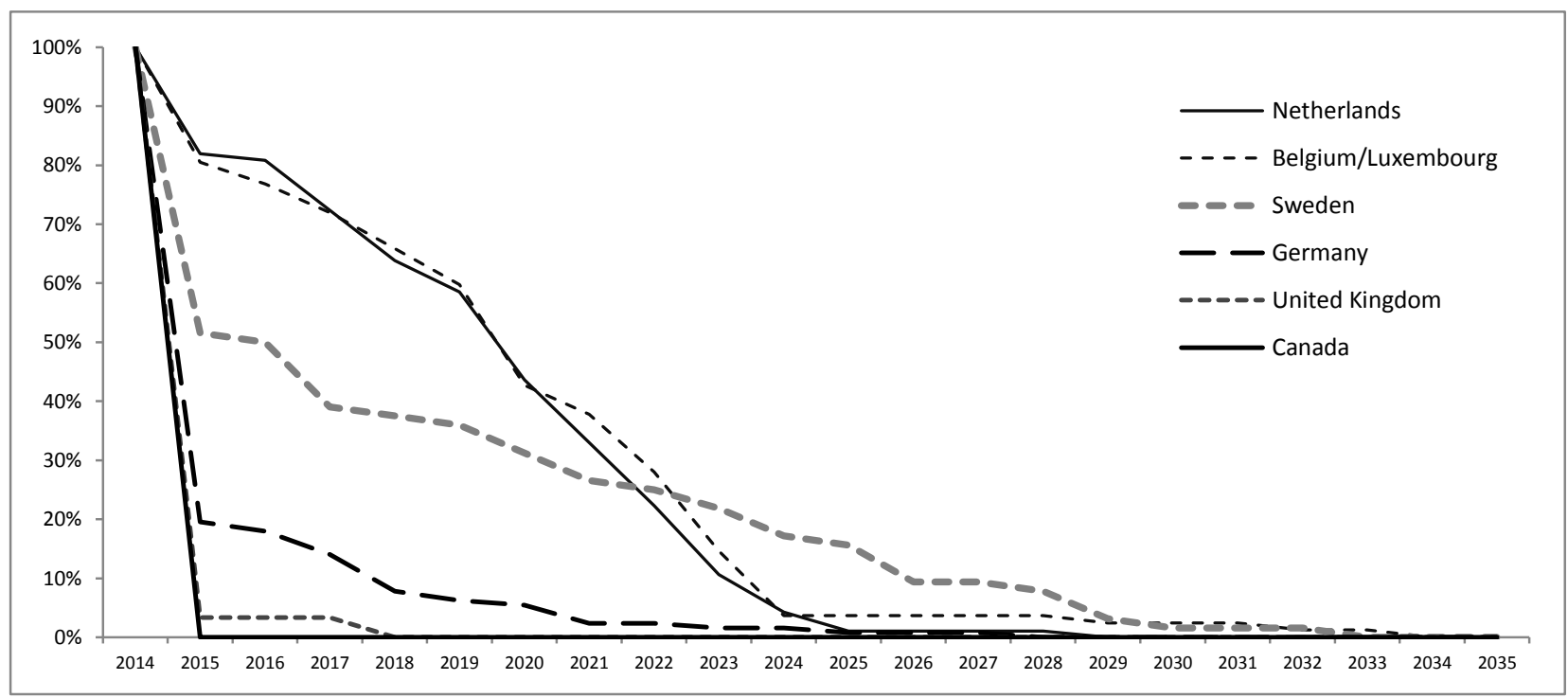

This reflection has some significance in cases where individual treaty partners decide to end their IIAs, as some countries have recently announced. In such scenarios, investors might be inclined to structure their investments through jurisdictions that have treaties with longer residual validity periods with respect to the countries that terminate their treaties. The treaty renewal policy - as the factor influencing residual validity - might create a comparative advantage for some jurisdictions to attract these investors.

\section{Intriguing policy choices}

The complex and differentiated rules on treaty validity, advance notices and effects beyond the end of a treaty's validity reflect a broad set of policy objectives. Although these objectives are not made explicit, including in documents that introduce model treaties or explain treaty content to parliaments called to ratify treaties, the individual objectives are relatively obvious and can arguably be summarised as follows:

- initial treaty validity periods seek to reward the negotiation effort by establishing a minimum validity duration;

- advance notice periods help treaty partners anticipate legal changes resulting from a denunciation and provide time to potentially renegotiate or revert a decision on denunciation; these advance notice periods also allow investors to anticipate the end of a protection under the treaty for new investments and potentially finish an investment project before the treaty termination date; and

- periods that procure treaty protection beyond the termination of the treaty protect sunk investments to allow for their amortisement or repatriation.

Against the background of these basic objectives, the intention of some policy choices in defining final provisions of treaties may warrant further reflection. The renewal of treaties for fixed terms, the undifferentiated length of effects beyond the treaty termination and the scope of investments that are covered by the treaty in case of termination are among these policy choices. 
While the aim of fixed-term renewals is arguably that it prolongs a given treaty's validity period to ensure greater predictability and stability of rights of investors, the approach creates strong fluctuations of the residual validity period of the treaty. Figure 10 shows the evolution of the residual validity of the Belgium/Luxembourg-Lithuania BIT (1997) over time (grey line); this treaty foresees, after the 10-year initial validity period, a tacit renewal for 10 year terms with 6-month notice to denunciation. The figure also shows the residual validity of the France-Moldova BIT (1997) (black dotted line), which allows for denunciation at any time with 12 months' notice once the initial validity period of 10 years has elapsed; it also allows the denunciation to the end of the initial validity period. Both treaties entered into force in late $1999 .{ }^{68}$

\section{Figure 10. Residual treaty validity of selected treaties at given points in time}

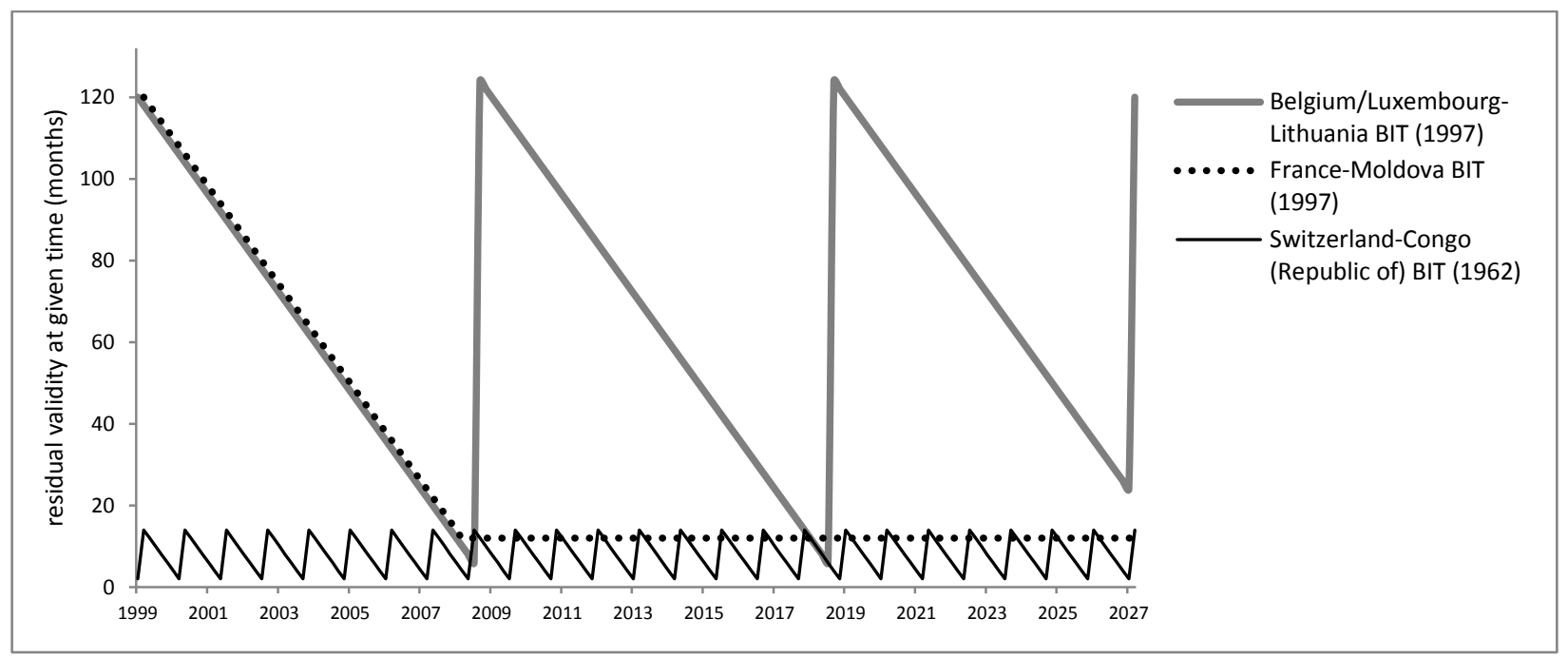

Figure 10 demonstrates that rather than providing an investor with a clear horizon of future treaty validity, the renewal for fixed terms leads to a dramatically changing horizon; this is all the more the case as the advance notice to denunciation of treaties that renew for fixed terms is usually shorter - typically 6 months as in the example - than the advance notice required in treaties that can be denounced at any time, where it is typically 12 months. In March 2009, for instance, an investor thus enjoyed the certainty of only 6 months treaty validity under the Belgium/Luxembourg-Lithuania BIT (1997); a few weeks later, the validity period jumped to 10.5 years, only to gradually decline again. An investor operating under the France-Moldova BIT (1997) would have enjoyed a residual treaty validity of at least 12 months at any given point in time.

The rationale behind such great fluctuation of the validity is not easy to identify. The approach may have been a continuation of a practice introduced in IIAs in the mid-1960s especially by Switzerland and the Netherlands. These treaties were renewed for fixed term periods, but unlike more recent treaties, the renewal periods were only one year long. In these early treaties, the fluctuation of the residual treaty validity had hardly any consequences, as the planning horizon for investors was always rather short. This is demonstrated in Figure 10, which also shows the validity cycle of the Switzerland-Congo (Republic

68 The Belgium/Luxembourg-Lithuania BIT (1997) entered into force on 23 September 1999, and the FranceMoldova BIT (1997) entered into force on 3 November 1999. 
of) BIT (1962) (fine black line), which came into effect in July 1964 and features 1 year renewal terms with 3 months advance notice to termination.

\section{b. Undifferentiated treaty effects beyond the end of the treaty validity}

Another interesting policy choice is the undifferentiated treatment of different categories of investment for the purpose of the treaty effects beyond a treaty's validity. Many forms of investments that are covered by the investment definition of IIAs, notably most portfolio investments, can be moved very quickly out of the country and do not necessarily warrant 10 or 20 -year protection periods. Such longer periods in turn may be easily justified for sunk investments which are difficult or impossible to transfer and may have long amortisation periods.

All but one of the treaties in the sample that grant treaty protections beyond the termination of the treaty do so regardless of the nature of the investment and the time it would take an investor to transfer the investment out of the country. The sole treaty that differentiates between investments for the purpose of the length of the treaty effects beyond termination, the Costa Rica-France BIT (1984), grants the longer period of 20 years for investments in the mineral sector; other investments benefit from only a 15 year period. This differentiation presumably takes into consideration the longer amortisation period of investments in this sector and the impossibility to transfer such investments. ${ }^{69}$

Beyond this case, no treaty has attempted to adapt the length of the protection beyond the end of the treaty validity to the nature of the investments and notably the time it would take to transfer the investment. To include all investments under the umbrella of the extended protection certainly has the merit of reducing legal uncertainty, but countries have otherwise not shied away from uncertainty in IIA provisions.

\section{c. Uncertainty of an investment's cover by treaty effects beyond the end of the treaty validity in case of termination}

Most treaties in the sample grant protections beyond the treaty's validity to all those investments that are made until the denunciation becomes effective. However, 39 treaties in the sample only protect investments that have been made until the notice of denunciation. ${ }^{70}$ Investments that are made after the notice do not benefit from the prolonged protection.

Investors are likely to be unaware that a notice of termination has been sent by or to their government. They are thus exposed to the risk that the treaty protections end altogether only six or twelve months after the notice of termination, while investors that have invested just before the notice benefit from the extended protection of a typically a decade. Depending on the treaty renewal mechanism, this risk may be permanent after the initial validity period - in treaties that are extended for an unlimited time, or it may reemerge - in cases of treaties that are renewed for fixed terms - in the period before the end of a validity term.

Investors have no way of managing this risk other than avoiding any investment during these periods, which, for treaties that are extended for an unlimited time, means permanently once the treaty has passed its initial validity period.

69

Article 13 alinea 3 of the Costa Rica-France BIT (1984) reads: "Al vencimiento del período de vigencia del presente convenio, las inversiones efectuadas durante su vigencia seguirán gozando de la protección de sus disposiciones durante un período suplementario de quince años, con excepción de las inversiones mineras cuyo plazo será de veinte años."

See above section 2 on "Treaty effects beyond the date of denunciation". 
Additional uncertainty stems from the imprecise definition of the exact cut-off date ${ }^{71}$ and from the possibility that a country could send a note earlier - even much earlier - than the exact 6 or 12 month period to the end of the validity period.

It is unclear what policy objective this treaty design serves and what potential benefits it could have for either the treaty partners or their investors.

\section{Editorial shortcomings and ambiguity}

The analysis of treaties' final provisions revealed, as a by-product, that a significant number of treaties have - in the version available to the Secretariat, which is often the official gazette of one of the treaty partners or a scan of the original, signed treaty - various editorial shortcomings in the short section that was analysed. These include: contradictory or incoherent design elements, incoherent grammar that obscures meaning, linguistic oversights, as well as obvious inconsistencies between different language versions of the same treaty. A number of treaties show very unusual design elements that suggest that they may not have been purposefully designed.

For 48 treaties in the sample, corresponding to $2.3 \%$ of the treaty sample, it was not possible to determine with any degree of certainty from the text of the treaty whether it has expired or when it will expire, or when or under which conditions it could be terminated. In many of these cases, language referring to unlimited extension is combined with language referring to renewal of the treaty validity for fixed periods. ${ }^{72}$ Hungary, the Czech Republic and, to a lesser extent, Korea, have repeated this language in a number of their treaties, and some other countries also occasionally use this language. ${ }^{73}$ The Belgium/Luxembourg-Morocco BIT (1999) mentions two different and competing advance notice periods, 6 months and 12 months. ${ }^{74}$ The Hungary-Turkey BIT (1992) refers to different and competing validity

71 Treaties in the sample specify the cut-off time with varying clarity: The Finland-Tunisia BIT (2001) states "fifteen years from the date of notification", the Italy-Lebanon BIT (1997) and the Romania-Mongolia BIT (1995) mention investments made "before the official notice was given". The Czech Republic-Norway BIT (1991) mentions the "receipt of the notice".

As an example of the 38 treaties featuring this problem, the Hungary-Ukraine BIT (1994), Art. 12 (2), states: "This Agreement shall remain in force for a period of ten years and shall continue in force thereafter unless, one year before the expiry of the initial or any subsequent periods, either Contracting Party notifies the other in writing of its intention to terminate the Agreement." (Emphasis added).

This language occurs in the following treaties: Bulgaria-Czech Republic BIT (1999), Bulgaria-Hungary BIT (1994), Czech Republic-Albania BIT (1994), Czech Republic-Croatia BIT (1996), Czech Republic-Egypt BIT (1993), Czech Republic-Hungary BIT (1993), Czech Republic-Korea BIT (1992), Czech Republic-Latvia BIT (1994), Czech Republic-Lithuania BIT (1994), Czech Republic-Peru BIT (1994), Czech RepublicRomania BIT (1993), Czech Republic-Tunisia BIT (1997), Czech Republic-Ukraine BIT (1994), Czech Republic-United Arab Emirates BIT (1994), Egypt-Hungary BIT (1995), Estonia-Azerbaijan BIT (2010), Hungary-Albania BIT (1996), Hungary-Kazakhstan BIT (1994), Hungary-Moldova BIT (1995), HungaryMongolia BIT (1994), Hungary-Romania BIT (1993), Hungary-Serbia BIT (2001), Hungary-Slovakia BIT (1993), Hungary-Ukraine BIT (1994), Hungary-Vietnam BIT (1994), Hungary-Yemen BIT (2004), IndonesiaSlovakia BIT (1994), Italy-Croatia BIT (1996), Korea-Algeria BIT (1999), Korea-Guatemala BIT (2000), Korea-Jamaica BIT (2003), Korea-South Africa BIT (1995), Korea-Vietnam BIT (1993), MoroccoTurkey BIT (1997), Poland-Vietnam BIT (1994), Sweden-Ukraine BIT (1995).

The treaty states, in Article 13(1): “A moins que l'une des Parties contractantes ne le dénonce au moins six mois avant l'expiration de sa période de validité, il est chaque fois reconduit tacitement pour une nouvelle période de dix ans, chaque Partie contractante se réservant le droit de le dénoncer par une notification introduite au moins douze mois avant la date d'expiration de la période de validité en cours." (Emphasis added). 
periods. ${ }^{75}$ The South Africa-Kuwait BIT (2005) states contradicting renewal periods of "...twenty (10) years..." The Greece-Albania BIT (1991) omits to state the initial validity period, focusing instead solely on the extension of the treaty. The Indonesia-Singapore BIT (2005) confuses singular and plural, ${ }^{76}$ leaving open whether the treaty can be extended once or multiple times.

In addition to these issues, quite a number of treaties in the sample feature language that - while being at times textually clear - invite dispute over legal consequences and interpretation. Many treaties for instance refer, for the scope of the rules applicable after the termination of the treaty, to specific articles of the treaty. The Spain-Ethiopia BIT (2006) for instance excludes Article 1 of the treaty, which contains definitions, from the scope of the provisions that continue to apply after the termination of the treaty. The Spain-Bolivia BIT (1990) includes only Articles 1 and 2, but not the substantive provisions of the treaty, in the scope of surviving clauses.

More generally, the reference to specific articles excludes - on the face of the treaty text - the preamble and the clause on the relation between different language versions - which is not included in a numbered article -, and in some cases the protocol linked to the treaty. This exclusion of treaty elements, which may contain substantive treaty content or at least clarify how the treaty is to be interpreted, creates some uncertainty about treaty content in the phase after treaty denunciation.

A third group of observations concern obvious oversights in the preparation of treaty text that suggest that, at times, little attention was given to their drafting. From among the ten treaties identified as having such issues, two examples may be cited as illustrations: The Germany-Kuwait BIT (1994), which states in Article 14 (1) and 14 (2) that "this Agreement shall remain in force for a period of (15) fifteen years [...] and shall continue to be effective for a further period of (20) twenty years ..." ${ }^{77}$ employing a very unusual order of text and bracketed numbers. The Germany-Cote d'Ivoire BIT (1966) has different text in the English and German language versions; the German text omits to mention the advance notice for termination at the end of the initial validity period.

Finally, a fourth group of treaties seems to reveal very unusual policy choices - so unusual in fact that one might wonder whether these are purposeful choices. The South Africa-Angola BIT (2005) for instance has no automatic renewal mechanism but enables the treaty partners to renew it for fixed periods. Moreover, the treaty effects beyond the termination of the treaty only apply if the treaty has been denounced, not in cases where it simply expired. ${ }^{78}$ Given that the treaty does not provide for automatic

The Hungary-Turkey BIT (1992) states, in Article 11(2): “Unless notice of termination has been given by either Contracting Party at least six months before the date of expiry of its validity, the present Agreement shall be extended tacitly for periods of 10 years, each Contracting Party reserving the right to terminate the Agreement upon notice at any time after the termination at the 15 year period."

The treaty states: "This agreement shall remain in force for a period of ten 910) years and shall continue in force thereafter for similar period unless either Contracting Party notifies the other Contracting Party in writing of its intention to terminate this Agreement one year before its expiration." (Emphasis added.)

77 Emphasis added.

The sections of Article 12 of the South Africa-Angola BIT (2005) read: “ [...] (2) This Agreement shall remain in force for a period of ten years whereafter it may be renews for succeeding periods of five (5) years. This renewal shall be made twelve (12) months before the expiration of the first ten year period and six (6) months before the expiration of the subsequent five year period. (3) Either Party may, at any time give notice of its intention to terminate this Agreement. In such a case, the Agreement shall continue in force until the expiration of twelve months from the date of the written notice of termination. (4) In respect of investments made prior to the date when the notice of termination becomes effective, the provisions of Articles 1 to 11 remain in force with respect to such investments for a further period of twenty (20) years from that date. [...]." 
renewal, expiry is the more likely scenario, and in this case, the treaty would have no effects beyond the end of its validity.

The South Africa-Guinea BIT (2007) provides for tacit renewal for 12-month periods; in addition to these unusually short renewal periods, the treaty also requires 12 -month advance notice. ${ }^{79}$ This combination of 12-month periods for renewal and advance notice has essentially the same result as if the treaty contained the possibility to denounce it at any time with 12 months' notice. The sole difference is that the denunciation can only be expressed at a specific time of the year. ${ }^{80}$

79 The clause in Article 12 (2) South Africa-Guinea BIT (2007) reads: "This Agreement shall remain in force for an initial period of ten years whereafter is shall automatically be renewed for further periods of twelve months, unless terminated by either Contracting Party by giving twelve months written notice in advance through the diplomatic channel to the other Contracting Party of its intention to terminate this Agreement."

The treaty has not yet entered into effect, but were it later denounced, its denunciation would take effect on the calendar day that follows the calendar day of the treaty's entry into force. 


\section{ANNEX 1: METHODOLOGY}

The sample for this survey consists of 2,061 treaties; the vast majority of these treaties are bilateral investment treaties (BITs), but 52 bilateral free trade agreements with investment provisions are also present in the sample. The sample covers bilateral investment agreements that the 55 economies that are invited to participate in the Freedom of Investment Roundtables ${ }^{81}$ have concluded with any other economy. ${ }^{82}$

The sample includes IIAs available on government websites of countries that participate in the Freedom of Investment Roundtables, as well as websites maintained by international or regional organisations. ${ }^{83}$ Agreements were included if they were available by October 2013 and if they were available in a language accessible to the Secretariat (English, French, German, Italian, Spanish, Portuguese). Every effort was made to verify the authenticity of the available treaty texts. However, the Secretariat was not always in a position to assess whether the reproduced text corresponds to the concluded text.

The treaty sample was composed in an endeavour to make it as complete as possible. It is therefore not necessarily representative, and may be biased for a number of reasons. Some treaties, especially those signed just prior to or in 2013 may not be available on publicly available databases used for this survey and are thus not included in this survey. FTAs are typically hosted on different government websites than BITs, and, unlike for BITs, no systematic collection of FTAs seems to have been attempted. The full list of bilateral treaties included in the sample is available in Annex 2.

Some multilateral investment agreements of which FOI participants are signatories or adherents were also considered for the analysis but are not included in aggregates and related calculations. These agreements include the Energy Charter Treaty (1991), CAFTA (2004), NAFTA (1992), China-Japan-

81 Argentina, Australia, Austria, Belgium, Brazil, Bulgaria, Canada, Chile, China, Colombia, Costa Rica, Czech Republic, Denmark, Egypt, Estonia, Finland, France, Germany, Greece, Hungary, Iceland, India, Indonesia, Ireland, Israel, Italy, Japan, Jordan, Korea, Latvia, Lithuania, Luxembourg, Malaysia, Mexico, Morocco, Netherlands, New Zealand, Norway, Peru, Poland, Portugal, Romania, Russian Federation, Saudi Arabia, Slovakia, Slovenia, South Africa, Spain, Sweden, Switzerland, Tunisia, Turkey, United Kingdom, United States and the European Union.

Where the term "country" is used in this paper, it does not imply any judgement by the OECD as to the legal or other status of any territorial entity. Belgium and Luxembourg have concluded treaties jointly as the "Belgium-Luxembourg Economic Union"; while they constitute a joint treaty partner, this report counts the Belgium-Luxembourg Economic Union as two countries, but counts treaties concluded by the Economic Union only once.

83 These include websites of the governments of Australia, Austria, Belgium, Canada, Chile, China, Colombia, Costa Rica, the Czech Republic, France, India, Indonesia, Italy, Japan, Mexico, Netherlands, New Zealand, Norway, Peru, Poland, Portugal, Romania, the Russian Federation, Slovenia, South Africa, Spain, Sweden, Switzerland, the United Kingdom and the United States. Additional treaties were drawn from the website of the German Institute of Arbitration, the United Nations Treaty database and the website of the OAS. Treaties that were not available on these websites were taken from the WIPO treaty database and from UNCTAD's BIT database. 
Korea trilateral Investment Agreement (2012), Investment Agreement for the COMESA Common Investment Area (2007), and the ASEAN Comprehensive Investment Agreement (2009).

Treaties have been included in the sample regardless of whether they are in force given the interest even of superseded treaties for tracing the historical development of treaty practice. ${ }^{84}$ Up to $16.4 \%$ of the treaties in the sample are not or may not be in force. This may lead to overstating of the size of countries' treaty stocks, relative to the true stock of countries' in-force treaties.

Numerous treaties in the sample have been concluded by entities that no longer exist or have changed their name. The name of economies in treaty names used in this document may thus not reflect the name of the economy that has initially concluded a treaty (e.g. USSR, Yugoslavia, Zaire, etc.); the names used to designate certain treaties attempt to reflect the current designation of the economy that has succeeded the initial treaty partner.

The distribution of treaties over time is uneven, reflecting largely variation in treaty making activity, and, to some extent, the greater likelihood that very recently concluded treaties and superseded treaties are not publicly available. Figure 11 shows the composition of the sample with respect to how many bilateral treaties have been concluded in a given year, distinguishing between BITs and non-BIT IIAs.

Figure 11. Number of sample treaties concluded by year in period 1959-2013

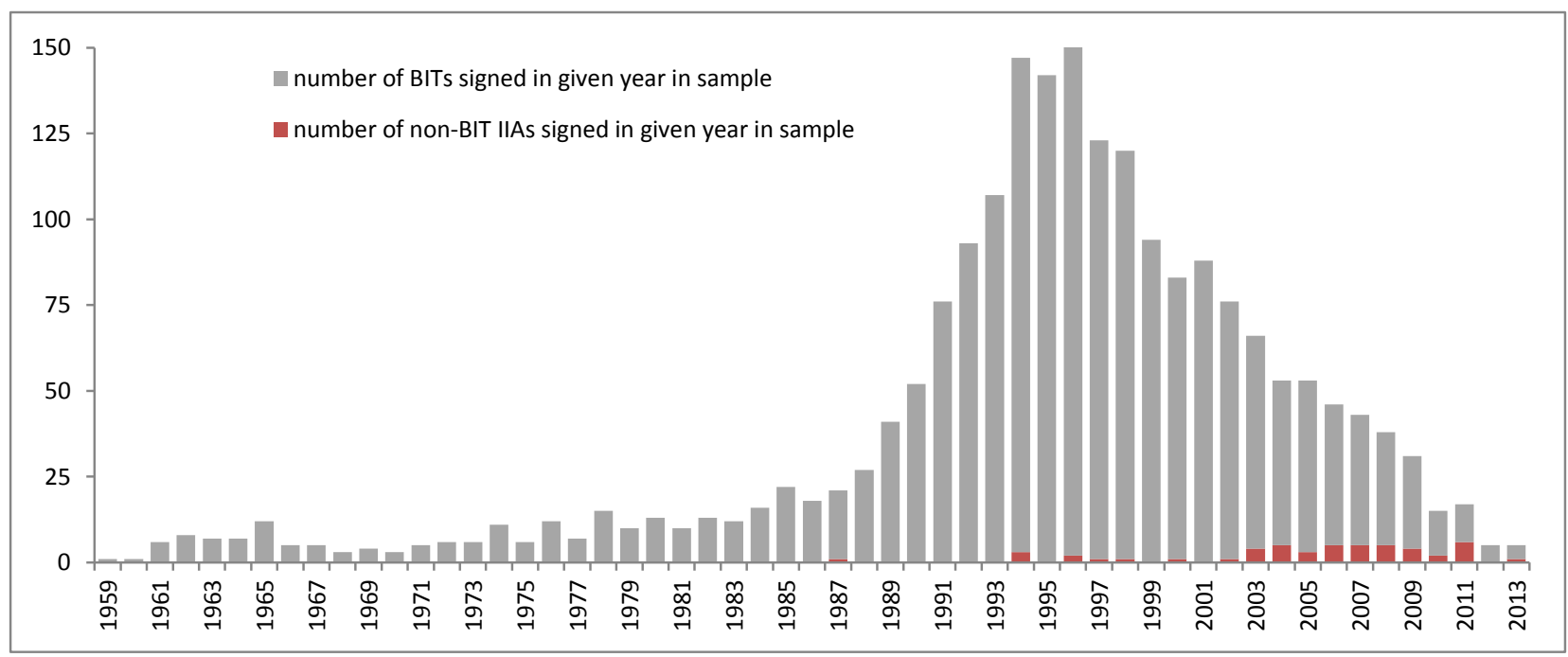

The survey technique involves identifying treaty language related to the subject matter, analysing the identified provisions with respect to a "grid" of characteristics based on language found in the treaty sample. Each treaty was "scored" with respect to all of these characteristics. Several OECD staff were involved in the treaty scoring process, and steps were taken to ensure that all staff scored treaties in the same way. These steps included cross checking and ex-post verification.

$84 \quad$ Treaties that at the time of writing were not yet in force, were denounced or suspended or superseded by later treaties, or treaties of which the entry into force could not be determined show in italics where they are mentioned in this document. Some additional treaties in the sample that do not show in italics may have expired; uncertainties in the definition of the validity periods in these treaties do not allow a definite answer as to whether they are still in force. 
The interpretation of provisions in some treaties was particularly challenging. In these cases, the Secretariat left the data entry blank or chose, for the purpose of calculations and graphic display of evolutions, the most likely interpretation.

Unless noted specifically, calculations and graphic representations of individual economies' treaty populations take into consideration all of a given economy's treaties included in the sample, that is, including superseded treaties. The rationale behind this inclusion is to show a given economy's policy approach, which is expressed in all of its treaties regardless of whether these treaties are in force. 


\section{ANNEX 2: TREATY SAMPLE}

This annex contains the list of treaties that have been analysed for the purpose of the present study. Treaties in italics were, according to publicly available information accessed by the Secretariat, not yet or no longer in force at the time of writing in October 2013. The treaties are listed in alphabetical order for each country, resulting in a double listing of treaties concluded between Roundtable participants. The electronic version of the present document provides access to the full text of the treaty through a hyperlink under the treaty name.

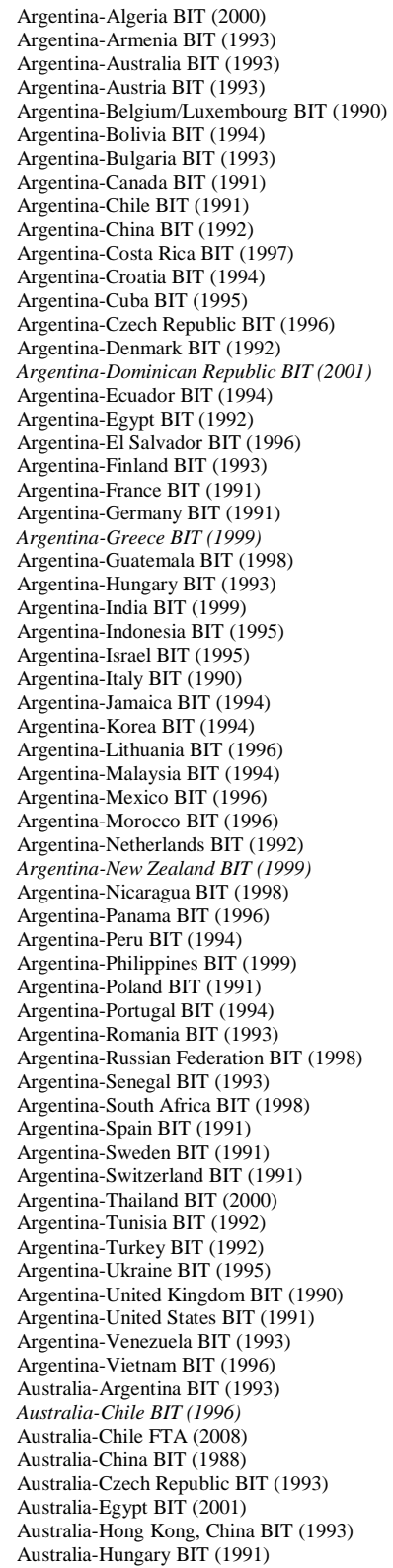

Australia-India BIT (1999)

Australia-Indonesia BIT (1992)

Australia-Lao PDR BIT (1994)

Australia-Lithuania BIT (1998)

Australia-Mexico BIT (1994)

Australia-New Zealand (ANZCERTA Investment Protocol) (2011)

Australia-Pakistan BIT (1998)

Australia-Papua New Guinea BIT (1990)

Australia-Peru BIT (1995)

Australia-Philippines BIT (1995)

Australia-Poland BIT (1991)

Australia-Romania BIT (1993)

Australia-Singapore FTA (2004)

Australia-Thailand FTA (2004)

Australia-Turkey BIT (2005)

Australia-United States FTA (2004)

Australia-Uruguay BIT (2001)

Australia-Vietnam BIT (1991)

Austria-Albania BIT (1993)

Austria-Algeria BIT (2003)

Austria-Argentina BIT (1993)

Austria-Arnenia BIT (2001)

Austria-Azerbaijan BIT (2000)

Austria-Bangladesh BIT (2000)

Austria-Belarus BIT (2001)

Austria-Belize BIT (2001)
Austria-Bolivia BIT (1997)

Austria-Bosnia and Herzegovina BIT (2000)

Austria-Bulgaria BIT (1997)

Austria-Cape Verde BIT (1991)

Austria-Chile BIT (1997)

Austria-China BIT (1985)

Austria-Croatia BIT (1997)

Austria-Cuba BIT (2000)

Austria-Czech Republic BIT (1990)

Austria-Egypt BIT (2001)

Austria-Estonia BIT (1994)

Austria-Ethiopia BIT (2004)

Austria-FYROM BIT (2001)

Austria-FYROM BIT (2001)

Austria-Georgia BIT (2001)

Austria-Guatemala BIT (2006)

Austria-Hong Kong, China BIT
Austria-Hungary BIT (1988)

Austria-Hungary BIT (1988)

Austria-India BIT (1999)

Austria-Iran BIT (2001)
Austria-Jordan BIT (2001)

Austria-Jordan BIT (2001)

Austria-Kazakhstan BIT (2010)

Austria-Korea BIT (1991)
Austria-Kosovo BIT (2010)

Austria-Kosovo BIT (2010)

Austria-Kuwait BIT (1996)

Austria-Latvia BIT (1994)
Austria-Lebanon BIT (2001)

Austria-Libya BIT (2002)

Austria-Lithuania BIT (1996)

Austria-Malaysia BIT (1985)

Austria-Malta BIT (2002)

Austria-Mexico BIT (1998)

Austria-Moldova BIT (2001)

Austria-Mongolia BIT (2001)

Austria-Morocco BIT (1992)

Austria-Morocco BIT (1992)

Austria-Namibia BIT (2003)

Austri-Paraguay BIT (1993)

Austria-Paraguay BIT (1993)

Austria-Philippines BIT (2002)

Austria-Poland BIT (1988)
Austria-Romania BIT (1996)

Austria-Russian Federation BIT (1990)

Austria-Saudi Arabia BIT (2001)

Austria-Serbia BIT (1989)

Austria-Slovenia BIT (2001)

Austria-South Africa BIT (1996)

Austria-Tunisia BIT (1995)

Austria-Turkey BIT (1988)

Austria-Ukraine BIT (1996)

Austria-United Arab Emirates BIT (2001)

Austria-Uzbekistan BIT (2000)

Austria-Vietnam BIT (1995)

Austria-Yemen BIT (2003)

Belgium/Luxembourg-Albania BIT (1999) Belgium/Luxembourg-Algeria BIT (1991)

Belgium/Luxembourg-Argentina BIT (1990)

Belgium/Luxembourg-Armenia BIT (2001)

Belgium/Luxembourg-Azerbaijan BIT (2004)

Belgium/Luxembourg-Azerbaijan BIT (2004)

Belgium/Luxembourg-Bangladesh BIT (1981)

Belgium/Luxembourg-Barbados BIT (2009)

Belgium/Luxembourg-Belarus BIT (2002)

Belgium/Luxembourg-Benin BIT (2001)

Belgium/Luxembourg-Bolivia BIT (1990)
Belgium/Luxembourg-Bosnia and Herzegovina BIT (2004)

Belgium/Luxembourg-Bosnia and Herzegovia
Belgium/Luxembourg-Bulgaria BIT (1988)

Belgium/Luxembourg-Burkina Faso BIT (2001)

Belgium/Luxembourg-Burundi BIT (1989)

Belgium/Luxembourg-Cameroon BIT (1980)

Belgium/Luxembourg-Chile BIT (1992)

Belgium/Luxembourg-China BIT (1984)

Belgium/Luxembourg-China BIT (2005)

Belgium/Luxembourg-Colombia BIT (2009)

Belgium/Luxembourg-Comoros BIT (2001)

Belgium/Luxembourg-Congo (Democratic Republic) BIT (2005)

Belgium/Luxembourg-Costa Rica BIT (2002)

Belgium/Luxembourg-Cote d Tvoire BIT (1999)

Belgium/Luxembourg-Croatia BIT (2001)

Belgium/Luxembourg-Cuba BIT (1998)

Belgium/Luxembourg-Cyprus BIT (1991) ${ }^{1}$

1. Footnote by Turkey: The information in this document with reference to "Cyprus" relates to the southern part of the Island. There is no single authority representing both Turkish and Greek Cypriot people on the Island. Turkey recognizes the Turkish Republic of Northern Cyprus (TRNC). Until a lasting and equitable solution is found within the context of the United Nations, Turkey shall 
Belgium/Luxembourg-Czech Republic BIT (1989) Belgium/Luxembourg-Egypt BIT (1977) (1999) Belgium/Luxembourg-El Salvador BIT (1999) Belgium/Luxembourg-Estonia BIT (1996) Belgium/Luxembourg-Ethiopia BIT (2006) Belgium/Luxembourg-FYROM BIT (1999) Belgium/Luxembourg-Gabon BIT (1998) Belgium/Luxembourg-Georgia BIT (1993) Belgium/Luxembourg-Guatemala BIT (2005) Belgium/Luxembourg-Hong Kong, China BIT (1996) Belgium/Luxembourg-Hungary BIT (1986) Belgium/Luxembourg-India BIT (1997) Belgium/Luxembourg-Indonesia BIT (1970) Belgium/Luxembourg-Kazakhstan BIT (1998) Belgium/Luxembourg-Korea BIT (1974) Belgium/Luxembourg-Korea BIT (2006) Belgium/Luxembourg-Kosovo BIT (2010) Belgium/Luxembourg-Kuwait BIT (2000) Belgium/Luxembourg-Latvia BIT (1996) Belgium/Luxembourg-Lebanon BIT (1999) Belgium/Luxembourg-Lebanon BIT (1999) Belgium/Luxembourg-Lithuania BIT (1997) Belgium/Luxembourg-Madagascar BIT (2005) Belgium/Luxembourg-Madagascar BIT (2005)
Belgium/Luxembourg-Malaysia BIT (1979) Belgium/Luxembourg-Malaysia BIT (1979)
Belgium/Luxembourg-Malta BIT (1987) Belgium/Luxembourg-Malta BIT (1987)
Belgium/Luxembourg-Mauritius BIT (2005) Belgium/Luxembourg-Mauritius BIT (2005) Belgium/Luxembourg-Mexico BIT (1998) Belgium/Luxembourg-Moldova BIT (1996) Belgium/Luxembourg-Mongolia BIT (1992) Belgium/Luxembourg-Morocco BIT (1965) Belgium/Luxembourg-Morocco BIT (1999) Belgium/Luxembourg-Mozambique BIT (2006) Belgium/Luxembourg-Nicaragua BIT (2005) Belgium/Luxembourg-Pakistan BIT (1998) Belgium/Luxembourg-Panama BIT (2009) Belgium/Luxembourg-Paraguay BIT (1992) Belgium/Luxembourg-Peru BIT (2005) Belgium/Luxembourg-Philippines BIT (1998) Belgium/Luxembourg-Poland BIT (1987)
Belgium/Luxembourg-Romania BIT (1978) Belgium/Luxembourg-Romania BIT (1978) Belgium/Luxembourg-Romania BIT (1996)
Belgium/Luxembourg-Russian Federation BIT (1989) Belgium/Luxembourg-Russian Federation B
Belgium/Luxembourg-Rwanda BIT (1983) Belgium/Luxembourg-Saudi Arabia BIT (2001) Belgium/Luxembourg-Saudi Arabia BIT
Belgium/Luxembourg-Serbia BIT (2004) Belgium/Luxembourg-Serbia BIT (2004) Belgium/Luxembourg-Singapore BIT (1978) Belgium/Luxembourg-Slovakia BIT (1989) Belgium/Luxembourg-Slovenia BIT (1999) Belgium/Luxembourg-South Africa BIT (1998) Belgium/Luxembourg-Sri Lanka BIT (1982) Belgium/Luxembourg-Sudan BIT (2005) Belgium/Luxembourg-Tajikistan BIT (2009) Belgium/Luxembourg-Thailand BIT (2002) Belgium/Luxembourg-Togo BIT (2009) Belgium/Luxembourg-Tunisia BIT (1964) Belgium/Luxembourg-Tunisia BIT (1997) Belgium/Luxembourg-Turkey BIT (1986) Belgium/Luxembourg-Uganda BIT (2005) Belgium/Luxembourg-Ukraine BIT (1996) Belgium/Luxembourg-United Arab Emirates BIT (2004) Belgium/Luxembourg-Uruguay BIT (1991)

preserve its
$\begin{aligned} & \text { concerning } \\ & \text { issue". }\end{aligned}$

2. Footnote by all the European Union Member States of the OECD and the European Union: The Republic of Cyprus is recognized by all members of the United Nations with the exception of Turkey. The information in this document relates to the area under the effective control of the Government of the Republic of Cyprus.
Belgium/Luxembourg-Uzbekistan BIT (1998) Belgium/Luxembourg-Venezuela BIT (1998) Belgium/Luxembourg-Vietnam BIT (1991) Belgium/Luxembourg-Yemen BIT (2000) Belgium/Luxembourg-Zambia BIT (2001) Brazil-Chile BIT (1994)

Brazil-Cuba BIT (1997)

Brazil-Denmark BIT (1995)

Brazil-Finland BIT (1995)

Brazil-Germany BIT (1995)

Brazil-Korea BIT (1995)

Brazil-Netherlands BIT (1998)

Brazil-Portugal BIT (1994)

Brazil-Venezuela BIT (1995)

Bulgaria-Albania BIT (1994)

Bulgaria-China BIT (1989)

Bulgaria-Cyprus BIT (1987)

Bulgaria-Czech Republic BIT (1999)

Bulgaria-Denmark BIT (1993)
Bulgaria-Egypt BIT (1998)

Bulgaria-Finl BI BIT (1997)

Bulgaria-Finland BIT (1997)

Bulgaria-France BIT (1989)

Bulgaria-Germany BIT (1986)

Bulgaria-Ghana BIT (1989)

Bulgaria-Greece BIT (1993)
Bulgaria-Hungary BIT (1994)

Bulgaria-Hungary BIT (1994)
Bulgaria-India BIT (1998)

Bulgaria-India BIT (1998)
Bulgaria-Indonesia BIT (2003)

Bulgaria-Indonesia BIT (2003)

Bulgaria-Israel BIT (1993)
Bulgaria-Italy BIT (1988)

Bulgaria-Italy BIT (1988)
Bulgaria-Kuwait BIT (1997)

Bulgaria-Lebanon BIT (1999)

Bulgaria-Malta BIT (1984)

Bulgaria-Morocco BIT (1996)

Bulgaria-Netherlands BIT (1988)

Bulgaria-Netherlands BIT (1999)

Bulgaria-Poland BIT (1994)

Bulgaria-Portugal BIT (1993)

Bulgaria-Romania BIT (1994)

Bulgaria-Singapore BIT (2003)

Bulgaria-Slovakia BIT (1994)

Bulgaria-Slovakia BIT (1994)

Bulgaria-Slovenia BIT (1998)

Bulgaria-Spain BIT (1995)

Bulgaria-Sweden BIT (1994)

Bulgaria-Thailand BIT (2003)

Bulgaria-Turkey BIT (1994)
Bulgaria-United Kingdom BIT (1995)

Bulgaria-United States BIT (1992)

Bulgaria-Vietnam BIT (1996)

Canada-Argentina BIT (1991)

Canada-Armenia BIT (1997)

Canada-Barbados BIT (1996)

Canada-Benin BIT (2013)

Canada-Chile FTA (1996)

Canada-China BIT (2012)

Canada-Colombia FTA (2008)

Canada-Costa Rica BIT (1998)

Canada-Croatia BIT (1997)

Canada-Czech Republic BIT (1990)

Canada-Czech Republic BIT (2009)

Canada-Ecuador BIT (1996)

Canada-Ecuador BIT (1996)

Canada-Egypt BIT (1996)
Canada-El Salvador BIT (1999)

Canada-El Salvador BIT (1999)

Canada-Hungary BIT (199)

Canada-Israel FTA (1996)

Canada-Jordan BIT (2009)

Canada-Kuwait BIT (2011)

Canada-Latvia BIT (1995)

Canada-Latva BIT (2009)

Canada-Lebanon BIT (1997)

Canada-Panama BIT (1996)

Canada-Panama FTA (2010)

Canada-Peru BIT (2006)

Canada-Peru FTA (2008)

Canada-Philippines BIT (1995)

Canada-Poland BIT (1990)

Canada-Romania BIT (1996)

Canada-Romania BIT (2009)

Canada-Russian Federation BIT (1989)

Canada-Slovakia BIT (1990)

Canada-Slovakia BIT (2012)

Canada-South Africa BIT (1995)

Canda-Tanzania BIT (2013)

Canada-Tanzania BIT (2013)

Canada-Trinidad and Tobago BIT (1995)

Canada-Ukraine BIT (1994)

Canada-United States FTA (1987)

Canada-Uruguay BIT (1997)

Canada-Venezuela BIT (1996)

Chile-Argentina BIT (1991)

Chile-Australia BIT (1996)

Chile-Australia FTA (2008)

Chile-Austria BIT (1997)
Chile-Belgium/Luxembourg BIT (1992)

Chile-Bolivia BIT (1994)

Chile-Brazil BIT (1994)

Chile-Canada FTA (1996)

Chile-China BIT (1994)

Chile-Colombia BIT (2000)

Chile-Colombia FTA (2006)

Chile-Costa Rica BIT (199)

Chile-Croatia BIT (1994

Chile-Cuba BIT (1996)

Chile-Czech Republic BIT (1995)

Chile-Denmark BIT (1993)

Chile-Ecuador BIT (1993)

Chile-Egypt BIT (1999)

Chile-El Salvador BIT (1996)

Chile-Finland BIT (1993)

Chile-France BIT (1992)

Chile-Germany BIT (1991)

Chile-Greece BIT (1996)

Chile-Guatemala BIT (1996)

Chile-Guatemala BIT (1996)

Chile-Honduras BIT (1996)

Chile-Hungary BIT (1997)

Chile-Indonesia BIT (1999)

Chile-Indonesia BIT (1999)

Chile-Italy BIT (1993)

Chile-Japan EPA (2007)

Chile-Korea BIT (1996)

Chile-Korea FTA (2003)

Chile-Lebanon BIT (1999)

Chile-Malaysia BIT (1992)

Chile-Mexico FTA (1998)

Chile-Netherlands BIT (1998)

Chile-New Zealand BIT (1999)

Chile-Nicaragua BIT (1996)

Chile-Norway BIT (1993)

Chile-Panama BIT (1996)

Chile-Paraguay BIT (1995)

Chile-Peru BIT (2000)

Chile-Peru FTA (2006)

Chile-Philippines BIT (1995)

Chile-Poland BIT (1995)

Chile-Porand BIT (1995)

Chile-Portugal BIT (1995)

Chile-Romania BIT (1995)

Chile-South Africa BIT (1998)

Chile-Spain BIT (1991)

Chile-Sweden BIT (1993)

Chile-Switzerland BIT (1999)

Chile-Tunisia BIT (1998)

Chile-Turkey BIT (1998)

Chile-Ukraine BIT (1995)

Chile-United Kingdom BIT (1996)

Chile-United States FTA (2003)

Chile-Uruguay BIT (1995)

Chile-Venezuela BIT (1993)

Chile-Vietnam BIT (1999)

China-Albania BIT (1993)

China-Algeria BIT (1996)

China-Argentina BIT (1992)

China-Australia BIT (1988)

China-Austria BIT (1985)

China-Bahrain BIT (1999)

China-Belgium/Luxembourg BIT (1984)

Chin-Belgiu/Luxemborg BIT (2005)

China-Belize BIT (1999)

China-Benin BIT (2004)

China-Bolivia BIT (1992)

China-Bosia and Herzegovina BIT (2002)

otswana BIT (2000)

China-Brunei Darussalam BIT (2000)

China-Bulgaria BIT (1989)

China-Cambodia BIT (1996)

China-Cameroon BIT (1997)

China-Canada BIT (2012)

China-Cap Verde BIT (1998)

China-Chile BIT (1994)

China-Colombia BIT (2008)

China-Cote d Tvoire BIT (2002)

China-Croatia BIT (1993)

China-Cuba BIT (1995)

China-Czech Republic BIT (2005)

China-Denmark BIT (1985)

China-Djibouti BIT (2003)

China-Djlbouti BIT (2003)

Chin-Ecuador BIT (1994)

China-Egypt BIT (1994)

China-Equatorial Guinea BIT (2005)

China-Estonia BIT (1993)

China-Ethiopia BIT (1998)

China-Finland BIT (1984)

China-Finland BIT (2004)

China-France BIT (1984)

China-France BIT (2007)

China-Georgia BIT (1993)

China-Germany BIT (1983)

China-Germany BIT (2003) 
China-Ghana BIT (1989) China-Greece BIT (1992) China-Guyana BIT (2003) China-Hungary BIT (1991) China-Iceland BIT (1994) China-India BIT (2006) China-Indonesia BIT (1994) China-Iran BIT (2000) China-Israel BIT (1995) China-Italy BIT (1985) China-Jamaica BIT (1994) China-Japan BIT (1988) China-Jordan BIT (2001) China-Korea BIT (1992) China-Korea BIT (2007) China-Kuwait BIT (1985) China-Lao PDR BIT (1993) China-Latvia BIT (2004) China-Lebanon BIT (1996) China-Lithuania BIT (1993) China-Madagascar BIT (2005) China-Mataysia BIT (1988) China-Me itius BIT (1996) China-Mauritius BIT (1996) China-Mexico BIT (2008) China-Mongolia BIT (1991) China-Myanmar BIT (2001) China-Netherlands BIT (1985) China-Netherlands BIT (2001) China-New Zealand BIT (1988) China-New Zealand FTA (2008) China-Nigeria BIT (2001) China-North Korea BIT (2005) China-Norway BIT (1984) China-Oman BIT (1995) China-Pakistan BIT (1989) China-Papua New Guinea BIT (1991) China-Peru BIT (1994) China-Peru FTA (2009) China-Philippines BIT (1992) China-Poland BIT (1988) China-Portugal BIT (1992) China-Portol BIT (1992) China-Portugal BIT (2095) China-Qatar BIT (1999) China-Russian Federation BIT (2006) China-Serbia BIT (1995) China-Singapore BIT (1985) China-Slovakia BIT (1991) China-Slovenia BIT (1993) China-South Africa BIT (1997) China-Spain BIT (1992) China-Spain BIT (2005) China-Sri Lanka BIT (1986) China-Sudan BIT (1997) China-Sweden BIT (1982) China-Switzerland BIT (1986) China-Switzerland BIT (2009) China-Syria BIT (1996) China-Thailand BIT (1985)

China-Trinidad and Tobago BIT (2002) China-Tunisia BIT (2004) China-Turkey BIT (1990) China-Turkey BIT (1990) China-United Arab Emirates BIT (1993) China-United Kingdom BIT (1986) China-Uruguay BIT (1993) China-Uruguay BIT (1993) China-Vietnam BIT (1992) Colombia-Belgium/Luxembourg BIT (2009) Colombia-Canada FTA (2008) Colombia-Chile BIT (2000) Colombia-Chile FTA (2006) Colombia-China BIT (2008) Colombia-India BIT (2009) Colombia-Japan BIT (2011) Colombia-Korea FTA (2013) Colombia-Mexico FTA (1994) Colombia-Peru BIT (1994) Colombia-Peru BIT (2007) Colombia-Spain BIT (1995) Colombia-Spain BIT (2005) Colombia-Switzerland BIT (2006) Colombia-United Kingdom BIT (2010) Colombia-United Kingdom BIT (2014
Costa Rica-Argentina BIT (1997) Costa Rica-Argentina BIT (1997)
Costa Rica-Belgium/Luxembourg BIT (2002) Costa Rica-Belgium/Luxembourg Costa Rica-Bolivia BIT (2002) Costa Rica-Chile BIT (1996) Costa Rica-Chinese Taipei BIT (1999) Costa Rica-Czech Republic BIT (1998) Costa Rica-Ecuador BIT (2001) Costa Rica-Finland BIT (2001) Costa Rica-France BIT (1984) Costa Rica-Germany BIT (1994)
Costa Rica-Korea BIT (2000) Costa Rica-Mexico FTA (1994) Costa Rica-Netherlands BIT (1999) Costa Rica-Paraguay BIT (1998) Costa Rica-Peru FTA (2011) Costa Rica-Singapore FTA (2010) Costa Rica-Spain BIT (1997) Costa Rica-Switzerland BIT (1965) Costa Rica-Switzerland BIT (2000) Costa Rica-United Kingdom BIT (1982) Costa Rica-Venezuela BIT (1997) Czech Republic-Albania BIT (1994) Czech Republic-Algeria BIT (2000) Czech Republic-Argentina BIT (1996) Czech Republic-Australia BIT (1993) Czech Republic-Austria BIT (1990) Czech Republic-Azerbaijan BIT (2011) Czech Republic-Bahrain BIT (2007) Czech Republic-Belarus BIT (1996) Czech Republic-Belgium/Luxembourg BIT (1989) Czech Republic-Bosnia and Herzegovina BIT (2002) Czech Republic-Bulgaria BIT (1999) Czech Republic-Cambodia BIT (2008) Czech Republic-Canada BIT (1990) Czech Republic-Canada BIT (2009) Czech Republic-Chile BIT (1995) Czech Republic-China BIT (2005) Czech Republic-Costa Rica BIT (1998) Czech Republic-Croatia BIT (1996) Czech Republic-Cyprus BIT (2001) Czech Republic-Denmark BIT (1991) Czech Republic-Egypt BIT (1993) Czech Republic-El Salvador BIT (1999) Czech Republic-Estonia BIT (1994) Czech Republic-Finland BIT (1990) Czech Republic-France BIT (1990) Czech Republic-FYROM BIT (2001) Czech Republic-Georgia BIT (2009) Czech Republic-Germany BIT (1990) Czech Republic-Greece BIT (1991) Czech Republic-Guatemala BIT (2003) Czech Republic-Hungary BIT (1993) Czech Republic-India BIT (1996) Czech Republic-Indonesia BIT (1998) Czech Republic-Indonesia BIT (1998) Czech Republic-Ireland BIT (1996) Czech Republic-lsrael BIT (1997) Czech Republic-ltaly BIT (1996) Czech Republic-Jordan BIT (1997) Czech Republic-Korea BIT (1992) Czech Republic-Kuwait BIT (1996) Czech Republic-Latvia BIT (1994) Czech Republic-Lebanon BIT (1997) Czech Republic-Lithuania BIT (1994) Czech Republic-Malaysia BIT (1996) Czech Republic-Malta BIT (2002) Czech Republic-Mauritius BIT (1999) Czech Republic-Mexico BIT (2002) Czech Republic-Moldova BIT (1999) Czech Republic-Mongolia BIT (1998) Czech Republic-Morocco BIT (2001) Czech Republic-Netherlands BIT (1991) Czech Republic-Nicaragu BTT (2002) Czech Republic-Nicaragua BIT (2002) Czech Republic-Nonh Korea BIT (1998) Czech Republic-Norway BIT (1991) Czech Republic-Parwa BIT (199) Czech Republic-Paraguay BIT (1998) Czech Republic-Peru BIT (1994) Czech Republic-Philippines BIT (1995) Czech Republic-Portugal BIT (1993) Czech Republic-Romania BIT (1993) Czech Republic-Saudi Arabia BIT (2009) Czech Republic-Serbia BIT (1997) Czech Republic-Singapore BIT (1995) Czech Republic-South Africa BIT (1998) Czech Republic-Spain BIT (1990) Czech Republic-Sweden BIT (1990) Czech Republic-Switzerland BIT (1990) Czech Republic-Syria BIT (2008) Czech Republic-Thailand BIT (1994) Czech Republic-Tunisia BIT (1997) Czech Republic-Turkey BIT (1992) Czech Republic-Turkey BIT (2009) Czech Republic-Turkey BIT (2009) Czech Republic-United Arab Emirates BIT (1994) Czech Republic-United Kingdom BIT (1990) Czech Republic-United Kingdon BIT (1990) Czech Republic-United States BIT (1991) Czech Republic-Uruguay BIT (1996) Czech Republic-Venezuela BIT (1995) Czech Republic-Vietnam BIT (1997) Czech Republic-Yemen BIT (2008) Czech Republic-Zimbabwe BIT (1999) Denmark-Albania BIT (1995) Denmark-Algeria BIT (1999)
Denmark-Argentina BIT (1992)
Denmark-Belarus BIT (2004)

Denmark-Bolivia BIT (1995)

Denmark-Bosnia and Herzegovina BIT (2004)

Denmark-Brazil BIT (1995)

Denmark-Bulgaria BIT (1993)

Denmark-Chile BIT (1993)

Denmark-China BIT (1985)

Denmark-Croatia BIT (2000)

Denmark-Cuba BIT (2001)

Denmark-Czech Republic BIT (1991)

Denmark-Egypt BIT (1999)

Denmark-Estonia BIT (1991)

Denmark-Ethiopia BIT (2001)

Denmark-Ghana BIT (1992)

Denmark-Hong Kong, China BIT (1994)

Denmark-Hungary BIT (1988)

Denmark-India BIT (1996)

Denmark-Indonesia BIT (1968)

Denmark-Indonesia BIT (2007)

Denmark-Korea BIT (1988)

Denmark-Korea BIT (1988)

Denmark-Kyrgyzstan BIT (2000)

Denmark-Lao PDR BIT (1998)

Denmark-Latvia BIT (1992)

Denmark-Lithuania BIT (1992)

Denmark-Malaysia BIT (1992)

Denmark-Mexico BIT (2000)

Denmark-Mongolia BIT (1995)

Denmark-Morocco BIT (2003)

Denmark-Nicaragua BIT (1995)

Denmark-North Korea BIT (1996)

Denmark-Pakistan BIT (1996)

Denmark-Peru BIT (1994)

Denmark-Philippines BIT (1997)

Denmark-Poland BIT (1990)

Denmark-Romania BIT (1980)

Denmark-Russian Federation BIT (1993)

Denmark-Slovenia BIT (1999)

Denmark-South Africa BIT (1996)

Denmark-Sri Lanka BIT (1985)

Denmark-Tanzania BIT (1996)

Denmark-Tunisia BIT (1996)

Denmark-Tunisia BIT (1996)

Dennark-Turkey BIT (1900)

Denmark-Uganda BIT (2001)

Denmark-Ukraine BIT (1992)

Denmark-Venezuela BIT (1994)

Denmark-Vietnam BIT (1993)

Egypt-Albania BIT (1993)

Egypt-Argentina BIT (1992)

Egypt-Armenia BIT (1996)

Egypt-Australia BIT (2001)

Egypt-Austria BIT (2001)

Egypt-Belarus BIT (1997)

Egypt-Belgium/Luxembourg BIT (1977)

Egypt-Belgium/Luxembourg BIT (1999)

Egypt-Bosnia and Herzegovina BIT (1998)

Egypt-Bulgaria BIT (1998)

Egypt-Cameroon BIT (2000)

Egypt-Canada BIT (1996)

Egypt-Central African Republic BIT (2000)

Egypt-Chile BIT (1999)

Egypt-Chile BIT (1999)

Egypt-Congo (Democratic Republic) BIT (1998)

Egypt-Croatia BIT (1997)

Egypt-Cyprus BIT (1998)

Egypt-Czech Republic BIT (1993)

Egypt-Denmark BIT (1999)

Egypt-Finland BIT (1980)

Egypt-Finland BIT (2004)

Egypt-France BIT (1974)

Egypt-FYROM BIT (1999)

Egypt-Georgia BIT (1999)

Egypt-Germany BIT (1974)

Egypt-Germany BIT (2005)

Egypt-Ghana BIT (1998)

Egypt-Greece BIT (1993)

Egypt-Guinea BIT (1998)

Egypt-Hungary BIT (1995)

Egypt-India BIT (1997)

Egypt-Indonesia BIT (1994)

Egypt-Italy BIT (1989)

Egypt-Jap B (1989)

Egypt-Japan BIT (1977)

Egypt-Kazakhstan BIT (1993)

Egypt-Korea BIT (1996)

Egypt-Korea BIT (1996)

Egypt-Latvia BIT (1997)

Egypt-Malaysia BIT (1997)

Egypt-Mauritius BIT (2003)
Egypt-Netherlands BIT (1976)

Egypt-Netherlands BIT (1996)

Egypt-Nigeria BIT (2000)

Egypt-Pakistan BIT (2000)

Egypt-Poland BIT (1995)

Egypt-Portugal BIT (1999) 
Egypt-Romania BIT (1976) Egypt-Romania BIT (1994) Egypt-Russian Federation BIT (1997) Egypt-Senegal BIT (1998) Eyypt-Serbia BIT (2005)

Egypt-Singapore BIT (1997)

Egypt-Slovakia BIT (1997)

Egypt-Slovenia BIT (1998)

Egypt-South Africa BIT (

Egypt-Sri Lanka BIT (1996)

Egypt-Sweden BIT (1978)

Egypt-Switzerland BIT (1973)

Egypt-Switzerland BIT (2010)

Egypt-Thailand BIT (2000)

Egypt-Turkey BIT (1996)

Egypt-Turkmenistan BIT (1995)

Egypt-Uganda BIT (1995)

Egypt-Ukraine BIT (1992)

Egypt-United Kingdom BIT (1975)

Egypt-United States BIT (1986)

Egypt-Vietnam BIT (1997)

Egypt-Vietnam BIT (1997)

Eypt-Zambia BIT (2000)

Estonia-Azerbaijan BIT (2010)

Estonia-Belgium/Luxembourg BIT (1996)

Estonia-China BIT (1993)

Estonia-Czech Republic BIT (1994)

Estonia-Denmark BIT (1991)

Estonia-Finland BIT (1992)

Estonia-France BIT (1992)

Estonia-Germany BIT (1992)

Estonia-Greece BIT (1997)

Estonia-Israel BIT (1994)

Estonia-Moldova BIT (2010)

Estonia-Netherlands BIT (1992)

Estonia-Norway BIT (1992)

Estonia-Poland BIT (1993)

Estonia-Spain BIT (1997)

Estonia-Sweden BIT (1992)

Estonia-Switzerland BIT (1992)

Estonia-T

Estonia-United Kingdom BIT (1994)

Estonia-United States BIT (1994)

Finland-Albania BIT (1997)

Finland-Algeria BIT (2005)

Finland-Argentina BIT (1993)

Finland-Armenia BIT (2004)

Finland-Azerbaijan BIT (2003)

Finland-Belarus BIT (1992)

Finland-Belarus BIT (2006)

Finland-Bosnia and Herzegovina BIT (2000)

Finland-Brazil BIT (1995)

Finland-Bulgaria BIT (1997)

Finland-Chile BIT (1993)

Finland-China BIT (1984)

Finland-China BIT (2004)

Finland-Costa Rica BIT (2001)

Finland-Croatia BIT (1999)

Finland-Czech Republic BIT (1990)

Finland-Dominican Republic BIT (2001)

Finland-Ecuador BIT (2001)

Finland-Egypt BIT (1980)

Finland-Egypt BIT (2004)

Finland-El Salvador BIT (2002)

Finland-Estonia BIT (1992)

Finland-Ethiopia BIT (2006)

ROM BIT (2001)

Finland-Guatemala BIT (2005)

Finland-Hungary BIT (1988)
Finland-India BIT (2002)

Finland-Indonesia BIT (1996)

Finland-Indonesia BIT (2006)

Finland-Iran BIT (2002)

Finland-Jordan BIT (2006)

Finland-Kazakhstan BIT (1992)

Finland-Kazakhstan BIT (2007)

Finland-Korea BIT (1993)

Finland-Kuwait BIT (1996)

Finland-Kyrgyzstan BIT (2003)

Finland-Latvia BIT (1992)

Finland-Lebanon BIT (1997)

Finland-Mabysi BIT (1985)

Finland-Malaysia BIT (1985)

Finland-Mauritius BIT (2007)

Finland-Mexico BIT (1999)

Finland-Moldova BIT (1995)

Finland-Montenegro BIT (2008)

Finland-Montenegro BIT (2008)

Finland-Morocco BIT (2001)

Finland-Mozambique BIT (2004)

Finland-Nepal BIT (2009)

Finland-Nicaragua BIT (2003)
Finland-Nigeria BIT (2005)
Finland-Oman BIT (1997)

Finland-Panama BIT (2009)

Finland-Peru BIT (1995)

Finland-Philippines BIT (1998)

Finland-Poland BIT (1990)

Finland-Poland BIT (1996)

Finland-Qatar BIT (2001)

Finland-Romania BIT (1992)
Finland-Russian Federation BIT (1989)

Finland-Serbia BIT (2005)

Finland-Slovakia BIT (1990)

Finland-Slovenia BIT (1998)

Finland-South Africa BIT (1998)

Finland-Sri Lanka BIT (1985)

Finland-Tanzania BIT (2001)

Finland-Thailand BIT (1994)

Finland-Tunisia BIT (2001)

Finland-Turkey BIT (1993)

Finland-Ukraine BIT (1992)

Finland-Ukraine BIT (2004)

Finland-United Arab Emirates BIT (1996)

Finland-Uruguy BIT (2002)

Finland-Uruguay BIT (2002)

Finland-Uzbekistan BIT (1992)

Finland-Vietnam BIT (1993)

Finland-Vietnam BIT (2008)

Finland-Zambia BIT (2005)

France-Albania BIT (1995)

France-Algeria BIT (1993)

France-Argentina BIT (1991)

France-Armenia BIT (1995)

France-Azerbaijan BIT (1998)

France-Bahrain BIT (2004)

France-Bangladesh BIT (1985)

France-Bolivia BIT (1989)

France-Bosnia and Herzegovina BIT (2003)

France-Bulgaria BIT (1989)

France-Cambodia BIT (2000)

France-Chile BIT (1992)

France-China BIT (1984)

France-China BIT (2007)

France-Congo (Democratic Republic) BIT (1972)

France-Costa Rica BIT (1984)

France-Costa Rica BIT (1984)

France-Croatia BIT (1996)

France-Cuba BIT (1997)
France-Czech Republic BIT (1990)

France-Czech Republic BIT

France-Djibouti BIT (2007)
France-Dominican Republic BIT (1999)

France-Ecuador BIT (1994)

France-Egypt BIT (1974)
France-El Salvador BIT (1978)

France-El Salvador BIT (1978)

France-Equatorial Guinea BIT

France-Ethiopia BIT (2003)

FYROM BIT (1998)

France-Georgia BIT (1997)

France-Ghana BIT (1999)

France-Guatemala BIT (1998)

France-Haiti BIT (1984)

France-Honduras BIT (1998)

France-Hong Kong, China BIT (1995)

France-Hungary BIT (1986)

France-India BIT (1997)

France-Indonesia BIT (1973)

France-Indonesia BIT (

France-Iran BIT (2003)

France-Israel BIT (1983)

France-Jamaica BIT (1993)

France-Kazakhstan BIT (1998)

France-Kazakhstan BIT (1998)

France-Kenya BIT (2007)

France-Korea BIT (1977)

France-Kuwait BIT (1989)

France-Kyrgyzstan BIT (1994)

France-Lao PDR BIT (1989)

France-Latvia BIT (1992)

France-Lebanon BIT (1996)

France-Liberia BIT (1979)

France-Libya BIT (2004)

France-Lithuania BIT (1992)

France-Madagascar BIT (2003)

France-Malaysia BIT (1975)

France-Malta BIT (1976)

France-Mauritius BIT (1973)

France-Mauritius BIT (1973)

France-Mexico BHT (1998)

France-Moldova BIT (1997)

France-Mongolia BIT (1991)

France-Morocco BIT (1975)

France-Morocco BIT (1996)
France-Mozambique BIT (2002)

France-Namibia BIT (1998)

France-Nepal BIT (1985)

France-Nicaragua BIT (1998)

France-Nigeria BIT (1990)

France-Oman BIT (1994)

France-Pakistan BIT (1983)
France-Panama BIT (1982)

France-Paraguay BIT (1978)

France-Peru BIT (1993)

France-Philippines BIT (1976)

France-Philippines BIT (1994)

France-Poland BIT (1989)

France-Qatar BIT (1996)

France-Romania BIT (1978)

France-Romania BIT (1995)

France-Russian Federation BIT (1989)

France-Saudi Arabia BIT (2002)

France-Serbia BIT (1974)

France-Serbia BIT (1974)

France-Singapore BIT (1975)

France-Slovakia BIT (1990)

France-Slovenia BIT (1998)

France-South Africa BIT (1995)

France-Sri Lanka BIT (1980)

France-Sudan BIT (1978)

France-Syria BIT (1977)

France-Tajikista (197) (2002)

France-Trinidad and Tobago BIT (1993)

France-Tunisia BIT (1963)

France-Tunisia BIT (1972)

France-Tunisia BIT (1997)

France-Turkey BIT (2006)

France-Turkmenistan BIT (1994)

France-Uganda BIT (2003)

France-Ukraine BIT (1994)

France-United Arab Emirates BIT (1991)

France-Uruguay BIT (1993)

France-Uzbekistan BIT (1993)

France-Venezuela BIT (2001)

France-Vietnam BIT (1992)

France-Yemen BIT (1984)

France-Zimbabwe BIT (2001)

Germany-Afghanistan BIT (2005)

Germany-Albania BIT (1991)

Germany-Algeria BIT (1996)

Germany-Angola BIT (2003)

Germany-Antigua and Barbuda BIT (1998)

Germany-Argentina BIT (1991)

Germany-Armenia BIT (1995)

Germany-Azerbaijan BIT (1995)

Germany-Bahrain BIT (2007)

Germany-Bangladesh BIT (1981)

Germany-Barbados BIT (1994)

Germany-Belarus BIT (1993)

Germany-Benin BIT (1978)

Germany-Bolivia BIT (1987)

Germany-Bosnia and Herzegovina BIT (2001)

Germany-Botswana BIT (2000)

Germany-Brazil BIT (1995)

Germany-Brunei Darussalam BIT (1998)

Germany-Bulgaria BIT (1986)

Germany-Burkina Faso BIT (1996)

Germany-Burundi BIT (1984)

Germany-Cambodia BIT (1999)

Germany-Cameroon BIT (1962)

Germany-Cape Verde BIT (1990)

Germany-Central African Republic BIT (1965)

Germany-Chad BIT (1967)

Germany-Chile BIT (1991)

Germany-China BIT (1983)

Germy-China BIT (2003)

Germany-Congo (Democratic Republic) BIT (1969)

Germany-Congo (Republic of) BIT (1965)

Germany-Costa Rica BIT (1994)

Germany-Cote d Tvoire BIT (1966)

Germany-Croatia BIT (1997)

Germany-Cuba BIT (1996)

Germany-Czech Republic BIT (1990)

Germany-Dominica BIT (1984)

Germany-Ecuador BIT (1996)

Germany-Egypt BIT (1974)

Germany-Egypt BIT (2005)

Germany-El Salvador BIT (1997)

Germany-Estonia BIT (1992)

Germany-Ethiopia BIT (2004)

Germany-FYROM BIT (1996)

Germany-Gabon BIT (1969)

Germany-Gabon BIT (1998)

Germany-Georgia BIT (1993)

Germany-Gera BIT (1995)

Germany-Ghana BIT (1995)

Germ

Germany-Guatemala BIT (2003)

Germany-Guinea BIT (1962)

Germany-Guinea BIT (2006)

Germany-Guyana BIT (1989)

Germany-Haiti BIT (1973)

Germany-Honduras BIT (1995)

Germany-Hong Kong, China BIT (1996)

Germany-Hungary BIT (1986)

Germany-India BIT (1995) 
Germany-Indonesia BIT (1968) Germany-Indonesia BIT (2003) Germany-Iran BIT (1965) Germany-Iran BIT (2002) Germany-Israel BIT (1976) Germany-Jamaica BIT (1992) Germany-Jordan BIT (1974) Germany-Jordan BIT (2007) Germany-Kazakhstan BIT (1992) Germany-Kenya BIT (1996) Germany-Korea BIT (1964) Germany-Kuwait BIT (1994) Germany-Kyrgyzstan BIT (1997) Germany-Lao PDR BIT (1996) Germany-Latvia BIT (1993) Germany-Lebanon BIT (1997) Germany-Lesotho BIT (1982) Germany-Liberia BIT (1961) Germany-Lithuania BIT (1992) Germany-Madagascar BIT (1962) Germany-Madoascar BIT (2006) Germany-Malas Germany-Malaysia BIT (1960) Germany-Mali BIT (1977) Germany-Malta BIT (1974) Germany-Mauritania BIT (1982) Germany-Mauritius BIT (1971) Germany-Mexico BIT (1998) Germany-Moldova BIT (1994) Germany-Mongolia BIT (1991) Germany-Morocco BIT (1961) Germany-Morocco BIT (2001) Germany-Mozambique BIT (2002) Germany-Namibia BIT (1994) Germany-Nepal BIT (1986) Germany-Nicaragua BIT (1996) Germany-Niger BIT (1964) Germany-Nigeria BIT (2000) Germany-Oman BIT (1979) Germany-Oman BIT (2007) Germany-Pakistan BIT (1959) Germany-Pakistan BIT (2009) Germany-Palestine BIT (2000) Germany-Palestine BIT (2000) Germany-Papua New Guinea BIT (1980) Germany-Paraguay BIT (1993) Germany-Peru BIT (1995) Germany-Philippines BIT (1997) Germany-Philippines BIT (1997) Germany-Poland BIT (1989) Germany-Portugal BIT (1980) Germany-Qatar BIT (1996) Germany-Romania BIT (1979) Germany-Romania BIT (1996) Germany-Russian Federation Germany-Saint Lucia BIT (1985) Germany-Saint Vincent and the Grenadines BIT (1986) Germany-Saudi Arabia BIT (1996) Germany-Senegal BIT (1964) Germany-Serbia BIT (1989) Germany-Sierra Leone BIT (1965) Germany-Singapore BIT (1973) Germany-Slovakia BIT (1990) Germany-Slovakia BIT (1990) Germany-Somalia BIT (1981) Germany-South Africa BIT (1995) Germany-Sri Lanka BIT (1963) Germany-Sri Lanka BIT (1963) Germany-Sudan BIT (1963) Germany-Sudan BIT (1963) Germany-Swaziland BIT (19) Germany-Syria BIT (1977) Germany-Tanzania BIT (1965) Germany-Thailand BIT (1961) Germany-Thailand BIT (2002) Germany-Timor-Leste BIT (2005) Germany-Togo BIT (1961) Germany-Trinidad and Tobago BIT (2006) Germany-Tunisia BIT (1963) Germany-Turkey BIT (1962) Germany-Turkmenistan BIT (1997) Germany-Uganda BIT (1966) Germany-Ukraine BIT (1993) Germany-United Arab Emirates BIT (1997) Germany-Uruguay BIT (1987) Germany-Uruguay BIT (1987) Germany-Uzbekistan BIT (1993) Germany-Venezuela BIT (1996) Germany-Vietnam BIT (1993) Germany-Yemen BIT (1974) Germany-Yemen BIT (2005) Germany-Zambia BIT (1966) Germany-Zimbabwe BIT (1995) Greece-Albania BIT (1991) Greece-Algeria BIT (2000)
Greece-Argentina BIT (1999)
Greece-Azerbaijan BIT (2004)

Greece-Bosnia and Herzegovina BIT (2000) Greece-Bulgaria BIT (1993)

Greece-Chile BIT (1996)

Greece-China BIT (1992)

Greece-Croatia BIT (1996)

Greece-Cuba BIT (1996)

Greece-Czech Republic BIT (1991)

Greece-Egypt BIT (1993)

Greece-Estonia BIT (1997)

Greece-Georgia BIT (1994)

Greece-Germany BIT (1961)

Greece-Hungary BIT (1989)

Greece-India BIT (2007)

Greece-Iran BIT (2002)

Greece-Jordan BIT (2005)

Greece-Kazakhstan BIT (2002)

Greece-Korea BIT (1995)

Greece-Latvia BIT (1995)

Greece-Lebanon BIT (1997)

Greece-Lect

Greece-Lithuania BIT (1996)

Greece-Mexico BIT (2000)

Greece-Moldova BIT (1998)

Greece-Morocco BIT (1994)

Greece-Poland BIT (1992)

Greece-Romania BIT (1991)
Greece-Russian Federation BIT (1993)

Greece-Serbia BIT (1997)
Greece-Slovenia BIT (1997)

Greece-Slovenia BIT (1997)
Greece-South Africa BIT (1998)

Greece-Syria BIT (2003)

Greece-Tunisia BIT (1992)

Greece-Turkey BIT (2000)

Greece-Uzbekistan BIT (1997)

Hungary-Albania BIT (1996)

Hungary-Argentina BIT (1993)

Hungary-Australia BIT (1991)

Hungary-Austria BIT (1988)

Hungary-Belgium/Luxembourg BIT (1986)

Hungary-Bosnia and Herzegovina BIT (2002)

Hungary-Bulgaria BIT (1994)

Hungary-Canad

Hungary-Canada BIT (1991)

Hungary-Chile BIT (1997)

Hungary-China BIT (1991)

Hungary-Croatia BIT (1996)

Hungary-Cuba BIT (1999)

Hungary-Czech Republic BIT (1993)

Hungary-Denmark

Hungary-Egypt BIT (1995)

Hungary-Finland BIT (1988)

Hungary-France BIT (1986)

Hungary-FYROM BIT (2001)

Hungary-Germany BIT (1986)

Hungary-Greece BIT (1989)

Hungary-India BIT (2003)

Hungary-Indonesia BIT (1992)

Hungary-Israel BIT (1991)

Hungary-Italy BIT (1987)

Hungary-Kazakhstan BIT (1994)

Hungary-Korea BIT (1988)

Hungary-Kuwait BIT (1989)

Hungary-Kuwait BIT (1989)

Hungary-Lebanon BIT (2001)

Hungary-Lebanon BIT (2001)

Hungary-Lithomia BIT (1999)

Hungary-Maysia BIT (1993)

Hungary-Moldova BIT (1995)

Hungary-Mongolia BIT (1994)

Hungary-Morocco BIT (1991)

Hungary-Netherlands BIT (1987)

Hungary-Paraguay BIT (1993)

Hungary-Poland BIT (1992)

Hungary-Portugal BIT (1992)

Hungary-Romania BIT (1993)

Hungary-Russian Federation BIT (1995)

Hungary-Serbia BIT (2001)

Hungary-Singapore BIT (1997)

Hungary-Slovakia BIT (1993)

Hungary-Slovenia BIT (1996)

Hungary-Spain BIT (1989)

Hungary-Sweden BIT (1987)

Hungary-Switzerland BIT (1988)

Hungary-S Thailatand BIT (1991)

Hungar-This

Hungary-Tunisia BIT (2003)

Hungary-Turkey BIT (1992)

Hungary-United Kingdom BIT (1987)

Hungary-United Kingdom BIT

Hungary-Uruguay BIT (1989)

Hungary-Uzbekistan BIT (2002)

Hungary-Vietnam BIT (1994)

Hungary-Yemen BIT (2004)

Iceland-Chile BIT (2003)

Iceland-China BIT (1994)

Iceland-India BIT (2007)
Iceland-Lebanon BIT (2004)

Iceland-Mexico BIT (2005)

India-Argentina BIT (1999)

India-Armenia BIT (2003)

India-Australia BIT (1999)

India-Austria BIT (1999)

India-Bahrain BIT (2004)

India-Bangladesh BIT (2009)

India-Belarus BIT (2002)

India-Belgium/Luxembourg BIT (1997)

India-Bosnia and Herzegovina BIT (2006)

India-Brunei Darussalam BIT (2008)

India-Bulgaria BIT (1998)

India-China BIT (2006)

India-Chinese Taipei BIT (2002)

India-Colombia BIT (2009)

India-Croatia BIT (2001)

India-Cyprus BIT (2002)

India-Czech Republic BIT (1996)

India-Denmark BIT (1996)

India-Egypt BIT (1997)

Indi-Finland BIT (2002)

India-Finland BIT (2002)

India-Fance BIT (1997)

India-FYROM BIT (2008)

India-Germany BIT (1995)

India-Ghana BIT (2002)

India-Greece BIT (2007)

India-Hungary BIT (2003)

India-Iceland BIT (2007)

India-Indonesia BIT (1999)

India-Israel BIT (1996)

India-Italy BIT (1995)

India-Japan EPA (2011)

India-Jordan BIT (2006)

India-Kazakhstan BIT (1996)

India-Korea BIT (1996)

India-Korea CEPA (2009)

India-Kuwait BIT (2001)

India-Kyrgyzstan BIT (1997)

India-Lao PDR BIT (2000)

India-Latvia BIT (2010)

India-Livya BIT (2007)

India-Libya BIT (2007)

India-Litha BIT (2007)

India-Malaysia BIT (1995)

India-Mauritus BIT (1998)

India-Mexico BIT (2007)

India-Mongolia BIT (2001)

India-Morocco BIT (1999)

India-Mozambique BIT (2009)

India-Myanmar BIT (2008)

India-Nepal BIT (2011)

ndia-Netherlands BIT (1995)

India-Oman BIT (1997)

India-Philippines BIT (2000)

India-Poland BIT (1996)

India-Portugal BIT (2000)

India-Qatar BIT (1999)

India-Romania BIT (1997)

India-Russian Federation BIT (1994)

India-Saudi Arabia BIT (2006)

India-Senegal BIT (2008)

Indi-Serbia BIT (2003)

India-Singapore CECA (2005)

India-Slovenia BIT (2011)

India-Spain BIT (1997)

India-Sri Lanka BIT (1997)

India-Sudan BIT (2003)

India-Sweden BIT (2000)

India-Switzerland BIT (1997)

India-Syria BIT (2008)

India-Tajikistan BIT (1995)

India-Thailand BIT (2001)

India-Trinidad and Tobago BIT (2007)

India-Turkey BIT (1998)

India-Turkmenistan BIT (1995)

India-Ukraine BIT (2001)

India-United Kingdom BIT (1994)

India-Uzbekistan BIT (1999)

India-Vietnam BIT (1997)

India-Yemen BIT (2002)

Indonesia-Algeria BIT (2000)

Indonesia-Argentin BIT (1995)

Indorsi-Algeria BIT (2000)

Indonesia-A stralla BIT (1992)

Indonesia-Bangladesh BIT (1998)

Indonesia-Bulgaria BIT (2003)

Indonesia-Cambodia BIT (1999)

Indonesia-Chile BIT (1999)

Indonesia-China BIT (1994)

Indonesia-Croatia BIT (2002)

Indonesia-Cuba BIT (1997)

Indonesia-Czech Republic BIT (1998)

Indonesia-Denmark BIT (1968) 
Indonesia-Denmark BIT (2007)

Indonesia-Egypt BIT (1994)

Indonesia-Finland BIT (1996)

Indonesia-Finland BIT (2006)

Indonesia-France BIT (1973)

Indonesia-Germany BIT (1968)

Indonesia-Germany BIT (2003)

Indonesia-Hungary BIT (1992)

Indonesia-India BIT (1999)

Indonesia-Italy BIT (1991)

Indonesia-Jamaica BIT (1999)

Indonesia-Japan EPA (2007)

Indonesia-Jordan BIT (1996)

Indonesia-Korea BIT (1991)

Indonesia-Kyrgyzstan BIT (1995)

Indonesia-Lao PDR BIT (1994)

Indonesia-Malaysia BIT (1994)

Indonesia-Mongolia BIT (1997)

Indonesia-Morocco BIT (1997)

Indonesia-Mozambique BIT (1999)

Indonesia-Mozambique BIT (1999)

Indonesia-Netherlands BIT (1994)

Indonesia-North Korea BIT (200)
Indonesia-Norway BIT (1991)

Indonesia-Pakistan BIT (1996)

Indonesia-Poland BIT (1992)

Indonesia-Romania BIT (1997)
Indonesia-Singapore BIT (2005)

Indonesia-Singapore BIT (2005)

Indonesia-Slovakia BIT (1994)

Indonesia-Spain BIT (1995)
Indonesia-Sri Lanka BIT (1996)

Indonesia-Sri Lanka BIT (1996)
Indonesia-Sudan BIT (1998)

Indonesia-Sweden BIT (1992)

Indonesia-Switzerland BIT (1974)

Indonesia-Syria BIT (1997)

Indonesia-Thailand BIT (1998)

Indonesia-Turkey BIT (1997)

Indonesia-Ukraine BIT (1996)

Indonesia-United Kingdom BIT (1976)

Indonesia-Uzbekistan BIT (1996)

Indonesia-Vietnam BIT (1991)

Indonesia-Yemen BIT (1998)

Indonesia-Yemen BIT (1998)

Indonesia-Zimbabwe BIT (1999)
Ireland-Czech Republic BIT (1996)

Ireland-Czech Republic BIT
Israel-Albania BIT (1996)

Israel-Albania BIT (1996)
Israel-Argentina BIT (1995)

Israel-Argentina BIT (1995)

Israel-Azerbaijan BIT (2007)

Israel-Canada FTA (1996)

Israel-China BIT (1995)

Israel-Croatia BIT (2000)

Israel-Czech Republic BIT (1997)

Israel-Estonia BIT (1994)

Israel-Ethiopia BIT (2003)

Israel-France BIT (1983)

Israel-Germany BIT (1976)

Israel-Hungary BIT (1991)

Israel-India BIT (1996)

Israel-Korea BIT (1999)

Israel-Poland BIT (1991)

Israel-Romania BIT (1998)

Israel-Slovakia BIT (1999)

Israel-Sloveni BIT (1998)

Israel-South Africa BIT (2004)

Israel-Thailand BIT (2000)

Israel-Thailand BIT (2000)

Israel-Turkey BIT (1996)

Italy-Albania BIT (1991)

Italy-Algeria BIT (1991)

Italy-Angola BIT (1997)
Italy-Argentina BIT (1990)

Italy-Argentina BIT (1990)

Italy-Armenia BIT (1998)

Italy-Azerbaijan BIT (1997)

Italy-Bangladesh BIT (1990)

Italy-Barbados BIT (1995)

Italy-Belarus BIT (1995)

Italy-Bosnia and Herzegovina BIT (2000)

Italy-Bulgaria BIT (1988)

Italy-Cameroon BIT (1999)

Italy-Chad BIT (1969)

Italy-Chile BIT (1993)

Italy-China BIT (1985)

Italy-Congo (Democratic Republic) BIT (1994)

Italy-Croatia BIT (1996)

Italy-Cuba BIT (1993)

Italy-Cuba BIT (1993)
Italy-Czech Republic BIT (1996)

Italy-Czech Republic BIT
Italy-Egypt BIT (1989)

Italy-Egypt BIT (1989)

Italy-Eritrea BIT (1996)

Italy-FYROM BIT (1997)

Italy-FYROM BIT (1997)

Italy-Gabon BIT (1999)

Italy-Georgia BIT (1997)
Italy-Guinea BIT (1964)

Italy-Hong Kong, China BIT (1995)

Italy-Hungary BIT (1987)
Italy-India BIT (1995)

Italy-Indonesia BIT (1991)

taly-Iran BIT (1999)

Italy-Jamaica BIT (1993)

Italy-Jordan BIT (1996)

Italy-Kazakhstan BIT (1994)

Italy-Kenya BIT (1996)

Italy-Korea BIT (1989)

Italy-Kuwait BIT (1987)

Italy-Lebanon BIT (1997)

Italy-Libya BIT (2000)

Italy-Lithuania BIT (1994)

Italy-Malaysia BIT (1988)

Italy-Malta BIT (1967)

Italy-Mexico BIT (1999)

Italy-Moldova BIT (1997)

Italy-Mongolia BIT (1993)

Italy-Morocco BIT (1990)

Italy-Nicaragua BIT (2004)

Italy-Nigeria BIT (2000)

Italy-Nigeria BIT (2000)

Italy-Pakistan BIT (1997)

Italy-Pakistan BIT (1997

Italy-Philippines BIT (1988)

Italy-Poland BIT (1989)

Italy-Qatar BIT (2000)

Italy-Romania BIT (1990)

Italy-Russian Federation BIT (1996)

Italy-Saudi Arabia BIT (1996)

Italy-Senegal BIT (2000)

taly-Slovenia BIT (2000)

Italy-South Africa BIT (1997)

Italy-Sri Lanka BIT (1987)

Italy-Tanzania BIT (2001)

Italy-Tunisia BIT (1985)

Italy-Turkey BIT (1995)

Italy-Uganda BIT (1997)

Italy-United Arab Emirates BIT (1995)

Italy-Uruguay BIT (1990)

Italy-Uzbekistan BIT (1997)

Italy-Venezuela BIT (2001)

Italy-Venezuela BIT (2001)

Italy-Vietnam BIT (1990)

Japan-Bangladesh BIT (1998)

Japan-Cambodia BIT (2007)

Japan-Chile EPA (2007)

Japan-China BIT (1988)

Japan-Colombia BIT (2011)

Japan-Egypt BIT (1977)

Japan-Hong Kong, China BIT (1997)

Japan-India EPA (2011)

Japan-Indonesia EPA (2007)

Japan-Iraq BIT (2012)

apan-Korea BIT (2002)

Japan-Kuwait BIT (2012)

Japan-Lao PDR BIT (2008)

Japan-Malaysia EPA (2005)

Japan-Mexico EPA (2004)

Japan-Mongolia BIT (2001)

Japan-Mozambique BIT (2013)

Japan-Pakistan BIT (1998)

Japan-Papua New Guinea BIT (2011)

Japan-Papua New Guine

Japan-Philippines EPA (2006)

Japan-Philippines EPA (2006)

Japan-Saudi Arabia BIT (2013)

Japan-Singapore EPA (2002)

Japan-Sri Lanka BIT (1982)

Japan-Switzerland EPA (2009)

Japan-Thailand EPA (2007)

Japan-Turkey BIT (1992)

Japan-Uzbekistan BIT (2008)

Japan-Vietnam BIT (2003)

Jordan-Algeria BIT (1996)

Jordan-Austria BIT (2001)

Jordan-Bahrain BIT (2000)

Jordan-Canada BIT (2009)

Jordan-China BIT (200I)

Jordan-Croatia BIT (1999)

Jordan-Czech Republic BIT (1997)

Jordan-Egypt BIT (1996)

Jorda-Finland BIT (2006)

Jordan-Finland BIT (2006)

Jord

Jordan-Germany BIT (1974)

Jordan-Germany BIT (2007)

Jordan-Hong Kong, China BIT (1979)

Jordan-Hong Kong, Chi

Jordan-India BIT (2006)
Jordan-Indonesia BIT (1996)

Jordan-Indonesia BIT (1996)

Jordan-Italy BIT (1996)

Jordan-Korea BIT (2004)
Jordan-Kuwait BIT (2001)

ordan-Lebanon BIT (2002)

Jordan-Morocco BIT (1998)
Jordan-Netherlands BIT (1997)

Jordan-Poland BIT (1997)

Jordan-Romania BIT (1992)

Jordan-Singapore BIT (2004)

Jordan-Spain BIT (1999)

Jordan-Switzerland BIT (1976)

Jordan-Syria BIT (2001)

Jordan-Thailand BIT (2005)

Jordan-Tunisia BIT (1995)

Jordan-Turkey BIT (1993)

Jordan-United Kingdom BIT (1979)

Jordan-United States BIT (1997)

Jordan-Yemen BIT (1996)

Korea-Albania BIT (2003)

Korea-Algeria BIT (1999)

Korea-Argentina BIT (1994)

Korea-Austria BIT (1991)

Korea-Bangladesh BIT (1986)

Korea-Belarus BIT (1997)

Korea-Belgium/Luxembourg BIT (1974)

Korea-Belgium/Luxembourg BIT (2006)

Korea-Bolivia BIT (1996)

Korea-Brazil BIT (1995)

Korea-Brunei Darussalam BIT (2000)

Korea-Burkina Faso BIT (2004)

Korea-Cambodia BIT (1997)

Korea-Chile BIT (1996)

Korea-Chile FTA (2003)

Korea-China BIT (1992)

Korea-China BIT (2007)

Korea-Colombia FTA (2013)

Korea-Congo (Democratic Republic) BIT (2005)

Korea-Costa Rica BIT (2000)

Korea-Croatia BIT (2005)

Korea-Czech Republic BIT (1992)

Korea-Denmark BIT (1988)

Korea-Egypt BIT (1996)

Korea-El Salvador BIT (1998)

Korea-Finland BIT (1993)

Korea-France BIT (1977)

Korea-Gabon BIT (2007)

Korea-Gern

Korea-Grece BIT (1995)

Korea-Guatema BIT (2000)

Korea-Ho

Korea-Hong Kong, China BIT (1997)

Korea-Hungary BIT (1988)

Korea-India BIT (1996)

Korea-India CEPA (2009)

Korea-Indonesia BIT (1991)

Korea-Iran BIT (1998)

Korea-Israel BIT (1999)

Korea-Italy BIT (1989)

Korea-Jamaica BIT (2003)

Korea-Japan BIT (2002)

Korea-Jordan BIT (2004)

Korea-Kazakhstan BIT (1996)

Korea-Kuwait BIT (2004)

Korea-Lao PDR BIT (1996)

Korea-Latvia BIT (1996)

Korea-Lebanon BIT (2006)

Korea-Libya BIT (2006)

Korea-Libya BIT (2006)

Korea-Lithuania BIT (1993)

Korea-Malaysia BIT (1988)

Korea-Mauritania BIT (2004)

Korea-Mexico BIT (2000)

Korea-Mongolia BIT (1991)

Korea-Morocco BIT (1999)

Korea-Netherlands BIT (1974)

Korea-Netherlands BIT (2003)

Korea-Nicaragua BIT (2000)

Korea-Nigeria BIT (1997)

Korea-Oman BIT (2003)

Korea-Pakistan BIT (1988)

Korea-Panama BIT (2001)

Korea-Paraguay BIT (1992)

Korea-Peru BIT (1993)

Korea-Peru FTA (2011)

Korea-Philippines BIT (1994)

Korea-Poland BIT (1989)

Korea-Portug BIT (1995)

Korea-Portugal BIT (1995)

Korea-Ro BIT (199)

Korea-Komania BIT (1990)

Korea-Saudi Arabia BIT (2002)

Korea-Senegal BIT (1984)

Korea-Singapore FTA (2005)

Korea-Slovakia BIT (2005)

Korea-South Africa BIT (1995)

Korea-Spain BIT (1994)

Korea-Sri Lanka BIT (1980)

Korea-Sweden BIT (1995)

Korea-Switzerland BIT (1971) 
Korea-Tajikistan BIT (1995) Korea-Thailand BIT (2002) Korea-Trinidad and Tobago BIT (2002) Korea-Tunisia BIT (1975) Korea-Turkey BIT (1991) Korea-Ukraine BIT (1996) Korea-United Arab Emirates BIT (2002) Korea-United Kingdom BIT (1976) Korea-United States FTA (2007) Korea-Uzbekistan BIT (1992 Korea-Vietnam BIT (1993) Latvia-Austria BIT (1994) Latvia-Belgium/Luxembourg BIT (1996) Latvia-Canada BIT (1995) Latvia-Canada BIT (2009) Latvia-China BIT (2004) Latvia-Croatia BIT (2002) Latvia-Czech Republic BIT (1994) Latvia-Denmark BIT (1992) Latvia-Egypt BIT (1997) Latvia-Finland BIT (1992) Latvia-France BIT (1992)
Latvia-Germany BIT (1993) Latvia-Germany BIT (1993)
Latvia-Greece BIT (1995) Latvia-Hungary BIT (1999) Latvia-Hungary BIT (1999)
Latvia-India BIT (2010) Latvia-India BIT (2010)
Latvia-Korea BIT (1996) Latvia-Korea BIT (1996)
Latvia-Kyrgyzstan BIT (2008) Latvia-Netherlands BIT (1994) Latvia-Norway BIT (1992) Latvia-Poland BIT (1991) Latvia-Portugal BIT (1995) Latvia-Romania BIT (2001) Latvia-Singapore BIT (1998) Latvia-Spain BIT (1995) Latvia-Sweden BIT (1992) Latvia-Switzerland BIT (1992) Latvia-Turkey BIT (1997) Latvia-United Kingdom BIT (1994) Latvia-United States BIT (1995) Lithuania-Albania BIT (2007) Lithuania-Argentina BIT (1996) Lithuania-Argentina BIT (1996) Lithuania-Australia BIT (1998)
Lithuania-Austria BIT (1996) Lithuania-Austria BIT (1996)
Lithuania-Belgium/Luxembourg BIT (1997) Lithuania-Belgium/Luxembourg BIT (1997)
Lithuania-Bosnia and Herzegovina BIT (2007) Lithuania-Bosnia and Herzeg
Lithuania-China BIT (1993) Lithuania-China BIT (1993)
Lithuania-Croatia BIT (2008) Lithuania-Croatia BIT (2008)
Lithuania-Czech Republic BIT (1994) Lithuania-Denmark BIT (1992) Lithuania-Finland BIT (1992) Lithuania-France BIT (1992) Lithuania-Germany BIT (1992) Lithuania-Greece BIT (1996) Lithuania-Hungary BIT (1999) Lithuania-India BIT (2011) Lithuania-Italy BIT (1994) Lithuania-Korea BIT (1993) Lithuania-Kuwait BIT (2001) Lithuania-Kyrgyzstan BIT (2008) Lithuania-Netherlands BIT (1994) Lithuania-Norway BIT (1992) Lithuania-Poland BIT (1992) Lithuania-Portugal BIT (1998) Lithuania-Romania BIT (1994)
Lithuania-Russian Federation BIT (1999) Lithuania-Russian Federation BIT
Lithuania-Slovenia BIT (1998) Lithuania-Slovenia BIT (1998)
Lithuania-Spain BIT (1994) Lithuania-Spain BIT (1994)
Lithuania-Sweden BIT (1992) Lithuania-Sweden BIT (1992)
Lithuania-Switzerland BIT (1992) Lithuania-Switzerland BIT (1992)
Lithuania-Turkey BIT (1994) Lithuania-Turkey BIT (1994)
Lithuania-United Kingdom BIT (1993) Lithuania-United States BIT (1998) Lithuania-Venezuela BIT (1995) Malaysia-Argentina BIT (1994) Malaysia-Austria BIT (1985) Malaysia-Belgium/Luxembourg BIT (1979) Malaysia-Bosnia and Herzegovina BIT (1994) Malaysia-Cambodia BIT (1994) Malaysia-Chile BIT (1992) Malaysia-China BIT (1988) Malaysia-Croatia BIT (1994) Malaysia-Czech Republic BIT (1996) Malaysia-Denmark BIT (1992) Malaysia-Denmark BIT (1992) Malaysia-Ethiopia BIT (1998) Malaysia-Ethiopia BIT (1998) Malaysia-France BIT (1975) Malaysia-France BIT (1975)
Malaysia-Germany BIT (1960) Malaysia-Germany BIT (1960)
Malaysia-Ghana BIT (1996) Malaysia-Ghana BIT (1996)
Malaysia-Hungary BIT (1993) Malaysia-India BIT (1995) Malaysia-Indonesia BIT (1994) Malaysia-Italy BIT (1988)
Malaysia-Japan EPA (2005)

Malaysia-Kazakhstan BIT (1996) Malaysia-Korea BIT (1988) Malaysia-Kyrgyzstan BIT (1995) Malaysia-Lebanon BIT (1998) Malaysia-Mongolia BIT (1995) Malaysia-Netherlands BIT (1971)
Malaysia-New Zealand FTA (2009) Malaysia-Norway BIT (1984) Malaysia-Peru BIT (1995) Malaysia-Poland BIT (1993) Malaysia-Saudi Arabia BIT (2000) Malaysia-Slovakia BIT (2007) Malaysia-Spain BIT (1995) Malaysia-Sweden BIT (1979) Malaysia-Switzerland BIT (1978) Malaysia-Turkey BIT (1998) Malaysia-United Arab Emirates BIT (1991) Malaysia-United Kingdom BIT (1981)

Malaysia-Uruguay BIT (1995)
Malaysia-Vietnam BIT (1992) Malaysia-Vietnam BIT (1992) Mexico-Argentina BIT (1996) Mexico-Australia BIT (1994) Mexico-Austria BIT (1998) Mexico-Belgium/Luxembourg BIT (1998) Mexico-Bolivia FTA (1994) Mexico-Chile FTA (1998) Mexico-China BIT (2008) Mexico-Colombia FTA (1994) Mexico-Costa Rica FTA (1994) Mexico-Cuba BIT (2001) Mexico-Czech Republic BIT (2002) Mexico-Denmark BIT (2000) Mexico-Finland BIT (1999) Mexico-France BIT (1998) Mexico-Germany BIT (1998) Mexico-Greece BIT (2000) Mexico-Iceland BIT (2005) Mexico-India BIT (2007) Mexico-Italy BIT (1999) Mexico-Ja BIT (1999) Mexico-Japan EPA (2004) Mexico-Netherlands BIT (1998) Mexico-Netherlands BIT (1998)
Mexico-Nicaragua FTA (1997) Mexico-Panama BIT (2005) Mexico-Panama BIT (2005) Mexico-Peru FTA (2011)
Mexico-Portugal BIT (1999) Mexico-Portugal BIT (1999) Mexico-Singapore BIT (2009)
Mexico-Slovakia BIT (2007) Mexico-Slovakia BIT (2007)
Mexico-Spain BIT (1995) Mexico-Spain BIT (2006) Mexico-Sweden BIT (2000) Mexico-Switzerland BIT (1995) Mexico-Trinidad and Tobago BIT (2006) Mexico-United Kingdom BIT (2006) Mexico-Uruguay BIT (1999) Mexico-Uruguay FTA (2003) Morocco-Argentina BIT (1996) Morocco-Austria BIT (1992)

Morocco-Belgium/Luxembourg BIT (1965) Morocco-Belgium/Luxembourg BIT (1999) Morocco-Belgium/Luxe Morocco-Benin BIT (2004) Morocco-Bulgaria BIT (1996) Morocco-Cameroon BIT (2007)
Morocco-Central African Republic BIT (2006) Morocco-Chad BIT (1997)
Morocco-Croatia BIT (2004) Morocco-Czech Republic BIT (2001) Morocco-Denmark BIT (2003) Morocco-Dominican Republic BIT (2002) Morocco-El Salvador BIT (1999) Morocco-Equatorial Guinea BIT (2005) Morocco-Finland BIT (2001) Morocco-France BIT (1975) Morocco-France BIT (1996) Morocco-Gabon BIT (1979) Morocco-Gambia BIT (2006) Morocco-Germany BIT (1961) Morocco-Germany BIT (2001) Morocco-Greece BIT (1994) Morocco-Guinea BIT (2002) Morocco-Hungary BIT (1991) Morocco-India BIT (1999) Morocco-Indonesia BIT (1997) Morocco-Italy BIT (1990) Morocco-Jordan BIT (1998) Morocco-Jordan BIT (1998) Morocco-Netherlands BIT (1971) Morocco-Pakistan BIT (2001) Morocco-Poland BIT (1994) Morocco-Portugal BIT (1988) Morocco-Portugal BIT (2007) Morocco-Romania BIT (1994)
Morocco-Senegal BIT (2006) Morocco-Slovakia BIT (2007) Morocco-Spain BIT (1989) Morocco-Spain BIT (1997) Morocco-Sweden BIT (1990) Morocco-Switzerland BIT (1985) Morocco-Turkey BIT (1997) Morocco-Ukraine BIT (2001) Morocco-United Kingdom BIT (1990) Morocco-United States BIT (1985) Morocco-United States FTA (2004) Netherlands-Albania BIT (1994) Netherlands-Algeria BIT (2007) Netherlands-Argentina BIT (1992) Netherlands-Armenia BIT (2005) Netherlands-Bahrain BIT (2007) Netherlands-Bangladesh BIT (1994) Netherlands-Belarus BIT (1995) Netherlands-Belize BIT (2002) Netherlands-Benin BIT (2001) Netherlands-Bolivin BIT (1992) Netherlands-Bosnia and Herzegovina BIT (1998) Netherlands-Brazil BIT (1998) Netherlands-Bulgaria BIT (1988) Netherlands-Bulgaria BIT (1999) Netherlands-Burkina Faso BIT (2000) Netherlands-Burundi BIT (2007) Netherlands-Cambodia BIT (2003) Netherlands-Cameroon BIT (1965) Netherlands-Cape Verde BIT (1991) Netherlands-Chile BIT (1998) Netherlands-China BIT (1985) Netherlands-China BIT (2001) Netherlands-Costa Rica BIT (1999) Netherlands-Cote d'Tvoire BIT (1965) Netherlands-Croatia BIT (1998) Netherlands-Cuba BIT (1999) Netherlands-Czech Republic BIT (1991) Netherlands-Dominican Republic BIT (2006) Netherlands-Ecuador BIT (1999) Netherlands-Egypt BIT (1976) Netherlands-El Salvador BIT (1999) Netherlands-Eritrea BIT (2003) Netherlands-Estonia BIT (1992) Netherlands-Ethiopia BIT (2003) Netherlands-Ethiopia BIT (2003)
Netherlands-FYROM BIT (1998) Netherlands-Gambia BIT (2002) Netherlands-Gambia BIT (2002) Netherlands-Georgia BIT (1998
Netherlands-Ghana BIT (1989) Netherlands-Guatemala BIT (2001) Netherlands-Honduras BIT (2001) Netherlands-Hong Kong, China BIT (1992) Netherlands-Hungary BIT (1987) Netherlands-India BIT (1995) Netherlands-Indonesia BIT (1994) Netherlands-Jamaica BIT (1991) Netherlands-Jordan BIT (1997) Netherlands-Kazakhstan BIT (2002) Netherlands-Kenya BIT (1970) Netherlands-Korea BIT (1974) Netherlands-Korea BIT (2003) Netherlands-Kuwait BIT (2001) Netherlands-Lao PDR BIT (2003) Netherlands-Latvia BIT (1994) Netherlands-Lebanon BIT (2002) Netherlands-Lithuania BIT (1994) Netherlands-Malawi BIT (2003) Netherlands-Malaysia BIT (1971) Netherlands-Mali BIT (2003) Netherlands-Malta BIT (1984) Netherlands-Mexico BIT (1998) Netherlands-Moldova BIT (1995) Netherlands-Mongolia BIT (1995) Netherlands-Morocco BIT (1971) Netherlands-Mozambique BIT (2001) Netherlands-Namibia BIT (2002) Netherlands-Nicaragua BIT (2000) Netherlands-Nigeria BIT (1992) Netherlands-Oman BIT (1987) Netherlands-Oman BIT (2009) Netherlands-Pakistan BIT (1988) Netherlands-Paktan BIT (1988) Netherlans-Pasna BIT (2000) Netherlands-Paraguay BIT (1992) Netherlands-Philippines BIT (1985) Netherlands-Poland BIT (1992) Netherlands-Romania BIT (1983) Netherlands-Romania BIT (1994) Netherlands-Russian Federation BIT (1989) Netherlands-Senegal BIT (1965) Netherlands-Senegal BIT (1979) Netherlands-Serbia BIT (1976) 
Netherlands-Serbia BIT (2002)

Netherlands-Singapore BIT (1972)

Netherlands-Slovakia BIT (1991)

Netherlands-South Africa BIT (1995)

Netherlands-Sri Lanka BIT (1984)

Netherlands-Sudan BIT (1970)

Netherlands-Sudan BIT (1970)
Netherlands-Suriname BIT (2005)

Netherlands-Tajikistan BIT (2002)

Netherlands-Tanzania BIT (2001)

Netherlands-Thailand BIT (1972)

Netherlands-Tunisia BIT (1963)

Netherlands-Tunisia BIT (1998)

Netherlands-Turkey BIT (1986)

Netherlands-Uganda BIT (2000)

Netherlands-Ukraine BIT (1994)

Netherlands-Uruguay BIT (1988)

Netherlands-Uzbekistan BIT (1996)

Netherlands-Venezuela BIT (1991)

Netherlands-Vietnam BIT (1994)

Netherlands-Yemen BIT (1985)

Netherlands-Yemen BIT (1985)

Netherlands-Zimbabwe BIT (1996)

Netherlands-Zimbabwe BIT (1996)

New Zealund-Argentina BIT (1999)

New Zealand-Australia (ANZCERTA Investment Protocol) (2011)

New Zealand-Chile BIT (1999)

New Zealand-China BIT (1988)
New Zealand-China FTA (2008)

New Zealand-China FTA (2008)

New Zealand-Malaysia FTA (2009)

New Zealand-Singapore CEPA (2000)

New Zealand-Thailand CEPA (2005)

Norway-Chile BIT (1993)

Norway-China BIT (1984)

Norway-Czech Republic BIT (1991)

Norway-Estonia BIT (1992)

Norway-Indonesia BIT (1991)

Norway-Latvia BIT (1992)

Norway-Lithuania BIT (1992)

Norway-Malaysia BIT (1984)

Norway-Peru BIT (1995)

Norway-Pol BT (1900)

Norway-Romin BIT (1990)

Norway-Russian Federation BIT (1995)

Norway-Russian Federation

Norway-Slovakia BIT (1991)

Perway-Srgentina BIT (1994)

Peru-Argentina BIT (1994)

Peru-Belgium/Luxembourg BIT (2005)

Peru-Bolivia BIT (1993)

Peru-Canada BIT (2006)

Peru-Canada FTA (2008)

Peru-Chile BIT (2000)

Peru-Chile FTA (2006)

Peru-China BIT (1994)

Peru-China FTA (2009)

Peru-Colombia BIT (1994)

Peru-Colombia BIT (2007)

Peru-Costa Rica FTA (2011)

Peru-Cuba BIT (2000)

Peru-Czech Republic BIT (1994)

Peru-Denmark BIT (1994)

Peru-Denar BIT (1999)

Peru-El Salvador BIT (1996)

Peru-Finland BIT (1995)

Peru-Finland BIT (1995)

Peru-France BIT (1993)

Peru-Guatemala FTA (2011)

Peru-Italy BIT (1994)

Peru-Japan BIT (2008)

Peru-Korea BIT (1993)

Peru-Korea FTA (2011)

Peru-Malaysia BIT (1995)

Peru-Mexico FTA (2011)

Peru-Netherlands BIT (1994)

Peru-Norway BIT (1995)

Peru-Panama FTA (2011)

Peru-Paraguay BIT (1994)

Peru-Portugal BIT (1994)

Peru-Romania BIT (1995)

Peru-Singapore BIT (2003)

Peru-Singapere FTA (2008)

Peru-Spain BIT (1994)

Peru-Spain BIT (1994)

Peru-Switzerland BIT (1991)

Peru-Switzerland BIT (1991)

Peru-United Kingdom BIT (1993)

Peru-United States FTA (2006)

Peru-Venezuela BIT (1996)

Poland-Albania BIT (1993)

Poland-Argentina BIT (1991)

Poland-Australia BIT (1991)

Poland-Austria BIT (1988)

Poland-Bangladesh BIT (1997)
Poland-Belgium/Luxembourg BIT (1987)

Poland-Bulgaria BIT (1994)

Poland-Canda BIT (1990)

Poland-Chile BIT (1995)

Poland-China BIT (1988)

Poland-Croatia BIT (1995)

Poland-Cyprus BIT (1992)

Poland-Denmark BIT (1990)

Poland-Egypt BIT (1995)

Poland-Estonia BIT (1993)

Poland-Finland BIT (1990)

Poland-Finland BIT (1996)

Poland-France BIT (1989)

Poland-FYROM BIT (1996)

Poland-Germany BIT (1989)

Poland-Greece BIT (1992)

Poland-Hungary BIT (1992)

Poland-India BIT (1996)

Poland-Indonesia BIT (1992)

Poland-Iran BIT (1998)

Poland-Israel BIT (1991)

Poland-Italy BIT (1989)

Poland-Tay BIT (1989)

Poland-Jordan BIT (1997)

Poland-Korea BIT (1989)

Poland-Kuwait BIT (1990)

Poland-Lithuania BIT (1992)

Poland-Malaysia BIT (1993)

Poland-Mongolia BIT (1995)

Poland-Morocco BIT (1994)

Poland-Netherlands BIT (1992)

Poland-Norway BIT (1990)

Poland-Portugal BIT (1993)
Poland-Romania BIT (1994)

Poland-Serbia BIT (1996)

Poland-Singapore BIT (1993)

Poland-Slovakia BIT (1994)

Poland-Slovenia BIT (1996)

Poland-Spain BIT (1992)

Poland-Sweden BIT (1989)

Poland-Switzerland BIT (1989)

Poland-Thailand BIT (1992)

Poland-Tunisia BIT (1993)

Poland-Turkey BIT (1991)

Poland-United Arab Emirates BIT (1993)

Poland-United Kingdom BIT (1987)

Poland-United States BIT (1990)

Poland-Uruguay BIT (1991)

Poland-Vietnam BIT (1994)

Portugal-Albania BIT (1998)

Portugal-Algeria BIT (2004)

Portugal-Angola BIT (1997)

Portugal-Argentina BIT (1994)

Portugal-Bosnia and Herzegovina BIT (2002)

Portugal-Brazil BIT (1994)

Portugal-Bulgaria BIT (1993)

Portugal-Cape Verde BIT (1991)

Portugal-Chile BIT (1995)

Portugal-China BIT (1992)

Portugal-China BIT (2005)

Portugal-Congo (Republic of) BIT (2010)

Portugal-Croatia BIT (1995)

Portugal-Czech Republic BIT (1993)

Portugal-Egypt BIT (1999)

Portugal-Gabon BIT (2001)

Portugal-Germany BIT (1980)

Portugal-Guinea Bissau BIT (1991)

Portugal-Hungary BIT (1992)

Portugal-India BIT (2000)

Portugal-Korea BIT (1995)

Portugal-Kuwait BIT (2007)

Portugal-Latvia BIT (1995)

Portugal-Libya BIT (2003)

Portugal-Lithuania BIT (1998)

Portugal-Macao, China BIT (2000)

Portugal-Mauritius BIT (1997)

Portugal-Mexico BIT (1999)

Portugal-Morocco BIT (1988)

Portugal-Morocco BIT (2007)

Portugal-Mozambique BIT (1995)

Portugal-Pakistan BIT (1995)

Portugal-Paraguay BIT (1999)

Portugal-Paraguay BIT (1999)

Portugal-Philippines BIT (2002)

Portugal-Philippines BIT (2002)

Portugal-Poland BIT (1993)

Portugal-Qatar BIT (2009)

Portugal-Russian Federation BIT (1994)

Portugal-Sao Tome and Principe BIT (1995)

Portugal-Senegal BIT (2011)

Portugal-Serbia BIT (2009)

Portugal-Slovakia BIT (1995)

Portugal-Slovenia BIT (1997)
Portugal-Timor-Leste BIT (2002)

Portugal-Tunisia BIT (2002)

Portugal-Turkey BIT (2002)

Portugal-Ukraine BIT (2002)

Portugal-United Arab Emirates BIT (2011)

Portugal-Uruguay BIT (1997)

Portugal-Uzbekistan BIT (2001)

Portugal-Venezuela BIT (1994)

Portugal-Zimbabwe BIT (1994)

Romania-Albania BIT (1994)

Romania-Algeria BIT (1994)

Romania-Argentina BIT (1993)

Romania-Armenia BIT (1994)

Romania-Australia BIT (1993)

Romania-Austria BIT (1976)

Romania-Austria BIT (1996)

Romania-Azerbaijan BIT (2002)

Romania-Bangladesh BIT (1987)

Romania-Belarus BIT (1995)

Romania-Belgium/Luxembourg BIT (1978)

Romania-Belgium/Luxembourg BIT (1996)

Romania-Belgin/Luxerite

Romania-Busiaria BIT (1994)

Romania-Bulgaria BIT (1994)

Romania-Cameroon BIT (1980)

Romania-Canada BIT (1996)

Romania-Canada BIT (2009)

Romania-Chile BIT (1995)

Romania-China BIT (1994)

Romania-Croatia BIT (1994)

Romania-Cuba BIT (1996)

Romania-Cyprus BIT (1991)

Romania-Czech Republic BIT (1993)

Romania-Denmark BIT (1980)

Romania-Ecuador BIT (1996)

Romania-Egypt BIT (1976)

Romania-Egypt BIT (1994)

Romania-Finland BIT (1992)

Romania-France BIT (1978)

Romania-France BIT (1995)

Romania-FYROM BIT (2000)

Romania-Gabon BIT (1979)

Romania-Geon BIT (1979)

Romania-Georgia BIT (1997)

Romania-Germany BIT (1979)

Romania-Germany BIT (1996)

Romania-Ghana BIT (1989)

Romania-Greece BIT (1991)

Romania-Hungary BIT (1993)

Romania-India BIT (1997)

Romania-Indonesia BIT (1997)

Romania-Iran BIT (2003)

Romania-Israel BIT (1998)

Romania-Italy BIT (1990)

Romania-Jordan BIT (1992)

Romania-Kazakhstan BIT (2010)

Romania-Korea BIT (1990)

Romania-Kuwait BIT (1991)

Romania-Latvia BIT (2001)

Romania-Lebanon BIT (1994)

Romania-Lithuania BIT (1994)

Romania-Mauritius BIT (2000)

Romania-Mongolia BIT (1995)

Romania-Mongolia BIT (1995)

Romania-Morocco BIT (1994)

Romania-Netherlands BIT (1983)

Romania-Netherlands BIT (1994

Romania-North Korea BIT (1998)

Romani-Nora Bor (1991)

Romani-Pakis BIT (1978)

Roma-Pakistan BIT (1978)

Romania-Pastan BIT (1995)

Romania-Philippines BIT (1994)

Romania-Poland BIT (1994)

Romania-Portugal BIT (1993)

Romania-Qatar BIT (1996)

Romania-Senegal BIT (1980)

Romania-Serbia BIT (1995)

Romania-Slovakia BIT (1994)

Romania-Slovenia BIT (1996)

Romania-Spain BIT (1995)

Romania-Sri Lanka BIT (1981)

Romania-Sweden BIT (2002)

Romania-Switzerland BIT (1993)

Romania-Syria BIT (2008)

Romani-Thailand BIT (1993)

Romani-Tunisi BIT (1995)

Romaia-Turkey BIT (2008)

Romania-United Arab Emirates BIT (1993)

Romania-United Kingdom BIT (1976)

Romania-United Kingdom BIT (1995)

Romania-United States BIT (1992)

Romania-Uruguay BIT (1990)

Romania-Vietnam BIT (1994)

Russian Federation-Albania BIT (1995) 
Russian Federation-Algeria BIT (2006) Russian Federation-Argentina BIT (1998) Russian Federation-Austria BIT (1990) Russian Federation-Belgium/Luxembourg BIT (1989) Russian Federation-Canada BIT (1989) Russian Russian Federation-Cuba BIT (1993) Russian Federation-Cyprus BIT (1997) Russian Federation-Denmark BIT (1993) Russian Federation-Egypt BIT (1997) Russian Federation-Ethiopia BIT (1999) Russian Federation-Finland BIT (1989) Russian Federation-France BIT (1989) Russian Federation-Germany BIT (1989) Russian Federation-Greece BIT (1993) Russian Federation-Hungary BIT (1995) Russian Federation-India BIT (1994) Russian Federation-Italy BIT (1996) Russian Federation-Japan BIT (1998) Russian Federation-Korea BIT (1990) Russian Federation-Kuwait BIT (1994) Russian Federation-Kuwait BIT (1994) Russian Federation-Lebanon BIT (1997) Russian Federation-Lithuania BIT (199)
Russian Federation-Lybia BIT (2008) Russian Federation-Lybia BIT (2008)
Russian Federation-Netherlands BIT (1989) Russian Federation-Netherlands BIT (1989) Russian Federation-Norway BIT (1995)
Russian Federation-Portugal BIT (1994) Russian Federation-Portugal BIT (1994) Russian Federation-Qatar BIT (2007) Russian Federation-Singapore BIT (2010) Russian Federation-South Africa BIT (1998) Russian Federation-Spain BIT (1990) Russian Federation-Sweden BIT (1995) Russian Federation-Switzerland BIT (1990) Russian Federation-Thailand BIT (2002) Russian Federation-Turkey BIT (1997) Russian Federation-Ukraine BIT (1998) Russian Federation-United Arab Emirates BIT (2010) Russian Federation-United Kingdom BIT (1989) Russian Federation-United States BIT (1992 Russian Federation-Venezuela BIT (2008) Russian Federation-Yemen BIT (2002) Sussian Federation-Yemen BIT (20d Saudi Arabia-Austria BIT (2001)
Saudi Arabia-Belgium/Luxembourg BIT (2001) Saudi Arabia-Czech Republic BIT (2009) Saudi Arabia-France BIT (2002) Saudi Arabia-Germany BIT (1996) Saudi Arabia-Germany BIT (1996 Saudi Arabia-India BIT (2006) Saudi Arabia-Italy BIT (1996) Saudi Arabia-Japan BIT (2013) Saudi Arabia-Korea BIT (2002) Saudi Arabia-Malaysia BIT (2000) Saudi Arabia-Philippines BIT (1994) Saudi Arabia-Singapore BIT (2006) Saudi Arabia-Sweden BIT (2008) Saudi Arabia-Switzerland BIT (2006) Saudi Arabia-Turkey BIT (2006) Slovakia-Belarus BIT (2005) Slovakia-Belgium/Luxembourg BIT (1989) Slovakia-Bosnia and Herzegovina BIT (2008) Slovakia-Bulgaria BIT (1994) Slovakia-Canada BIT (1990) Slovakia-Canada BIT (2012) Slovakia-China BIT (1991) Slovakia-Croatia BIT (1996) Slovakia-Cuba BIT (1997) Slovakia-Egypt BIT (1997) Slovakia-Finland BIT (1990) Slovakia-France BIT (1990) Slovakia-Germany BIT (1990) Slovakia-Hungary BIT (1993) Slovakia-India BIT (2006) Slovakia-Indonesia BIT (1994) Slovakia-Israel BIT (1999) Slovakia-Korea BIT (2005) Slovakia-Lebanon BIT (2009) Slovakia-Malaysia BIT (2007) Slovakia-Mexico BIT (2007) Slovakia-Morocco BIT (2007) Slovakia-Netherlands BIT (1991) Slovakia-North Korea BIT (1998) Slovakia-Norway BIT (1991) Slovakia-Poland BIT (1994) Slovakia-Portugal BIT (1995) Slovakia-Romania BIT (1994) Slovakia-Serbia BIT (1996) Slovakia-Singapore BIT (2006) Slovakia-Singapore BIT (2006) Slovakia-Slovenia BIT (1993) Slovakia-Switzerland BIT (1990) Slovakia-Switzerland BIT (1990) Slovakia-Turkey BIT (1992)
Slovakia-United States BIT (1991) Slovenia-Albania BIT (1997) Slovenia-Austria BIT (2001) Slovenia-Belgium/Luxembourg BIT (1999)
Slovenia-Bosnia and Herzegovina BIT (2001) Slovenia-Bulgaria BIT (1998) Slovenia-China BIT (1993)

Slovenia-Denmark BIT (1999) Slovenia-Egypt BIT (1998) Slovenia-Finland BIT (1998) Slovenia-France BIT (1998) Slovenia-Germany BIT (1993) Slovenia-Greece BIT (1997) Slovenia-Hungary BIT (1996) Slovenia-India BIT (2011) Slovenia-Israel BIT (1998) Slovenia-Italy BIT (2000) Slovenia-Kuwait BIT (2002) Slovenia-Lithuania BIT (1998) Slovenia-Malta BIT (2001) Slovenia-Moldova BIT (2003) Slovenia-Netherlands BIT (1996) Slovenia-Poland BIT (1996) Slovenia-Portugal BIT (1997) Slovenia-Romania BIT (1996) Slovenia-Semania BIT (1996) Sloveni-Sebia BIT (2002) Slovenia-Singapore BIT (1999) Slovenia-Slovakia BIT (1993) Slovenia-Spain BIT (1998) Slovenia-Sweden BIT (1999)
Slovenia-Switzerland BIT (1995 Slovenia-Switzerland BIT (1995) Slovenia-Thailand BIT (2000) Slovenia-Turkey BIT (2004) Slovenia-Ukraine BIT (1999) Slovenia-United Kingdom BIT (1996) Slovenia-Uzbekistan BIT (2003) South Africa-Algeria BIT (2000) South Africa-Angola BIT (2005) South Africa-Argentina BIT (1998) South Africa-Austria BIT (1996) South Africa-Belgium/Luxembourg BIT (1998) South Africa-Canada BIT (1995) South Africa-Chile BIT (1998) South Africa-China BIT (1997) South Africa-Congo (Democratic Republic) BIT (2004) South Africa-Congo (Republic of) BIT (2005) South Africa-Cuba BIT (1995) South Africa-Czech Republic BIT (1998) South Africa-Denmark BIT (1996) South Africa-Egypt BIT (1998) South Africa-Egypt BIT (1998) South Africa-Equatorial Guinea BIT
South Africa-Ethiopia BIT (2008) South Africa-Finland BIT (1998) South Africa-France BIT (1995) South Africa-Gabon BIT (2005) South Africa-Germany BIT (1995) South Africa-Ghana BIT (1998) South Africa-Greece BIT (1998) South Africa-Guinea BIT (2007) South Africa-Iran BIT (1997) South Africa-Israel BIT (2004) South Africa-Italy BIT (1997) South Africa-Korea BIT (1995) South Africa-Kuwait BIT (2005) South Africa-Libya BIT (2002) South Africa-Madagascar BIT (2006) South Africa-Mauritius BIT (1998) South Africa-Mozambique BIT (1997) South Africa-Mozambique BIT (1997) South Africa-Qatar BIT (2003) South Africa-Qatar BIT (2003) South Africa-Russian Federation
South Africa-Rwanda BIT (2000) South Africa-Rwanda BIT (200)
South Africa-Spain BIT (1998) South Africa-Spain BIT (1998)
South Africa-Sudan BIT (2007) South Africa-Sudan BIT (2007)
South Africa-Sweden BIT (1998) South Africa-Sweden BIT (1998) South Africa-Tanzania BIT (2005) South Africa-Tunisia BIT (2002) South Africa-Turkey BIT (2000) South Africa-United Kingdom BIT (1994) South Africa-Yemen BIT (2003) South Africa-Zimbabwe BIT (2009) Spain-Albania BIT (2003) Spain-Algeria BIT (1994) Spain-Argentina BIT (1991) Spain-Bolivia BIT (1990) Spain-Bolivia BIT (1990) Spain-Bosnia and Herzegovina BIT (2002) Spain-Bulgaria BIT (1995) Spain-Chile BIT (1991) Spain-Chile BIT (1991) Spain-China BIT (1992) Spain-China BIT (2005) Spain-Colombia BIT (1995) Spain-Colombia BIT (2005) Spain-Costa Rica BIT (1997) Spain-Croatia BIT (1997) Spain-Cuba BIT (1994) Spain-Czech Republic BIT (1990)
Spain-Dominican Republic BIT (1995)

Spain-Ecuador BIT (1996)

Spain-Egypt BIT (1992)

Spain-El Salvador BIT (1995)

Spain-Equatorial Guinea BIT (2003)

Spain-Estonia BIT (1997)

Spain-Ethiopia BIT (2006)

Spain-FYROM BIT (2005)

Spain-Gabon BIT (1995)

Spain-Guatemala BIT (2002)

Spain-Honduras BIT (1994)

Spain-Hungary BIT (1989)

Spain-India BIT (1997)

Spain-Indonesia BIT (1995)

Spain-Iran BIT (2002)

Spain-Jamaica BIT (2002)

Spain-Jordan BIT (1999)

Spain-Kazakhstan BIT (1994)

Spain-Korea BIT (1994)

Spain-Kuwait BIT (2005)

Spain-Latvia BIT (1995)

Spain-Latwa BIT (1995)

Spain-Lebanon BIT (1996)

Spain-Libya BIT (2007)

Spain-Lithuania BIT (1994)

Spain-Malaysia BIT (1995)

Spain-Mexico BIT (1995)

Spain-Mexico BIT (2006)
Spain-Moldova BIT (2006)

Spain-Moldova BIT (2006)

Spain-Morocco BIT (1989)

Spain-Morocco BIT (1997)

Spain-Namibia BIT (2003)

Spain-Nicaragua BIT (1994)

Spain-Nigeria BIT (2002)

Spain-Pakistan BIT (1994)

Spain-Panama BIT (1997)

Spain-Paraguay BIT (1993)

Spain-Peru BIT (1994)

Spain-Philippines BIT (1993)

Spain-Poland BIT (1992)

Spain-Romania BIT (1995)

Spain-Russian Federation BIT (1990)

Spain-Serbia BIT (2002)

Spain-South Africa BIT (1998)

Spain-South Africa BIT

Spain-Syria BIT (2003)
Spain-Trinidad and Tobago BIT (1999)

Spain-Trinidad and Tobago

Spain-Tunisia BIT (1991)

Spain-Turkey BIT (1995)

Spain-Ukraine BIT (1998)

Spain-Uruguay BIT (1992)

Spain-Uzbekistan BIT (2003)

Spain-Venezuela BIT (1995)

Spain-Vietnam BIT (2006)

Sweden-Albania BIT (1995)

Sweden-Algeria BIT (2003)

Sweden-Argentina BIT (1991)

Sweden-Armenia BIT (2006)

Sweden-Belarus BIT (1994)

Sweden-Bolivia BIT (1990)

Sweden-Bosnia and Herzegovina BIT (2000)

Sweden-Bulgaria BIT (1994)

Sweden-Chile BIT (1993)

Sweden-Chile BIT (1993)

Sweden-Cote d'Tvoire BIT (1965)

Sweden-Cote d Tvoire BIT (1965-Croatia BIT (2000)

Sweden-Czech Republic BIT (1990)

Sweden-Ecuador BIT (2001)

Sweden-Ecuador BIT (2001)

Sweden-Egypt BIT (1978)

Sweden-Estonia BIT (1992)

Sweden-Ethiopia BIT (2004)

Sweden-FYROM BIT (1998)

Sweden-Georgia BIT (2008)

Sweden-Guatemala BIT (2004)

Sweden-Hong Kong, China BIT (1994)

Sweden-Hungary BIT (1987)

Sweden-India BIT (2000)

Sweden-Indonesia BIT (1992)

Sweden-Iran BIT (2005)

Sweden-Kazakhstan BIT (2004)

Sweden-Korea BIT (1995)

Sweden-Kuwait BIT (1999)

Sweden-Kyrgyzstan BIT (2002)

Sweden-La PDR BIT (1996)

Sweden-Latvia BIT (1992)

Sweden-Latvia BIT (19)

Sweden-Lebanon BIT (2001)

Sweden-Lithuania BIT (1992)

Sweden-Madagasear BIT (1966)

Sweden-Malaysia BIT (1979)

Sweden-Malta BIT (1999)

Sweden-Mauritius BIT (2004)

Sweden-Mexico BIT (2000)

Sweden-Mongolia BIT (2003)

Sweden-Morocco BIT (1990)

Sweden-Mozambique BIT (2001) 
Sweden-Oman BIT (1995)

Sweden-Pakistan BIT (1981)

Sweden-Panama BIT (2008)

Sweden-Peru BIT (1994)

Sweden-Philippines BIT (1999)

Sweden-Poland BIT (1989)

Sweden-Romania BIT (2002)
Sweden-Russian Federation BIT (1995)

Sweden-Saudi Arabia BIT (2008)

Sweden-Senegal BIT (1967)

Sweden-Serbia BIT (1978)

Sweden-Slovakia BIT (1990)

Sweden-Slovenia BIT (1999)

Sweden-South Africa BIT (1998)

Sweden-Sri Lanka BIT (1982)

Sweden-Tanzania BIT (1999)

Sweden-Thailand BIT (2000)

Sweden-Tunisia BIT (1984)

Sweden-Turkey BIT (1997)

Sweden-Ukraine BIT (1995)

Sweden-United Arab Emirates BIT (1999)

Sweden-Uruguay BIT (1997)

Sweden-Uzbekistan BIT (2001)

Sweden-Uabekistan BIT (2001)

Sweden-Venezuela BIT (1996)

Sweden-Vietnam BIT (1993)

Sweden-Yemen BIT (1983)

Sweden-Zimbabwe BIT (1997)

Switzerland-Albania BIT (1992)

Switzerland-Algeria BIT (2004)

Switzerland-Argentina BIT (1991)

Switzerland-Armenia BIT (1998)

Switzerland-Azerbaijan BIT (2006)

Switzerland-Bangladesh BIT (2000)

Switzerland-Barbados BIT (1995)

Switzerland-Belarus BIT (1993)

Switzerland-Benin BIT (1966)

Switzerland-Bolivia BIT (1987)

Switzerland-Bosnia and Herzegovina BIT (2003)

Switzerland-Botswana BIT (1998)

Switzerland-Bulgaria BIT (1991)

Switzerland-Burkina Faso BIT (1969)
Switzerland-Cambodia BIT (1996)

Switzerland-Cambodia BIT (1996)

Switzerland-Cameroon BIT (1963)

Switzerland-Central African Republic BIT (1973)

Switzerland-Central African R

Switzerland-Chad BIT (1967)

Switzerland-Chile BIT (1999)

Switzerland-China BIT (1986)

Switzerland-China BIT (2009)
Switzerland-Colombia BIT (2006)

Switzerland-Colombia BIT (2006)
Switzerland-Congo (Democratic Republic) BIT (1972)

Switzerland-Congo (Republic of) BIT (1962)

Switzerland-Costa Rica BIT (1965)

Switzerland-Costa Rica BIT (2000)
Switzerland-Cote d Tvoire BIT (1962)

Switzerland-Croatia BIT (1996)

Switzerland-Cuba BIT (1996)

Switzerland-Czech Republic BIT (1990)

Switzerland-Djibouti BIT (2001)

Switzerland-Dominican Republic BIT (2004)

Switzerland-Ecuador BIT (1968)

Swizerland-Egypt BIT (1973)

Switzerland-Egypt BIT (1973)

Switzerland-Egypt BIT (2010)

Switzerland-Estonia BIT (1992)

Switzerland-Ethiopia BIT (1998)

Switzerland-Gabon BIT (1972)

Switzerland-Gabon BIT (1972)
Switzerland-Gambia BIT (1993)

Switzerland-Gambia BIT (1993)
Switzerland-Ghana BIT (1991)

Switzerland-Ghana BIT (1991)

Switzerland-Guatemala BIT (2002)
Switzerland-Honduras BIT (1993)

Switzerland-Honduras BIT (1993)
Switzerland-Hong Kong, China BIT (1994)

Switzerland-Hungary BIT (1988)

Switzerland-India BIT (1997)

Switzerland-Indonesia BIT (1974)

Switzerland-Iran BIT (1998)

Switzerland-Jamaica BIT (1990)

Switzerland-Japan EPA (2009)

Switzerland-Jordan BIT (1976)

Switzerland-Kazakhstan BIT (1994)

Switzerland-Kenya BIT (2006)

Switzerland-Korea BIT (1971)

Switzerland-Kosovo BIT (2011)

Switzerland-Kuwait BIT (1998)

Switzerland-Kyrgyzstan BIT (1999)

Switzerland-Lao PDR BIT (199)

Switzerland-Latvia BIT (1992)

Switzerland-Lebanon BIT (2000)

Switzerland-Lesotho BIT (2004)

Switzerland-Liberia BIT (1963)

Switzerland-Libya BIT (2003)

Switzerland-Lithuania BIT (1992)

Switzerland-Madagascar BIT (1964)
Switzerland-Madagascar BIT (2008)

Switzerland-Malaysia BIT (1978)

Switzerland-Mali BIT (1978)

Switzerland-Malta BIT (1965)

Switzerland-Mauritania BIT (1976)

Switzerland-Mauritius BIT (1998)

Switzerland-Mexico BIT (1995)

Switzerland-Moldova BIT (1995)

Switzerland-Mongolia BIT (1997)

Switzerland-Morocco BIT (1985)

Switzerland-Mozambique BIT (2002)

Switzerland-Namibia BIT (1994)

Switzerland-Nicaragua BIT (1998)

Switzerland-Niger BIT (1962)

Switzerland-Nigeria BIT (2000)

Switzerland-North Korea BIT (1998)

Switzerland-Oman BIT (2004)

Switzerland-Pakistan BIT (1995)

Switzerland-Panama BIT (1983)

Switzerland-Paraguay BIT (1992)

Switzerland-Peru BIT (1991)

Switzerland-Philippines BIT (1997)

Switzerland-Poland BIT (1989)

Switzerland-Qatar BIT (2001)

Switzerland-Romania BIT (1993)

Switzerland-Russian Federation BIT (1990)

Switzerland-Saudi Arabia BIT (2006)

Switzerland-Senegal BIT (1962)

Switzerland-Serbia BIT (2005)

Switzerland-Singapore BIT (1978)

Switzerland-Slovakia BIT (1990)

Switzerland-Slovenia BIT (1995)

Switzerland-South Africa BIT (1995)

Switzerland-Sri Lanka BIT (1981)

Switzerland-Sudan BIT (1974)

Switzerland-Syria BIT (1977)

Switzerland-Syria BIT (2007)

Switzerland-Tanzania BIT (2004)

Switzerland-Thailand BIT (1997)

Switzerland-Togo BIT (1964)

Switzerland-Trinidad and Tobago BIT (2010)

Switzerland-Tunisia BIT (1961)

Switzerland-Tunisia BIT (2012)

Switzerlat-Turey BIT (1988)

Switzerland-Turkmenistan BIT (2008)

Switzerland-Uganda BIT (1971)

Switzerland-Ukraine BIT (1995)

Switzerland-United Arab Emirates BIT (1998)

Switzerland-Uruguay BIT (1988)

Switzerland-Uzbekistan BIT (1993)

Switzerland-Venezuela BIT (1993)

Switzerland-Vietnam BIT (1992)

Switzerland-Zambia BIT (1994)

Switzerland-Zimbabwe BIT (1996)

Tunisia-Argentina BIT (1992)

Tunisia-Austria BIT (1995)

Tunisia-Belgium/Luxembourg BIT (1964)

Tunisia-Belgium/Luxembourg BIT (1997)

Tunisia-Chile BIT (1998)

Tunisia-China BIT (2004)
Tunisia-Czech Republic BIT (1997)

Tunisia-Denmate BIT (1996)

Tunisia-Denmark BIT (1996)

Tunisia-Ethiopia BIT (2000)

Tunisia-Finland BIT (2001)

Tunisia-France BIT (1963)

Tunisia-France BIT (1972)

Tunisia-France BIT (1997)

Tunisia-Germany BIT (1963)

Tunisia-Greece BIT (1992)

Tunisia-Hungary BIT (2003)

Tunisia-Italy BIT (1985)

Tunisia-Jordan BIT (1995)

Tunisia-Korea BIT (1975)

Tunisia-Netherlands BIT (1963)

Tunisia-Netherlands BIT (1998)

Tunisia-Pakistan BIT (1996)

Tunisia-Poland BIT (1993)

Tunisia-Portugal BIT (2002)

Tunisia-Romania BIT (1995)

Tunisia-South Africa BIT (2002)

Tunisia-Spain BIT (1991)

Tunisia-Sweden BIT (1984)

Tunisia-Sweden BIT (1984)

Tunisia-Switzerland BIT (1961)

Tunisia-United Kingdom BIT (1989)

Tunisia-United States BIT (1990)

Turkey-Albania BIT (1992)

Turkey-Algeria BIT (1998)

Turkey-Argentina BIT (1992)

Turkey-Australia BIT (2005)

Turkey-Austria BIT (1988)

Turkey-Bangladesh BIT (1987)

Turkey-Belgium/Luxembourg BIT (1986)

Turkey-Bosnia and Herzegovina BIT (1998)
Turkey-Bulgaria BIT (1994)

Turkey-Chile BIT (1998)

Turkey-China BIT (1990)

Turkey-Cuba BIT (1997)

Turkey-Czech Republic BIT (1992)

Turkey-Czech Republic BIT (2009)

Turkey-Denmark BIT (1990)

Turkey-Egypt BIT (1996)

Turkey-Estonia BIT (1997)

Turkey-Ethiopia BIT (2000)

Turkey-Finland BIT (1993)

Turkey-France BIT (2006)

Turkey-Germany BIT (1962)

Turkey-Greece BIT (2000)

Turkey-Hungary BIT (1992)

Turkey-India BIT (1998)

Turkey-Indonesia BIT (1997)

Turkey-Iran BIT (1996)

Turkey-Israel BIT (1996)

Turkey-Italy BIT (1995)

Turkey-Japan BIT (1992)

Turkey-Jordan BIT (1993)

Turkey-Kazakhstan BIT (1992)

Turkey-Korea BIT (1991)

Turkey-Kyrgyzstan BIT (1992)

Turkey-Latvia BIT (1997)

Turkey-Lebanon BIT (2004)

Turkey-Libya BIT (2009)

Turkey-Lithuania BIT (1994)

Turkey-Malaysia BIT (1998)

Turkey-Malta BIT (2003)

Turkey-Moldova BIT (1994)

Turkey-Morocco BIT (1997)

Turkey-Netherlands BIT (1986)

Turkey-Nigeria BIT (2011)

Turkey-Oman BIT (2007)

Turkey-Pakistan BIT (1995)

Turkey-Philippines BIT (1999)

Turkey-Poland BIT (1991)

Turkey-Portugal BIT (2002)

Turkey-Qatar BIT (2001)

Turkey-Romania BIT (1991)

Turkey-Romania BIT (2008)

Turkey-Russian Federation BIT (1997)

Turkey-Saudi Arabia BIT (2006)

Turkey-Serbia BIT (2001)

Turkey-Singapore BIT (2008)

Turkey-Slovakia BIT (1992)

Turkey-Slovenia BIT (2004)

Turkey-South Africa BIT (2000)

Turkey-Spain BIT (1995)

Turkey-Sudan BIT (1999)

Turkey-Sweden BIT (1997)

Turkey-Switzerland BIT (1988)

Turkey-Syria BIT (2004)

Turkey-Tajikistan BIT (1996)

Turkey-Thailand BIT (2005)

Turkey-Turkmenistan BIT (1992)

Turkey-Ukraine BIT (1996)

Turkey-United Kingdom BIT (1991)

Turkey-United States BIT (1985)

Turkey-Uzbekistan BIT (1992)

Turkey-Uzbekistan BIT (1992

Uurkey-Yemen BIT (2000)

United Kingdom-Albania BIT (1994)

United Kingdom-Antigua and Barbuda BIT (1987)

United Kingdom-Argentina BIT (1990)

United Kingdom-Armenia BIT (1993)

United Kingdom-Azerbaijan BIT (1996)

United Kingdom-Bahrain BIT (1991)

United Kingdom-Bangladesh BIT (1980)

United Kingdom-Barbados BIT (1993)

United Kingdom-Belarus BIT (1994)

United Kingdom-Belize BIT (1982)

United Kingdom-Benin BIT (1987)

United Kingdom-Bolivia BIT (1988)

United Kingdom-Bosnia and Herzegovina BIT (2002)

United Kingdom-Bulgaria BIT (1995)

United Kingdom-Burundi BIT (1990)

United Kingdom-Cameroon BIT (1982)

United Kingdom-Chile BIT (1996)

United Kingdom-China BIT (1986)

United Kingdom-China BIT (1986)

United Kingdom-Congo (Republic of) BIT (1989)

United Kingdom-Costa Ric BIT (1982)

United King

United Kingom-Cote dvoire BIT (1997)

Uning

United Kingdom-Czech Republic BIT (1990)

United Kingdom-Dominican Republic BIT (1987)

United Kingdom-Ecuador BIT (1994)

United Kingdom-Egypt BIT (1975)

United Kingdom-El Salvador BIT (1999)

United Kingdom-Estonia BIT (1994) 
United Kingdom-Ethiopia BIT (2009) United Kingdom-Georgia BIT (1995) United Kingdom-Ghana BIT (1989) United Kingdom-Grenada BIT (1988) United Kingdom-Guyana BIT (1989) United Kingdom-Haiti BIT (1985) United Kingdom-Honduras BIT (1993) United Kingdom-Hong Kong, China BIT (1998) United Kingdom-Hungary BIT (1987) United Kingdom-India BIT (1994)

United Kingdom-Indonesia BIT (1976) United Kingdom-Jamaica BIT (1987) United Kingdom-Jordan BIT (1979) United Kingdom-Kazakhstan BIT (1995) United Kingdom-Kenya BIT (1999) United Kingdom-Korea BIT (1976) United Kingdom-Kyrgyzstan BIT (1994) United Kingdom-Lao PDR BIT (1995) United Kingdom-Latvia BIT (1994) United Kingdom-Lebanon BIT (1999) United Kingdom-Lesotho BIT (1981) United Kingdom-Lithuai BIT (1993) United Kingdon-Lithania BIT (1993) United Kingdom-Malaysia BIT (1981) United Kingdom-Malta BIT (1986) United Kingdom-Mauritius BIT (1986) United Kingdom-Mexico BIT (2006) United Kingdom-Moldova BIT (1996) United Kingdom-Mongolia BIT (1991) United Kingdom-Morocco BIT (1990) United Kingdom-Nepal BIT (1993) United Kingdom-Nicaragua BIT (1996) United Kingdom-Nigeria BIT (1990) United Kingdom-Oman BIT (1995) United Kingdom-Pakistan BIT (1994) United Kingdom-Panama BIT (1983) United Kingdom-Papua New Guinea BIT (1981) United Kingdom-Paraguay BIT (1981) United Kingdom-Peru BIT (1993) United Kingdom-Philippines BIT (1980) United Kingdom-Poland BIT (1987) United Kingdom-Romania BIT (1976)
United Kingdom-Romania BIT (1995) United Kingdom-Russian Federation BIT (1989) United Kingdom-Saint Lucia BIT (1983) United Kingdom-Senegal BIT (1980) United Kingdom-Sierra Leone BIT (2000) United Kingdom-Singapore BIT (1975) United Kingdom-Slovenia BIT (1996) United Kingdom-South Africa BIT (1994) United Kingdom-Sri Lanka BIT (1980) United Kingdom-Swaziland BIT (1995) United Kingdom-Tanzania BIT (1994) United Kingdom-Thailand BIT (1978) United Kingdom-Tonga BIT (1997) United Kingdom-Trinidad and Tobago BIT (1993) United Kingdom-Tunisia BIT (1989) United Kingdom-Turkey BIT (1991) United Kingdom-Turkmenistan BIT (1995) United Kingdom-Uganda BIT (1998) United Kingdom-Ukraine BIT (1993) United Kingdom-United Arab Emirates BIT (1992) United Kingdom-Uruguay BIT (1991) United Kingdom-Vanuatu BIT (2003) United Kingdom-Vietnam BIT (2002) United Kingdom-Yemen BIT (1982) United Kingdom-Zimbabwe BIT (1995) United States-Albania BIT (1995)
United States-Argentina BIT (1991) United States-Argentina BIT (1991) United States-Armenia BIT (1992)
United States-Australia FTA (2004) United States-Azerbaijan BIT (1997) United States-Bahrain BIT (1999) United States-Bangladesh BIT (1986) United States-Bolivia BIT (1998) United States-Bulgaria BIT (1992) United States-Cameroon BIT (1986) United States-Canada FTA (1987) United States-Chile FTA (2003)

United States-Congo (Democratic Republic) BIT (1984) United States-Congo (Republic of) BIT (1990)

United States-Croatia BIT (1996)
United States-Czech Republic BIT (1991)

United States-Ecuador BIT (1993) United States-Egypt BIT (1986) United States-El Salvador BIT (1999) United States-Estonia BIT (1994) United States-Georgia BIT (1994) United States-Grenada BIT (1986) United States-Haiti BIT (1983) United States-Honduras BIT (1995) United States-Jamaica BIT (1994) United States-Jordan BIT (1997) United States-Kazakhstan BIT (1992) United States-Korea FTA (2007) United States-Kyrgyzstan BIT (1993) United States-Latvia BIT (1995) United States-Lithuania BIT (1998) United States-Moldova BIT (1993) United States-Mongolia BIT (1994) United States-Morocco BIT (1985) United States-Morocco FTA (2004) United States-Mozambique BIT (1998) United States-Mozambique BIT (1998) United States-Nicaragua BIT (1995) United Staes-Oman FTA (2006) United States-Panama BIT (1982) United States-Peru FTA (2006) United States-Poland BIT (1990) United States-Romania BIT (1992) United States-Russian Federation BIT (1992) United States-Rwanda BIT (2008) United States-Senegal BIT (1983) United States-Singapore FTA (2003) United States-Slovakia BIT (1991) United States-Sri Lanka BIT (1991) United States-Trinidad and Tobago BIT (1994) United States-Tunisia BIT (1990) United States-Turkey BIT (1985) United States-Ukraine BIT (1994) United States-Uruguay BIT (2005) United States-Uzbekistan BIT (1994) 


\section{ANNEX 3: ACKNOWLEDGEMENTS}

Ms Fanny Sarnel, intern in the OECD Investment Division at the time of the preparation of the survey, made significant contributions to the evaluation of the treaties and contributed ideas on the presentation of the material. 



\section{(3) $)$ OECD}

www.oecd.org/investment/working-papers.htm 